FINAL TECHNICAL REPORT

\title{
Microwave Assisted Electrolyte Cell for Primary Aluminum Production
}

\author{
DE-FC36-02ID14402 \\ Project Period: September 2002 through March 2006 \\ Submitted: June 15, 2006, revised April 18, 2007 \\ Principle Investigator: Dr. Xiaodi Huang, 906-487-1822, xihuang@mtu.edu \\ Co-Investigator: J.Y. Hwang, 906-487-2600, jhwang@mtu.edu \\ Michigan Technological University \\ Institute of Materials Processing \\ 1400 Townsend Drive \\ Houghton, MI 49931-1295
}

Acknowledgment: This report is based upon work supported by the U.S. Department of Energy under Award No. DE-FC36-02ID14402.

Disclaimer: Any findings, opinions, and conclusions or recommendations expressed in this report are those of the author(s) and do not necessarily reflect the views of the Department of Energy. 


\begin{abstract}
This research addresses the high priority research need for developing inert anode and wetted cathode technology, as defined in the Aluminum Industry Technology Roadmap and Inert Anode Roadmap, with the performance targets: a) significantly reducing the energy intensity of aluminum production, b) ultimately eliminating anode-related $\mathrm{CO}_{2}$ emissions, and c) reducing aluminum production costs.

This research intended to develop a new electrometallurgical extraction technology by introducing microwave irradiation into the current electrolytic cells for primary aluminum production. This technology aimed at accelerating the alumina electrolysis reduction rate and lowering the aluminum production temperature, coupled with the uses of nickel based superalloy inert anode, nickel based superalloy wetted cathode, and modified salt electrolyte.

Michigan Technological University, collaborating with Cober Electronic and Century Aluminum, conducted bench-scale research for evaluation of this technology. This research included three sub-topics: a) fluoride microwave absorption; b) microwave assisted electrolytic cell design and fabrication; and c) aluminum electrowinning tests using the microwave assisted electrolytic cell. This research concludes that the typically used fluoride compound for aluminum electrowinning is not a good microwave absorbing material at room temperature. However, it becomes an excellent microwave absorbing material above $550^{\circ} \mathrm{C}$. The electrowinning tests did not show benefit to introduce microwave irradiation into the electrolytic cell. The experiments revealed that the nickel-based superalloy is not suitable for use as a cathode material; although it wets with molten aluminum, it causes severe reaction with molten aluminum. In the anode experiments, the chosen superalloy did not meet corrosion resistance requirements. A nicked based alloy without iron content could be further investigated.
\end{abstract}




\section{TABLE OF CONTENTS}

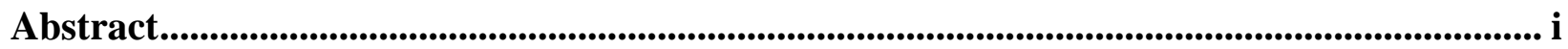

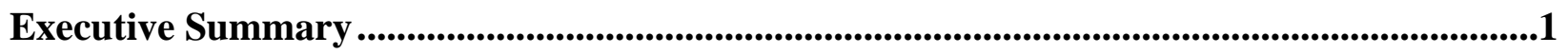

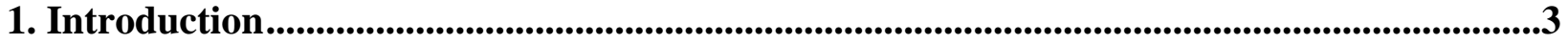

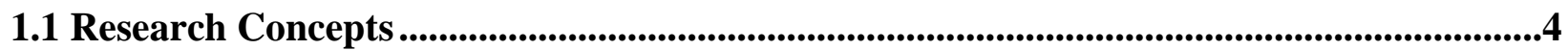

1.2 Microwave/material interactions...............................................................................

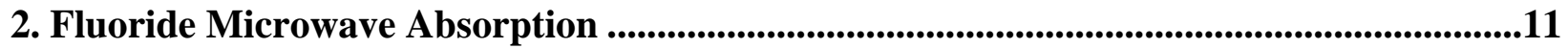

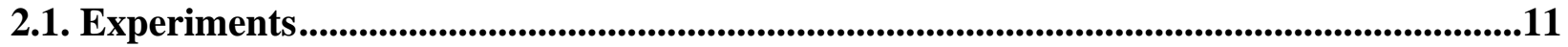

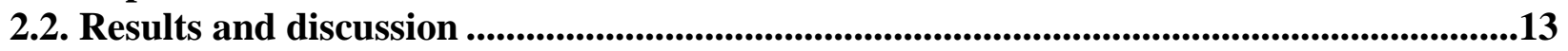

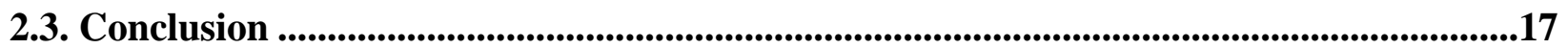

3. Design and Fabrication of Microwave Assisted Electrolytic Cell .....................................18

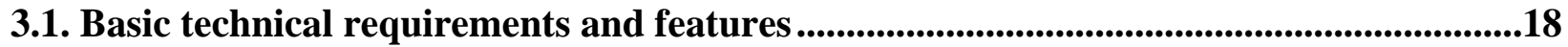

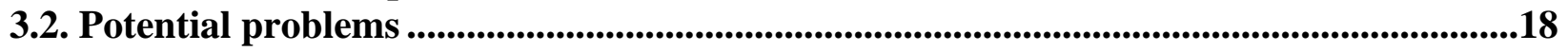

3.3. Design consideration ...................................................................................................................19

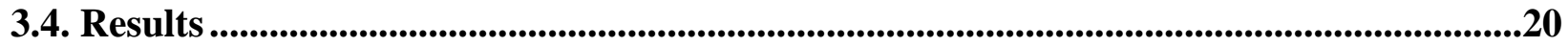

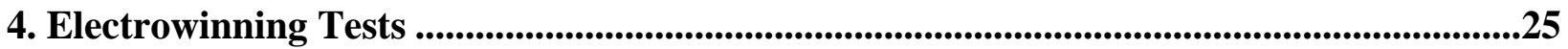

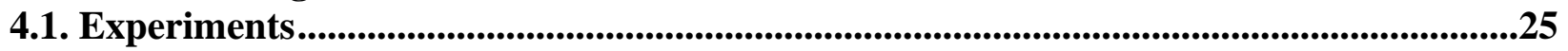

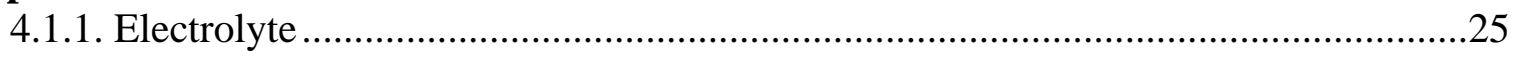

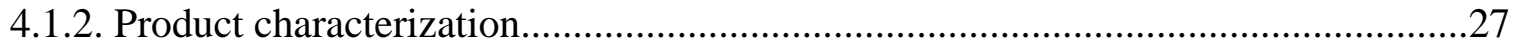

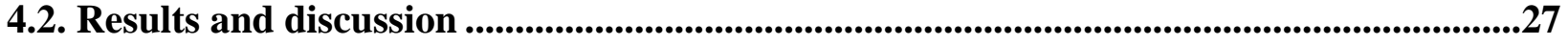

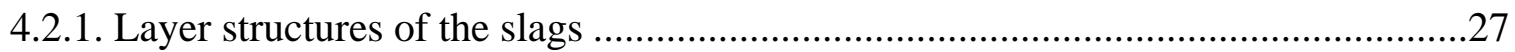

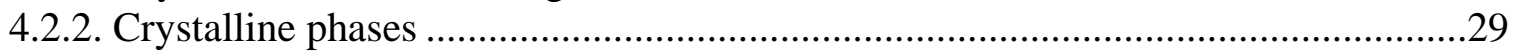

4.2.3. Metallic aluminum obtained by electrowinning ...............................................32

4.2.4. Features of the slags without microwave irradiation ...........................................35

4.2.5. Features of the slags with microwave irradiation ............................................45

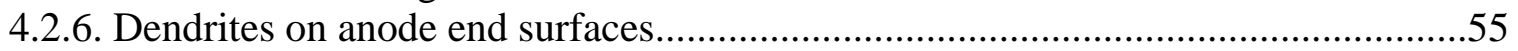

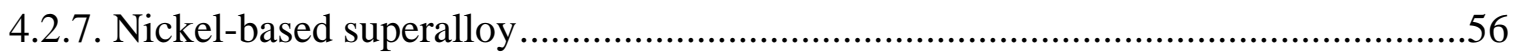

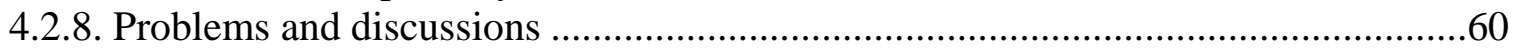

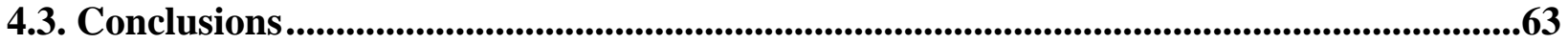

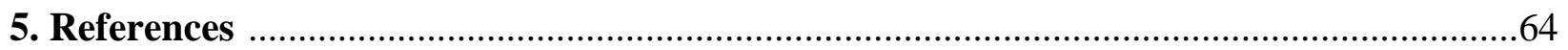

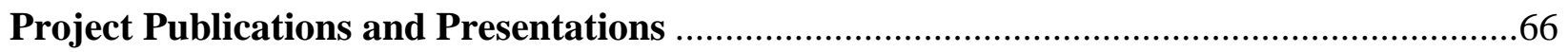




\section{LIST OF FIGURES}

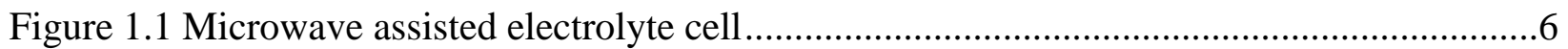

Figure 1.2 Mechanism of interaction between microwave and materials ....................................8

Figure 2.1 Sketch of the modified microwave oven ................................................................12

Figure 2.2 Modified commercial microwave oven ........................................................................12

Figure 2.3 Physical appearance of fluoride after heating ................................................................14

Figure 2.4 Cooling curve of sample after preheating at $700^{\circ} \mathrm{C}$.................................................14

Figure 2.5 Comparison of the cooling curves using metallic boat and ceramic boat ....................15

Figure 2.6 Melted fluorides after microwave radiation .................................................................17

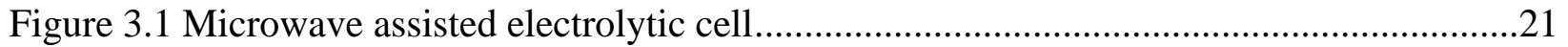

Figure 3.2 Microwave assisted electrolytic cell system.............................................................22

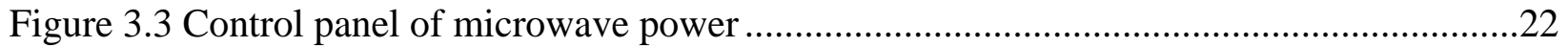

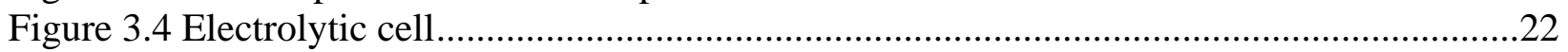

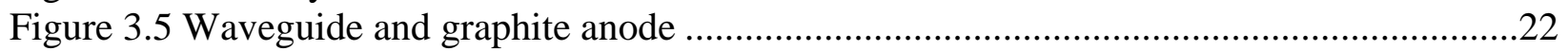

Figure 3.6 Electrolyte bath (cathode made of a nickel-based superalloy) ......................................23

Figure 3.7 Preheating element underneath the superalloy bath ......................................................23

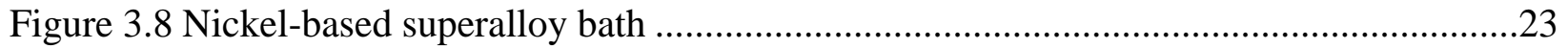

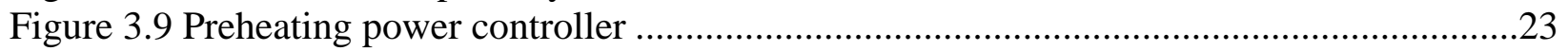

Figure 3.10 Graphite anode with cone bottom and notches............................................................24

Figure 3.11 Direct current supplier, providing DC up to 200A..................................................24

Figure 4.1 The melting temperature of the fluorite mixture is $700^{\circ} \mathrm{C}$

based on the $\mathrm{CaF}_{2}-\mathrm{AlF}_{3}-\mathrm{Na}_{3} \mathrm{AlF}_{6}$ phase diagram....................................................25

Figure 4.2 XRD pattern of the fluoride mixture ……………....................................................25

Figure 4.3 Normal appearance of slag after electrowinning..........................................................27

Figure 4.4 Multi-layer structures of solidified slags (with microwave irradiation)........................28

Figure 4.5 Dendrites on the bottom surface of graphite anode......................................................28

Figure 4.6 Comparison of XRD patterns of upper and lower section of

the slag without microwave irradiation..........................................................................29

Figure 4.7 Comparison of XRD patterns of upper and lower section

of the slag with microwave irradiation ........................................................................30

Figure 4.8 XRD pattern of dendrite on the surface of anode bottom .........................................30

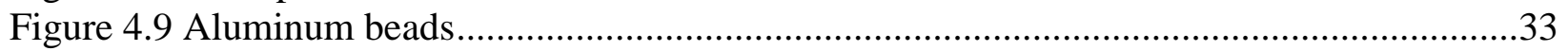

Figure 4.10 Aluminum beads in the porous layer..........................................................................33

Figure 4.11 Aluminum beads contacted graphite lining ...............................................................34

Figure 4.12 Size of the aluminum beads increased with microwave irradiation .............................34

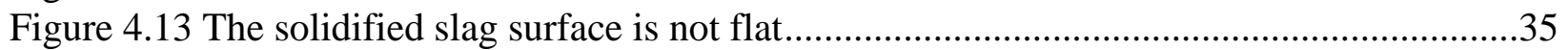

Figure 4.14 Micrograph of the near surface region of the upper section....................................36

Figure 4.15 SEM picture of the microcrystalline sublayer............................................................37

Figure 4.16 Spherical crystalline with septum-shaped single crystals ...........................................37

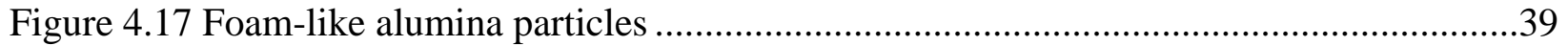

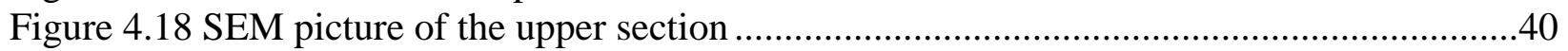

Figure 4.19 Chains of plate-like cryolite crystals ......................................................................4

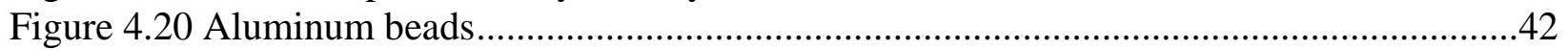

Figure 4.21 Fluoride particle coherent to the aluminum beads .......................................................43

Figure 4.22 Surface film and the spherical particles below the film .............................................44 
Figure 4.23 SEM micrograph of the radiate fluoride fibers near the surface ..............................46

Figure 4.24 SEM picture of broken surface of upper section ..............................................47

Figure 4.25 Remaining alumina particle surrounded by fluoride matrix.....................................48

Figure 4.26 Fluoride particles in center of the upper section ...............................................50

Figure 4.27 Spherical particles with high calcium fluoride content ........................................51

Figure 4.28 Atomic composition of cross section ............................................................52

Figure 4.29 Fully crystallized structure below the outlet of the waveguide..............................53

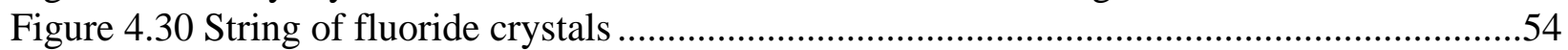

Figure 4.31 Internal surfaces of the pores......................................................................55

Figure 4.32 Dendrite crystals of aluminum fluoride on the anode end .....................................55

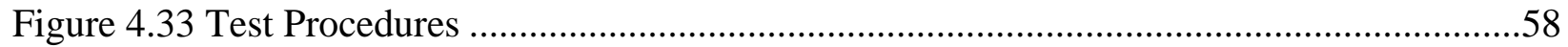

Figure 4.34 Ni-based superalloy in solidified fluoride melt ...............................................58

Figure 4.35 Corrosion of Ni-based alloy in fluoride melts ..................................................59

Figure 4.36 SEM picture of superalloy specimen after 2 hours corrosion .................................60

Figure 4.37 Corrosion rate of Ni-based alloy ..................................................................60

Figure 4.38 Bath temperature difference ..................................................................61

Figure 4.39 Fluoride in graphite channel without microwave irradiation ................................62

Figure 4.40 Fluoride in graphite channel with microwave irradiation .....................................62

\section{LIST OF TABLES}

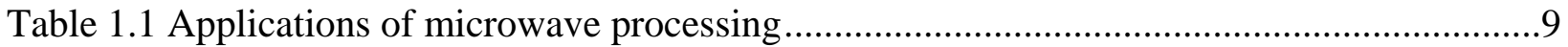

Table 2.1 Microwave absorbing capabilities of fluorides.....................................................13

Table 2.2 Physical appearance of fluoride powder after heating.............................................13

Table 2.3 Fluoride microwave absorption at elevated temperatures ........................................16

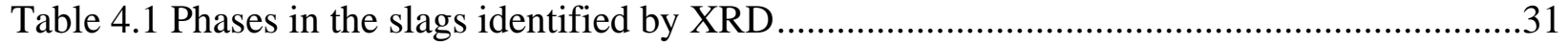

Table 4.2 Composition of Microcrystalline sublayer ..............................................................36

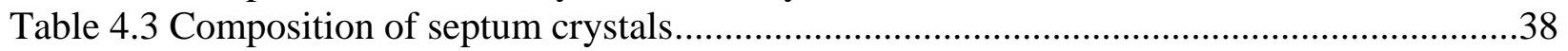

Table 4.4 Composition of the matrix hosting septum-shaped crystals .....................................38

Table 4.5 Composition of the foam-like alumina particles...................................................39

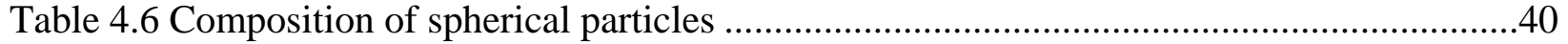

Table 4.7 Composition of the cryolite crystal chains ...........................................................41

Table 4.8 Composition of the intergranulates between cryolite crystal chains ............................42

Table 4.9 Composition of the aluminum bead surface ........................................................42

Table 4.10 Composition of the fluoride compound on the aluminum bead surfaces ..................44

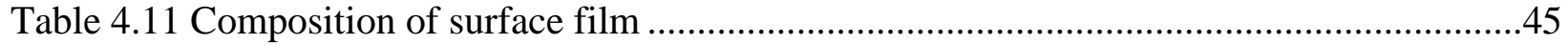

Table 4.12 Composition of aluminum fluoride fibers ..............................................................46

Table 4.13 Composition of spherical particles .......................................................................47

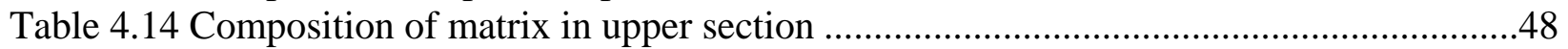

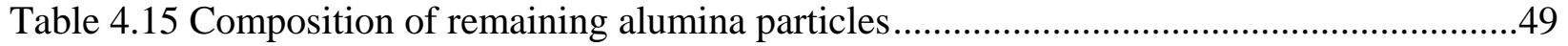

Table 4.16 Composition of rod-shaped particles ................................................................49

Table 4.17 Composition of the upper section underneath the waveguide outlet..........................50

Table 4.18 Composition of the spherical particles in the lower section .....................................52

Table 4.19 Composition of the particles of the lower section below waveguide .........................53

Table 4.20 Composition of the slag at the bath bottom ........................................................54

Table 4.21 Composition of the dendrite crystals ...................................................................56 


\section{EXECUTIVE SUMMARY}

The U.S. aluminum industry produced 3.79 million tons of primary aluminum in 1999. All primary aluminum is produced by the electrometallurgical extraction of alumina using the HallHeroult process, which was invented more than one hundred years ago. Although many efforts have been made to advance the process, two key problems remain which prevent further improvement. These are the anodes and cathodes currently used in the major production equipment, the electrolytic cell. The current anodes and cathodes are made of carbon, which are electrically conductive, salt corrosion resistant, and have high temperature strength. The drawback of using a carbon anode is the reaction of carbon with the oxygen discharged from the alumina, which releases $\mathrm{CO}_{2}$ to the atmosphere. Molten aluminum is not wetted with a carbon cathode, which prevents decreasing the anode-cathode distance. Narrowing the distance between the anode and cathode could reduce energy consumption up to $25 \%$ for primary aluminum production. This research tried to take advantage of the microwave capability to increase reaction kinetics, so the chemical reaction could occur at an acceptable rate at lower operating temperatures. The technical target was to lower the electrochemical reaction temperature from the current $950^{\circ} \mathrm{C}$ to $750^{\circ} \mathrm{C}$. The lower operating temperature makes it possible to use a nickel based superalloy for the anode and cathode. The nickel based superalloy is inert to oxidation at $750^{\circ} \mathrm{C}$, wetted with molten aluminum, and has excellent salt corrosion resistance.

This program was a fundamental research study primarily conducted by Michigan Technological University (MTU). This program tried to considerably reduce energy consumption, reduce environmental impacts and enhance economic competitiveness of the U.S. aluminum industry. This program was a direct response to the call for reducing and eliminating anode-related $\mathrm{CO}_{2}$ emissions, improving the performance of the Hall-Heroult cell, and developing inert anode and wetted cathode stated by the Aluminum Industry Technology Roadmap and the Inert Anode Roadmap.

The industrial participant, Cober Electronics, Inc., provided a microwave instrument and consulting services for microwave technical, economic and industrial application assessments for the program. Another industrial participant, Century Aluminum Company, provided the currently used industry electrolyte material for the experiments and consulting services for the electrolytic cell design and fabrication and aluminum extraction tests.

The goal of this research effort was to develop a microwave assisted electrolyte cell technology for primary aluminum productions, which could greatly increase energy efficiency, reduce $\mathrm{CO}_{2}$ emissions, and lower production cost. The scope of this project was to built a bench-top microwave assisted $100 \mathrm{amp}$ electrolyte cell, and conduct a series of tests to provide technical data for evaluation of this technology and decision making for further development.

The objectives of this proposed project were to a) design and build a bench-top microwave assisted electrolyte cell, b) modify electrolyte chemistry, c) generate a series of technical, d) evaluate opportunities and barriers, e) accumulate knowledge and experiences for future development, and f) promote learning and training of students. 
This research concluded that the typically used fluoride compound for aluminum electrowinning is not a good microwave absorbing material at room temperature. However, it becomes an excellent microwave absorbing material above $550^{\circ} \mathrm{C}$. The electrowinning tests did not show a benefit to introduce microwave irradiation into the electrolytic cell. The experiments revealed that the nickel-based superalloy is not suitable for use as a cathode material; although it wets with molten aluminum, it also causes severe reactions with molten aluminum. In the anode experiments, the chosen superalloy did not meet corrosion resistance requirements. A nicked based alloy without iron content could be further investigated. 


\section{Introduction}

Currently, all primary aluminum is produced by the electrometallurgical extraction of alumina using the Hall-Heroult process, which was invented over one hundred years ago. Although many efforts have been made to advance the process, two key problems remain which prevent further improvement. The two problems are related to the materials to make the anodes and cathodes for the major production equipment, the electrolytic cell. The current anodes and cathodes are made of carbon, which has the required electrical conductivity, salt corrosion resistance, and high temperature strength. The drawback of using a carbon anode is the reaction of carbon with the oxygen discharged from the alumina, which releases a great amount of $\mathrm{CO}_{2}$ to the atmosphere. Molten aluminum is not wetted with a carbon cathode, which prevents decreasing the anodecathode distance.

The U.S. Department of Energy in collaboration with the aluminum industry prepared the Aluminum Industry Technology Roadmap and Inert Anode Roadmap in 2001 and 1998. The roadmaps defined the development of inert anode and wetted cathode technology as the high priority research need. By estimations, a successful inert anode and wetted cathode technology could achieve great economic benefit, energy saving and environmental benefit as briefly described below.

Economic benefit The major economic benefit of a successful inert anode and wetted cathode technology would come from electricity savings of $4.18 \mathrm{kWh} / \mathrm{kg}$ of primary aluminum production. It is due to a decrease in the anode-cathode distance and will save 25 to $30 \%$ of the current electricity usage. Lower operating temperature should also save energy and thus dollars. The current electricity prices are about $\$ 0.06 / \mathrm{kWh}$ and the current annual primary aluminum production is about 3,790 million kilograms in the United States. Assuming a successful technology is ready for full scale implementation in 15 years and assuming $5 \%$ increases in both electricity price and primary aluminum production every year for the next fifteen years, the proposed technology will save \$3,726 million of production cost in 2017 (3,790 x 1.0514 x 4.18 $\mathrm{x} 0.06 \mathrm{x}$ 1.0514). Other economic benefits include lower anode cost, less operating labor and increases in space utilization and production per unit volume.

Energy saving

The current energy consumption for primary aluminum production in the United States is $15.18 \mathrm{kWh} / \mathrm{kg}$. The performance target of a successful technology is to reduce the energy consumption to $11 \mathrm{kWh} / \mathrm{kg}$ mainly by decreasing the anode-cathode distance. This is $4.18 \mathrm{kWh}$ energy saving to produce one kilogram of primary aluminum. The United States produces about 3,790 million kilograms of primary aluminum today. Assuming 5\% increases in primary aluminum production every year for the next fifteen years, a successful technology will save energy of 31,366 million kilowatt hours, or 106,959,670 million BTUs, in $2017(3,790 \times 1.0514$ x 4.18 x 3410).

Environmental benefits The main environmental concern of the electrowinning operation for primary aluminum production is $\mathrm{CO}_{2}$ emissions, about $1.4 \mathrm{~kg} / \mathrm{kg}$ of aluminum. The utilization of an inert anode eliminates these emissions completely. The total annual reduction of $\mathrm{CO}_{2}$ emissions will be 10.506 million tons in 2017 (3,790 x $\left.1.0514 \times 1.4 / 1,000\right)$, assuming 5\% increases in primary aluminum production every year for the next fifteen years. A successful 
technology also eliminates other greenhouse gas $\left(\mathrm{CF}_{4}\right.$ and $\left.\mathrm{C}_{2} \mathrm{~F}_{6}\right)$ emissions and reduces emissions of polycyclic organic matter, hydrogen fluoride, and carbonyl sulfide due to the elimination of carbon anode manufacture and the lower electrowinning temperature.

Domestic technology status In 1886, Hall in the United States and Heroult in France independently developed the primary aluminum production method: passing an electric current between a carbon anode and a carbon cathode in a molten salt containing dissolved alumina and depositing molten aluminum on the cathode. This technology is still being used today in the United States. Although it has evolved, the Hall-Heroult technology still uses carbon anodes and carbon cathodes. The carbon anode reacts with discharged oxygen from the reduction of $\mathrm{Al}_{2} \mathrm{O}_{3}$ and produces a great amount of $\mathrm{CO}_{2}$. The unwetted carbon cathode prevents further energy reduction through reducing anode-cathode distance. The domestic aluminum industry, universities and government agencies are working together to develop inert anode and wetted cathode technologies which have the potential to greatly improve the century old Hall-Heroult process. Typical examples include $\mathrm{NiO}-\mathrm{NiF}_{2} \mathrm{O}_{4}-\mathrm{Cu}$ anode, $\mathrm{TiB}_{2}-\mathrm{Al}_{2} \mathrm{O}_{3}$ cathode, and nickel compound shell concept proposed by Alcoa, anode busbar with input fuel gas concept proposed by Gas Research Institute, dynamic inert metal anodes concept proposed by Argonne National Laboratory, inert metal anode life in low temperature $\left(750^{\circ} \mathrm{C}\right)$ aluminum reduction process concept proposed by Brooks Rand, novel ceramic composition for Hall-Heroult cell anode concept proposed by Advanced Refractory Tech, wettable ceramic-based drained cathode concept proposed by Advanced Refractory Tech, and wetted cathodes for low temperature $\left(750^{\circ} \mathrm{C}\right)$ aluminum smelting concept proposed by Northwest Aluminum Tech. Each concept presents unique features, merits and limitations. It is too early to judge which one can satisfactorily solve the century old problem, using inert anode and wetted cathode. More alternative methods need to be explored before a satisfactory solution can be found.

World technology status The Hall-Heroult process is used worldwide. The world aluminum production technology is basically the same as used in the United States. Use of inert anodes and wetted cathodes is the common desire, but no breakthrough has been made yet.

\subsection{Research concept}

This research concept proposed to retrofit the current electrolyte cell for primary aluminum production by introducing microwave radiation through a waveguide into the cell. The microwave radiation will accelerate the electrowinning process and lower the process temperature. As a part of the technology, the currently used carbon anode and cathode will be replaced by an inert and wetted superalloy anode and cathode and the currently used salt electrolyte will be modified to lower its melting point. This concept includes three aspects: microwave assisted chemical reaction, superalloy anode and cathode, and modification of salt electrolyte.

This proposed technology tries to take advantage of the microwave capability to increase reaction kinetics, so the chemical reaction can occur at an acceptable rate at lower operating temperatures. This technology targets lowering the electrochemical reaction temperature from the current $950^{\circ} \mathrm{C}$ to $750^{\circ} \mathrm{C}$. The lower operating temperature makes it possible to use a nickel 
based superalloy for the anode and cathode. The nickel based superalloy is inert to oxidation at $750^{\circ} \mathrm{C}$, wetted with molten aluminum, and has excellent salt corrosion resistance.

Microwave assisted electrowinning Microwave radiation is capable of accelerating a chemical reaction and lowering the reaction temperature due to its capability of exciting molecules to higher speed and higher frequency vibration. The microwave energy is converted to molecule vibration and motion energy. Higher speed and higher frequency vibration of molecules provides more opportunity of impingement of reactant molecules and lowers the activation energy of a reaction. This advantage has been utilized in chemical vapor deposition (CVD), digestion of samples for chemical analyses, and some chemical reactions. Microwave assisted diamond CVD enhances the diamond film formation at a temperature as low as $1200^{\circ} \mathrm{C}$ in partial hydrogen pressures less than one atmosphere, in contrast to the ultra high pressure and ultra high temperature diamond formation. Digestion times of many materials under microwave radiation have been shortened to less than one tenth of ordinary digestion times. We expect that the introduction of microwave radiation will considerably improve the electrowinning efficiency.

Superalloy anode and cathode $\quad$ A qualified inert anode material should be resistant to oxidation and salt corrosion at the electrowinning temperature. Lowering the electrowinning temperature from $950^{\circ} \mathrm{C}$ to $750^{\circ} \mathrm{C}$, assisted by microwave radiation, offers opportunities to select a metal as the inert anode material. We can examine the situation of salt bath furnaces. Salt bath furnaces are widely used in the heat treatment of ferrous and nonferrous alloys. In this type of furnace, steel electrodes are submerged or immersed in a molten salt bath contained by a steel pot. The electrodes pass current through the salt to obtain an operating temperature, which has some similarity to the aluminum electrowinning process. The service life of the electrodes and pot are strongly dependant on the operating temperature. The electrodes will last for 3-6 months if the bath is operated at $1010^{\circ} \mathrm{C}$. However, the electrodes will last for $12-24$ months if the bath is operated at $735^{\circ} \mathrm{C}$. The pot will last for $1-3$ months if the bath is operated at $920^{\circ} \mathrm{C}$, but the pot will last for $9-12$ months if the bath is operated at $840^{\circ} \mathrm{C}$. It is not difficult to find a metal for making the electrodes and pot for the salt bath because no oxygen is generated during the salt bath operation. Currently however, the harsh environment of oxidation, salt corrosion and high temperature encountered in the aluminum electrolyte cell preclude the use of metal components. But, an electrowinning temperature drop from $950^{\circ} \mathrm{C}$ to $750^{\circ} \mathrm{C}$ allows for the selection of a nickel based alloy as the anode and cathode material, which can satisfy the combined oxidation resistance, corrosion resistance and elevated temperature requirements. For example, Alloy X, a Ni-Cr-Fe-Mo alloy, possesses an exceptional combination of oxidation resistance, hightemperature strength and corrosion resistance. It exhibits good properties after prolonged exposure at $760^{\circ} \mathrm{C}$ for 16,000 hours in an oxidizing and corrosive environment. A nickel based alloy is also wetted with molten aluminum. Therefore, a nickel based alloy is also a good choice for cathode material.

Nickel alloys are mainly used for corrosion resistance and/or heat resistance. They are considered the best metal materials for these applications. Examples include aircraft gas turbines, steam turbine power plants, space vehicles, heat treatment equipment, nuclear power systems, chemical and petrochemical equipment, pollution control equipment, and coal gasification and liquefaction systems. Many nickel alloys are commonly used in the temperature range from 500$800^{\circ} \mathrm{C}$ and are readily available. 
Electrolyte chemistry modification

In primary aluminum production, purified bauxite from the Bayer process is added to the molten salt electrolyte, cryolite $\left(\mathrm{Na}_{3} \mathrm{AlF}_{6}\right)$, to about 1 to $8 \%$ together with minor additions of $\mathrm{CaF}_{2}$ and $\mathrm{AlF}_{3}$. The melting point of cryolite $\left(1010^{\circ} \mathrm{C}\right)$ is lowered by the addition of $\mathrm{CaF}_{2}$ and $\mathrm{AlF}_{3}$ to $900-1000^{\circ} \mathrm{C}$. In this proposed technology, the chemistry of the electrolyte will be modified with different percentages of $\mathrm{CaF}_{2}$ and $\mathrm{AlF}_{3}$ and additions of other fluorides selected from $\mathrm{Na}_{3} \mathrm{AlF}_{6}, \mathrm{CaF}_{2}, \mathrm{AlF}_{3}, \mathrm{BF}, \mathrm{NaF}, \mathrm{NaBF}_{4}, \mathrm{Li}_{3} \mathrm{AlF}_{6}$, and $\mathrm{MgF}$. The target is to lower the new electrolyte's melting point to about $750^{\circ} \mathrm{C}$. The dissolution rate of bauxite in the electrolyte will be enhanced by the microwave radiation to compensate for the decreased dissolution rate due to the lower temperature. Figure 1 illustrates the proposed concept.

Phase diagrams show that small percentages of $\mathrm{Na}_{3} \mathrm{AlF}_{6}, \mathrm{CaF}_{2}, \mathrm{AlF}_{3}, \mathrm{BF}_{3}, \mathrm{NaF}, \mathrm{NaBF}_{4}, \mathrm{Li}_{3} \mathrm{AlF}_{6}$, and $\mathrm{MgF}$ can significantly reduce the melting point of cryolite. Lowering the melting point of cryolite to $750^{\circ} \mathrm{C}$ should be possible.

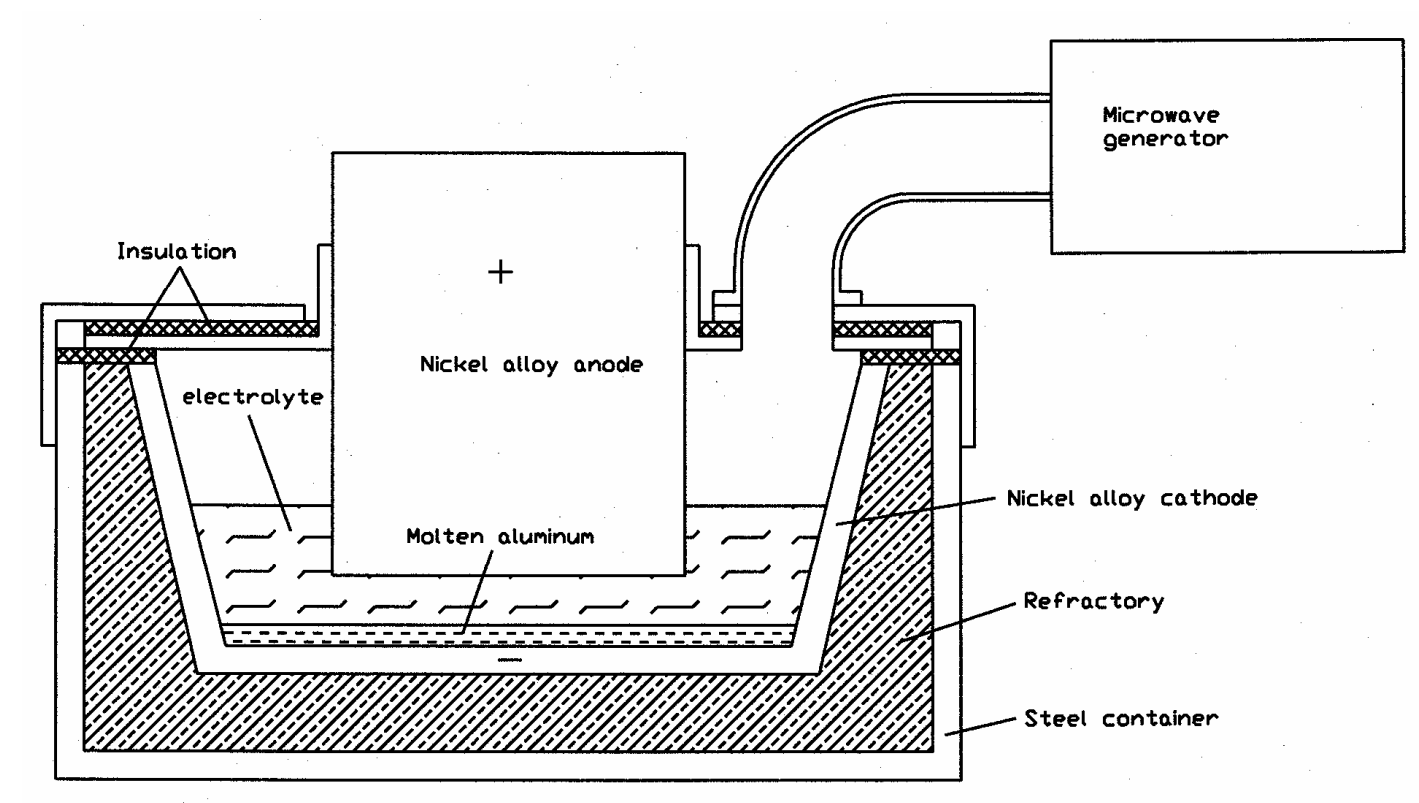

Figure 1.1 Microwave assisted electrolyte cell

Technology targets

Three technical targets were set for the concept. First, the electrowinning temperature is lowered to about $750^{\circ} \mathrm{C}$. Second, the service life of anodes and cathodes are longer than two years, with reduced spalling and erosion. Third, the anode-cathode distance is narrowed to one inch.

Research breakdown This research was divided into three parts: microwave absorbing capability of fluorides, design and fabrication of microwave assisted electrolytic cell, and microwave assisted electrowinning. 


\subsection{Microwave/material interactions}

Microwave in general Microwaves have extensive application in the field of communication, but certain frequencies are allocated for industrial and scientific application. Microwaves are electromagnetic waves with frequencies that range from 0.3 to $300 \mathrm{GHz}$. Microwave frequencies include three bands: the ultrahigh frequency (UHF: $0.3 \mathrm{GHz}$ to $3 \mathrm{GHz}$ ), the superhigh frequency (SHF: $3 \mathrm{GHz}$ to $30 \mathrm{GHz}$ ) and the extremely high frequency (EHF: 30 $\mathrm{GHz}$ to $300 \mathrm{GHz}$ ). Microwaves obey the laws of optics and can be transmitted, absorbed or reflected. The behavior of microwave depends on the type of materials interacted with.

Microwaves are generated from magnetrons. Microwave energy is converted from electric energy and the frequency of the generated microwave is a dominant parameter of the conversion efficiency. The frequency of a generated microwave depends on the design of the circuit associated with magnetrons. The microwave energy generated by a magnetron is dependent on the line voltage applied on the magnetron and on the amount of time the magnetron has been operated.

The basic power equation for a microwave oven is stated as follows:

$$
P_{G}=P_{R}+P_{A}+P_{D}
$$

The power generated by a magnetron, $\mathrm{P}_{\mathrm{G}}$, equals the power reflected back to the magnetron, $\mathrm{P}_{\mathrm{R}}$, plus the power absorbed by the microwave oven cavity and feed system, $\mathrm{P}_{\mathrm{A}}$, plus the power delivered to the load inside the microwave oven, $\mathrm{P}_{\mathrm{D}}$.

Behavior of materials under microwave irradiation Microwaves can be reflected, absorbed and transmitted by materials with which they interact. Reflection and absorption are due to the interaction of atoms inside materials with the electric field of microwave. Transmission is the result of partial reflection and incomplete absorption.

Materials reflect and absorb microwave energy to various degrees depending on their composition, structure, temperature and the frequency of the microwave. With regard to their response to microwaves, materials are divided into three categories: transmitters, absorbers or reflectors. Metals and graphite, at least in bulk form, are excellent reflectors and do not absorb microwaves at all. Some minerals (magnetite, iron titanite, galena et al.) are excellent absorbers.

The absorption degree of some materials can be changed through various methods, which include changing the temperature, adding absorbing constituents, altering the microstructure and defect structure of materials, changing the form of materials (e.g. bulk vs. powder), and changing the frequency of the incident microwave. At room temperature, many ceramics and polymers do not appreciably absorb microwaves with a frequency of $2.45 \mathrm{GHz}$, however, their absorption can be increased by increasing the temperature of processing.

Mechanism of interaction Microwaves can interact with materials through either dielectric polarization or ionic conduction, as illustrated by Figure 1.2. Dielectric polarization involves the 
short-range displacement of a charge through the formation and rotation of electric dipoles. Ionic conduction involves the long-range transport of charge.

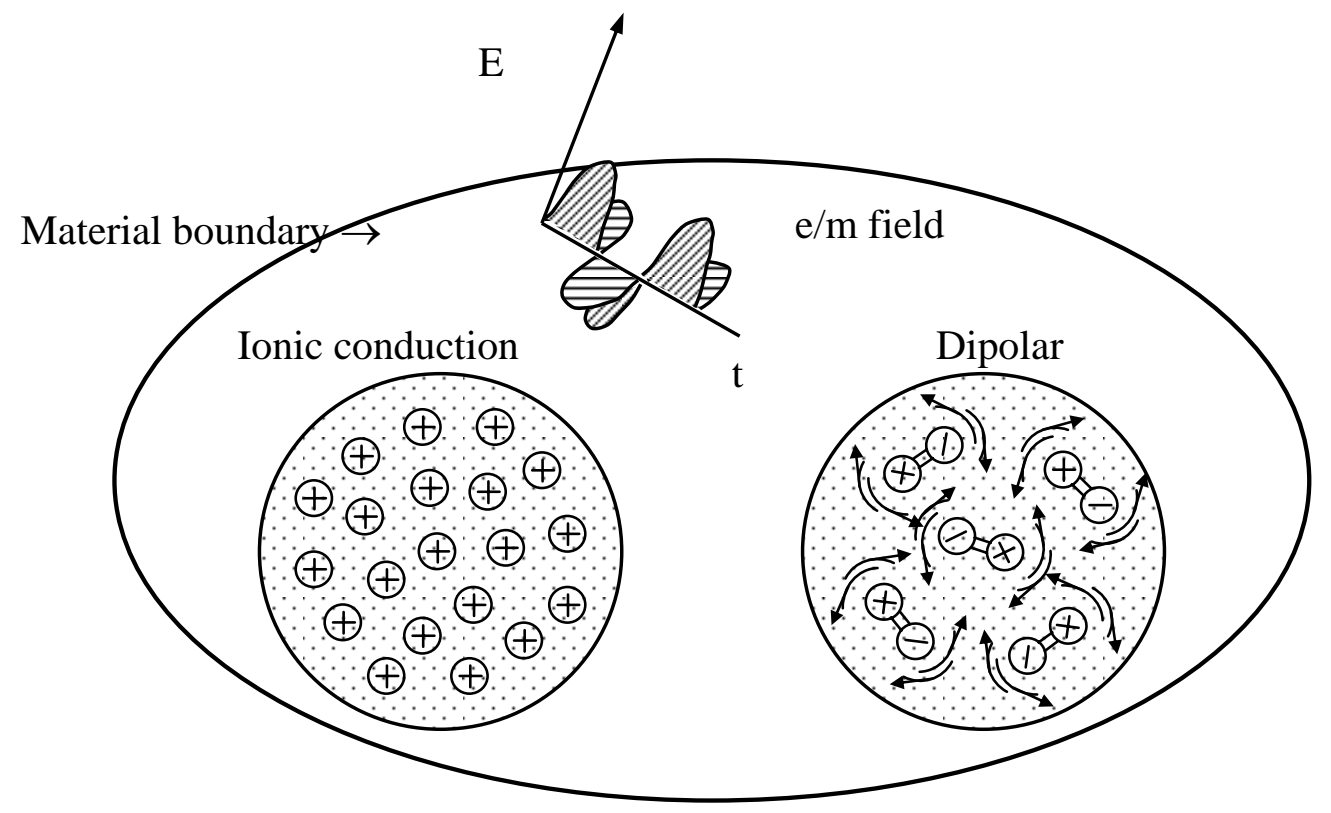

Figure 1.2. Mechanism of interaction between microwave and materials

Both processes result in the absorption of microwave energy by materials. Microwave energy loss through ionic conduction is due to the well-known ohmic losses, which occur when ions move through materials and collide with other species. The time allowed for an ion's transport in the direction of the field decreases with increasing frequency of microwave, so ionic conduction is the dominant process at low frequencies. In a microwave region, dipoles are formed and rotate to align themselves in phase with the reversing electric field. The extent of dipolar polarization depends on the power of the electric field, the strength of dipole's moment, and the mobility of dipoles. Microwave energy loss through dielectric polarization results from the lag of polarization behind the change of the electric field. Dielectric polarization is the dominant process at high frequencies.

Microwave absorption At the macroscopic level, the microwave absorption by materials can be quantitatively stated as follows:

$$
P_{A}=2 \pi f \varepsilon_{0} \varepsilon_{e f f}^{\prime}(E)^{2}
$$

Where $\mathrm{P}_{\mathrm{A}}$ is the average absorbed power per unit volume, $\mathrm{f}$ is the frequency of microwave, $\varepsilon$ is the permittivity of free space, $\varepsilon_{\text {eff }}^{\prime}$ is the relative dielectric loss factor, and $\mathrm{E}$ is the internal electric field. An internal electric field (E) is generated within the material when microwaves penetrate and propagate through a dielectric material. The internal electric field (E) is dependent on the relative dielectric constant $\varepsilon^{\prime}$ and $\varepsilon^{\prime}$ eff. 
Microwave processing Microwave processing of materials is a thermally activated process based on microwave energy absorption. In contrast to all other conventional heating methods, microwave processing allows volumetric heating of materials. Microwave energy transforms into heat inside materials in microwave processing, which eliminates the need for spending energy on heating the walls of the furnace. Due to volumetric heating, the role of heat transfer becomes less important; materials can be quickly heated in microwave processing. These unique features of microwave processing result in significant reduction of energy consumption and processing duration; energy and time play a decisive role in most applications of microwave processing.

Microwave processing also has other benefits over conventional heating methods: rapid heating of thermal insulators such as ceramics and polymers, precise and controlled heating, material selective heating, reduction of hazardous emissions, increased product yield, environmentally friendly (clean and quiet), and cost savings.

In general, microwave processing will achieve energy savings, ranging from 10 to $90 \%$ higher efficiency compared with that of conventional heating. It is reported that the efficiency of microwave use increases significantly when the size of the load is increased. Besides the wellknown and extensive application in food manufacture and heating, microwave processing finds its way into many areas, which are roughly classified and summarized in Table 1.1.

\begin{tabular}{|c|c|}
\hline & Table 1.1 Applications of microwave processing \\
\hline Processes & Examples \\
\hline Recovery & $\begin{array}{l}\text { Waste remediation, extraction of Zn from EAF dust, Beneficiation of } \\
\text { minerals }\end{array}$ \\
\hline Synthesis & $\begin{array}{l}\text { SiC synthesis, TiC synthesis, decomposition of PCS, Catalysis and } \\
\text { synthesis of organic compounds }\end{array}$ \\
\hline Removal of phases & $\begin{array}{l}\text { Drying and anhydration of material, solvent volatilization, binder } \\
\text { burnout }\end{array}$ \\
\hline Fabrication & Ceramic joining, CVI, coating, reduction of metal oxides \\
\hline Consolidation & $\begin{array}{l}\mathrm{Si}_{3} \mathrm{~N}_{4} \text { sintering, alumina sintering, melting, Polymer curing, organic } \\
\text { matrix composite curing }\end{array}$ \\
\hline $\begin{array}{l}\text { Post-Fabrication } \\
\text { treatments }\end{array}$ & $\begin{array}{l}\text { Annealing of } \mathrm{Si}_{3} \mathrm{~N}_{4} \text {, surface modification, nucleation/crystallization, } \\
\text { sealing }\end{array}$ \\
\hline Sample digestion & Mineral leaching \\
\hline
\end{tabular}

Microwave non-thermal effect

Numerous observations have been reported in the literature of enhanced mass transport and enhanced reaction rates during microwave processing of various materials. These empirical observations of microwave enhancements have been broadly called the microwave effect or microwave non-thermal effect. One of the phenomena about enhanced mass transport first observed by Janney, was the enhancement of oxygen diffusion in sapphire crystals heated in a $28 \mathrm{GHz}$ microwave furnace. A 40\% decrease in the apparent activation energy for bulk diffusion was observed under microwave processing as compared to conventional heating. One of the phenomena about enhanced reaction rates was observed by Gedye et al. in their investigation of organic reactions. They observed that microwave processing increases the reaction rate about 10 to 1200 times, as compared to conventional heating. 
The existence of a microwave non-thermal effect means many unique benefits, which microwave processing can provide but conventional heating can not. These benefits include not only the benefits mentioned earlier but also improved quality and properties of the processed materials. In Bykov's study on nanostructured porous alumina membranes, it was found that the porosity decreases consistently with increasing time of microwave processing, and that conventional heating causes no changes in the surface porosity of membranes.

Among the theoretical models for microwave non-thermal effect, the model based on the concept of non-equilibrium excitation seems natural and sound. The process of thermal energy absorption by materials is usually viewed as the excitation of lattice oscillations that have an equilibrium spectrum. Changes in the temperature of materials through thermally heating mean the slow evolution of the spectrum, which at all times remains in quasi-equilibrium. Microwave radiation not only increases the temperature of materials through microwave energy absorption, but also excites electron oscillations inside materials through interaction between electron and electromagnetic fields. Electron oscillations induce periodic distortion of the lattice potential and thereby modify the spectrum of lattice vibrations, that is, drive it from equilibrium. The fraction of energy stored in non-equilibrium excitations is determined by the time constant of the lattice vibrational modes and the electromagnetic field of microwave. The energy stored in nonequilibrium excitation is within the same order of magnitude as the energy of the electromagnetic field of microwave. Mass transport rate and reaction rate can be expressed in a general form as equation (3). Both the transport coefficient and the reaction coefficient are dependent on activation energy and temperature. The energy stored in non-equilibrium excitation will increase the activation energy for transport and reaction. The driving force is considered to be controlled by the concentration gradient or capillary stress, which are unaffected by microwave.

$$
\text { Rate }=(\text { driving force }) \times(\text { coefficient })
$$

Microwave processing systems A microwave processing system is made up of four basic components: power supply, magnetron, applicator (i.e., oven) for processing the target materials, and waveguide for transporting microwaves from the magnetron to the applicator.

Currently, the maximum output power of single magnetron produced is $90 \mathrm{~kW}$. Large microwave processing units can be built through connecting many magnetrons in parallel to multiply the power output.

Many companies such as Dennis Tool Co. (USA) and Fuji Denpa (Japan) offer standard microwave processing furnaces, and many companies will design and build a microwave processing system to meet their client's specifications. Prices depend on the power output and frequency needed. The most inexpensive and common frequency used for microwave processing is $2.45 \mathrm{GHz}$.

Many systems used for microwave processing have been commercialized. An example of a commercial system is the Stoke-Type microwave system, which is developed by Dennis Tool Co. (USA) and is used to manufacture carbide. 


\section{Fluoride Microwave Absorption}

In order for microwave irradiation to enhance a reaction in a medium, the medium must be a good microwave absorber or capable of being excited by microwave irradiation. The first feasibility study of this technology was to investigate the microwave absorbing capability of the electrolyte. If the electrolyte did not absorb microwaves, microwave irradiation would not affect the electrowinning process. The microwave absorbing capability of a material may change as temperature changes. A material could be a poor microwave absorber at room temperature but becomes a good microwave absorber at a higher temperature. $\mathrm{NaF}$ and $\mathrm{AlF}_{3}$ constitute the major components of the electrolyte currently used in aluminum electrowinning. This study examined

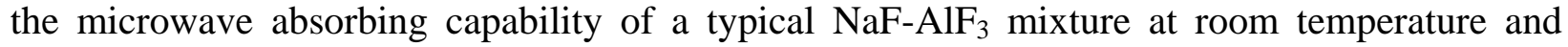
elevated temperatures.

\subsection{Experiments}

According to previous investigations on fluoride melting, the lowest melting temperature of fluoride in the $\mathrm{NaF}_{-} \mathrm{AlF}_{3}$ system is $684^{\circ} \mathrm{C}$ and occurs at the eutectic composition $\left(63.66 \% \mathrm{AlF}_{3}\right.$ and $36.34 \% \mathrm{NaF}$ by weight). The fluoride samples used for this study were prepared according to this ratio, using reagent grade chemicals. Both $\mathrm{NaF}$ and $\mathrm{AlF}_{3}$ were purchased from Alfa Aesar, a Johnson Matthey Company. Each sample weighed 2g.

The microwave furnace used for this study was a commercial microwave oven (Hotpoint, Model RVM1335, 2.45MHz, 900W) with modifications for additional resistance heating. Figure 2.1 shows a schematic of the modified furnace, with the actual furnace setup shown in Figure 2.2. A quartz tube (50 $\mathrm{mm}$ in diameter), wrapped with heating coil, was placed in the center of the furnace. A controller was used to power the heating coil and set heating temperature and holding time. A thermocouple with a metallic sheath was inserted through a small hole in the quartz tubing, the tip positioned $1.5-2.0 \mathrm{~cm}$ above the sample boat.

Initial experiments revealed that $\mathrm{NaF}$ and $\mathrm{AlF}_{3}$ absorb very little microwave energy at room temperature. Next, the fluoride samples were preheated to a series of temperatures to see if the dielectric constant of the fluoride mixture could change to start significant microwave absorption.

The modified microwave furnace was operated in the way that preheating could be accomplished in situ. First, a sample was preheated by resistance heating to a designated temperature, and then the resistance heating was shut off and microwave power was turned on. The sample temperature was recorded vs time. The resulting Temperature-Time curve was compared with the Temperature-Time curve of the same sample without microwave heating after preheating.

By comparing the Temperature-Time profiles (T-T curves) between the experiments with and without microwave heating, it is possible to evaluate the extent of microwave absorption of the fluoride. 

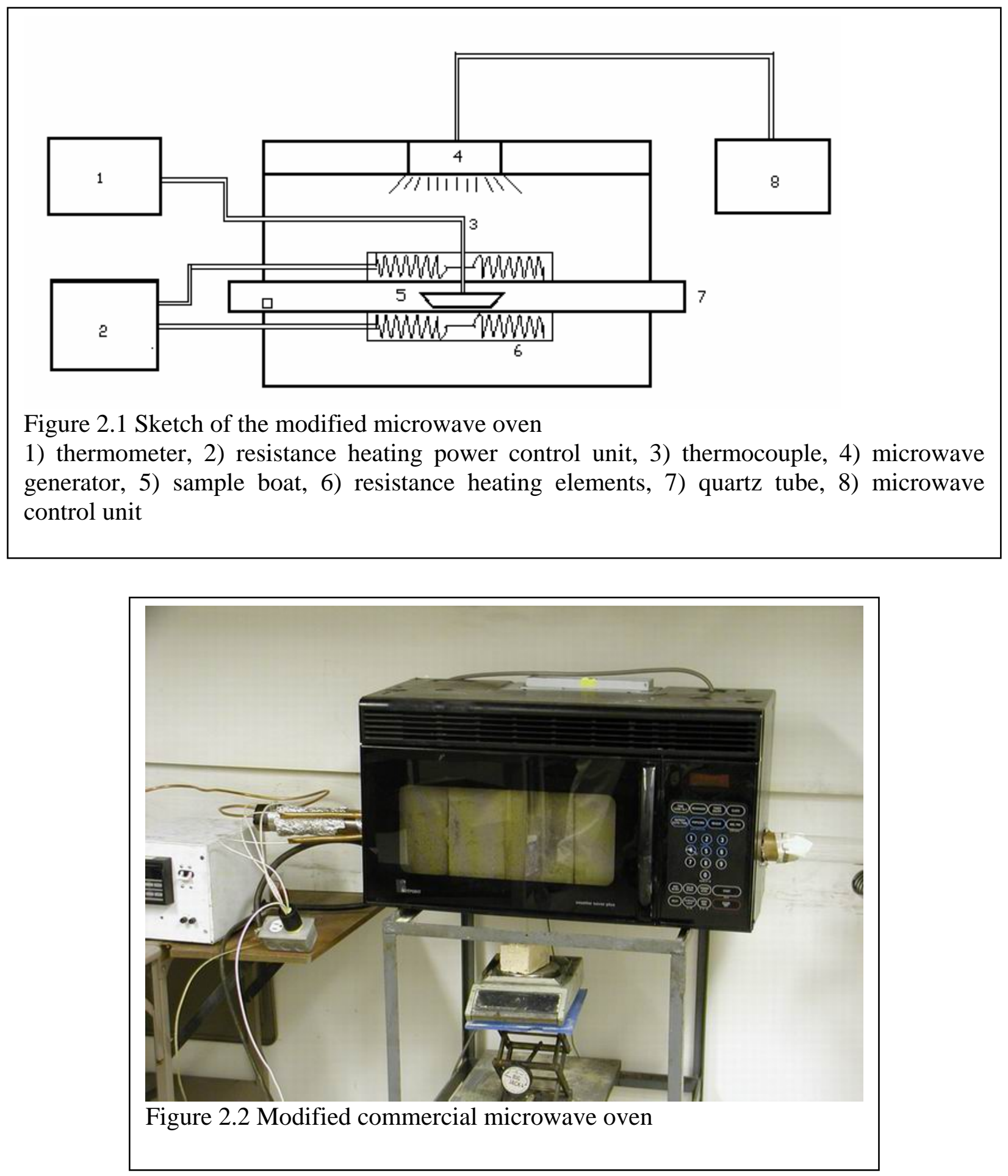


\subsection{Results and discussion}

Table 2.1 presents the preliminary microwave absorbing test results of several fluorides at room temperature. These fluorides are commonly used as constituents of the electrolyte for aluminum electrowinning. The results show that the fluorides have almost no microwave absorption at room temperature.

\begin{tabular}{|c|c|c|c|c|c|}
\hline \multicolumn{6}{|c|}{ Table 2.1 Microwave absorbing capabilities of fluorides } \\
\hline Sample & $\begin{array}{c}\text { Weight } \\
\text { g }\end{array}$ & $\begin{array}{c}\text { Microwave } \\
\text { mode }\end{array}$ & $\begin{array}{c}\text { Time } \\
\text { min }\end{array}$ & $\begin{array}{c}\text { Final sample } \\
\text { temperature, }{ }^{\circ} \mathbf{C}\end{array}$ & $\begin{array}{c}\text { Microwave chamber } \\
\text { temperature, }{ }^{\circ} \mathbf{C}\end{array}$ \\
\hline $\mathrm{MgF}_{2}$ & 3 & Multi-mode & 2.40 & 36 & 24 \\
\hline $\mathrm{CaF}_{2}$ & 3 & Multi & 2.40 & 44 & 24 \\
\hline $\mathrm{AlF}_{3} \cdot 3 \mathrm{H}_{2} \mathrm{O}$ & 3 & Multi & 2.40 & 34 & 24 \\
\hline $\mathrm{NaF}$ & 3 & Multi & 2.40 & 43 & 24 \\
\hline $\mathrm{LiF}$ & 3 & Multi & 2.40 & 42 & \\
\hline $\begin{array}{l}\text { Instrument: Sharp Carousel } 1200 \mathrm{~W} \\
\text { Room temperature: } 2{ }^{\circ} \mathrm{C}\end{array}$ \\
\hline
\end{tabular}

Table 2.2 presents the test results for the $\mathrm{NaF}-\mathrm{AlF}_{3}$ system. The samples were preheated to $500^{\circ} \mathrm{C}$, $550^{\circ} \mathrm{C}, 600^{\circ} \mathrm{C}, 650^{\circ} \mathrm{C}, 700^{\circ} \mathrm{C}$, and $750^{\circ} \mathrm{C}$ and held for five minutes at each set point by electric resistance heating. Microwave heating was then applied for an additional two or five minutes. Samples were also tested with only resistance heating applied to reach each temperature set point and held for either five or ten minutes. Figure 2.3 shows the appearance of three samples removed from the furnace after the experiments.

\begin{tabular}{|c|c|c|c|c|}
\hline \multicolumn{5}{|c|}{ Table 2.2 Physical appearance of fluoride powder after heating } \\
\hline $\begin{array}{c}\text { Preheating } \\
\text { temperature } \\
{ }^{\mathbf{C}} \mathbf{C}\end{array}$ & $\begin{array}{c}\text { Microwave heating after } \mathbf{5} \text { minute } \\
\text { resistance preheating }\end{array}$ & \multicolumn{2}{l|}{ Resistance heating only } \\
\hline & $\mathbf{2}$ min. & $\mathbf{5}$ min. & $\mathbf{5}$ min. & $\mathbf{1 0}$ min. \\
\hline 750 & $\begin{array}{c}\text { Completely } \\
\text { melted }\end{array}$ & $\begin{array}{c}\text { Completely } \\
\text { melted }\end{array}$ & Began to melt & $\begin{array}{c}7 / 8 \\
\text { melted }\end{array}$ \\
\hline 700 & $\begin{array}{c}\text { Completely } \\
\text { melted }\end{array}$ & $\begin{array}{c}\text { Completely } \\
\text { melted }\end{array}$ & Sintered & \\
\hline 650 & & Partially melted & Began to sinter & \\
\hline 600 & & Sintered & Began to sinter & \\
\hline 550 & & Began to sinter & No sintering & \\
\hline 500 & & No sintering & No sintering & \\
\hline
\end{tabular}

It was found that the fluoride treated by resistance heating only began to sinter at $600^{\circ} \mathrm{C}$ and melt at $750^{\circ} \mathrm{C}$ (Figure 2.3). In comparison, microwave irradiation apparently accelerated fluoride melting. The fluoride began to sinter with the microwave radiation after preheating at $550^{\circ} \mathrm{C}$ and partially melted by microwave radiation after preheating at $650^{\circ} \mathrm{C}$. Complete melting with recrystalization was observed with 2 minutes of microwave radiation following preheating at $700^{\circ} \mathrm{C}$. Preheating to $500^{\circ} \mathrm{C}$ followed by microwave heating did not show any changes to the 
physical appearance of the sample. This suggests that the fluoride becomes a good microwave absorber above $550^{\circ} \mathrm{C}$.

It was also noted that the microwave intensity was not high enough to increase or maintain the thermocouple temperature above the preheating temperature (Figure 2.4). However, microwave radiation did contribute somewhat to sample heating. Without microwave radiation, the samples cooled at faster rates. The duration of microwave heating was set for 5 minutes. After the microwave was shut off, the sample cooled at faster rates as well.

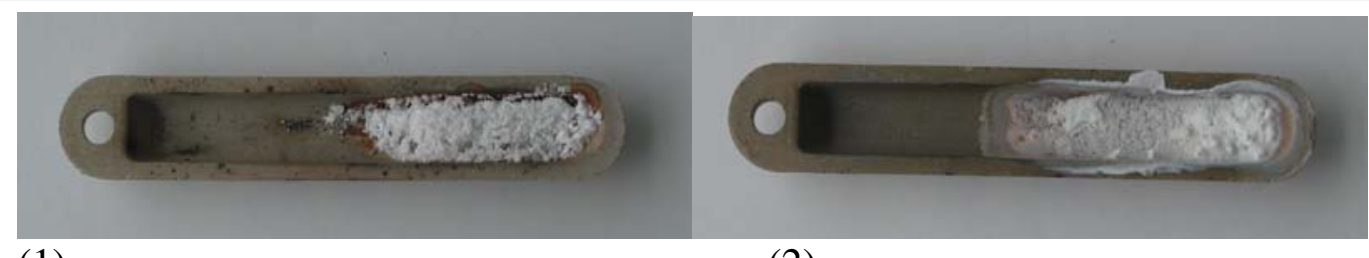

(1)

(2)

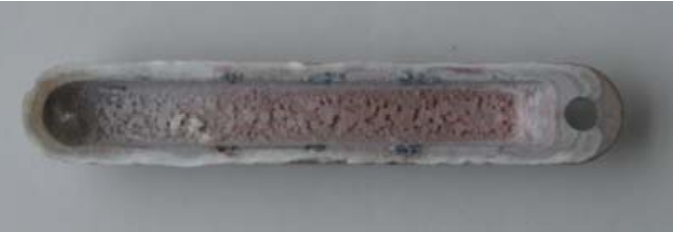

(3)

Figure 2.3 Physical appearance of fluoride after heating

(1) Resistance preheating at $750^{\circ} \mathrm{C}$ for 10 minutes; (2) 2 minute microwave heating after preheating at $650^{\circ} \mathrm{C}$, about $2 / 3$ fluoride was melted; (3) 2 minute microwave heating after preheating at $700^{\circ} \mathrm{C}$, the fluoride was completely melted and re-crystallized

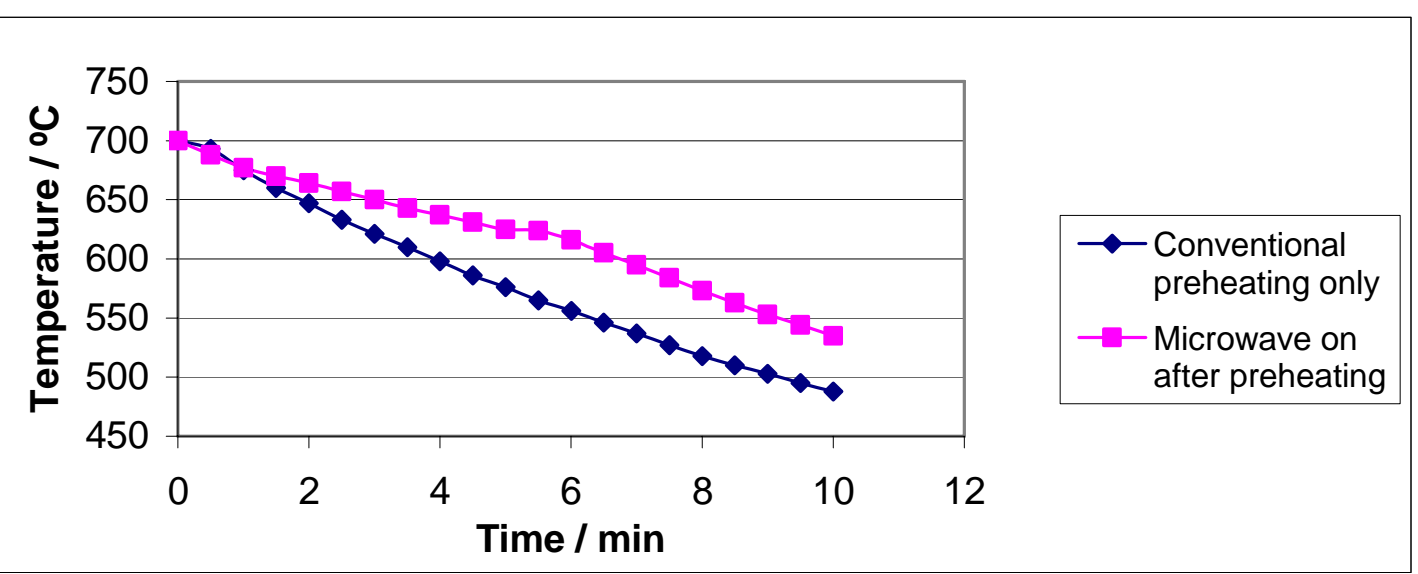

Figure 2.4 Cooling curve of sample after preheating at $700^{\circ} \mathrm{C}$ 
Table 2.2 also revealed inconsistency of melting points between microwave heating and resistance heating. The resistance heating resulted in melting of the fluoride at $750^{\circ} \mathrm{C}$. In comparison, the microwave heating resulted in melting of the fluoride at as low as $650^{\circ} \mathrm{C}$. It was believed that the inconsistency was due to the thermocouple reading. The thermocouple tip was 1.5 to $2 \mathrm{~mm}$ above the sample. It did not read the sample body temperature directly but the temperature adjacent to the sample. The heated small sample could not release enough heat to homogenate the sample body temperature and the adjacent temperature.

To rule out the potential microwave heating on the ceramic boat which held the fluoride, a steel boat was also used to hold the fluoride. The temperature-time curves of the experiments using the ceramic boat and the steel boat were compared. The cooling curve of the sample held in the steel boat was parallel to that held in the ceramic boat, but at $10-15^{\circ} \mathrm{C}$ lower. The heat loss from the steel boat was more rapid, which accelerated the cooling of the sample (Figure 2.5). However, this did not prevent fluoride melting from occurring. Since the steel boat does not absorb microwave energy, the fluoride melting has to result from the absorption of microwave radiation by the fluoride.

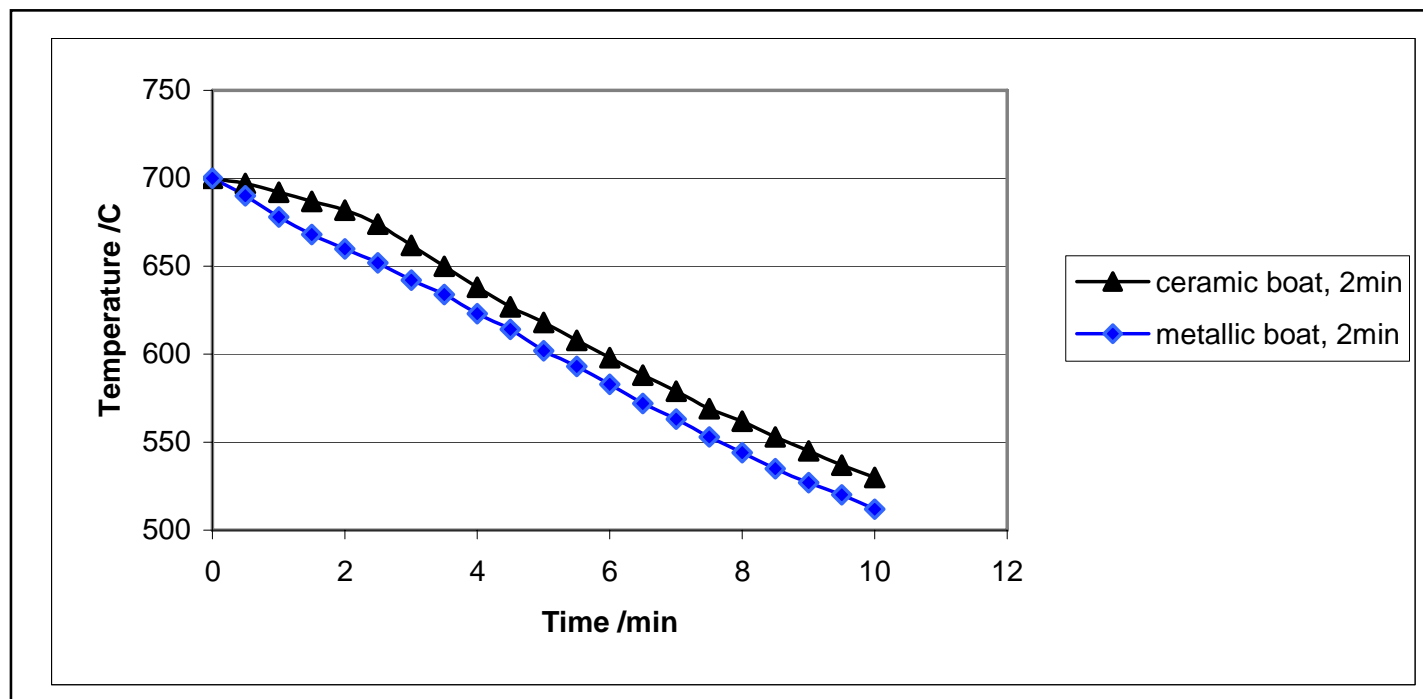

Figure 2.5 Comparison of the cooling curves using metallic boat and ceramic boat

Since the thermocouple tip was not embedded in the fluoride sample, it is almost certain that the fluoride sample temperature under microwave radiation was actually higher than the thermocouple reading. However, it is also problematic to embed the thermocouple tip inside the sample because this may introduce a potential interaction between the microwave radiation and the thermocouple, which has occurred in many microwave heating research studies.

\section{Confirming experiments}

To further confirm the microwave absorption of the fluoride over a temperature range and rule out the thermocouple reading uncertainty, more experiments were carried out using a separate conventional electric furnace and a separate microwave oven. In the experiments, the composition of the fluoride samples was the same as the previous experiments (consisting of 
63.66wt\% $\mathrm{AlF}_{3}$ and $36.34 \mathrm{wt} \% \mathrm{NaF}$ ). Each sample weight was increased from 2 grams to 50 grams.

In the experiments, each fluoride sample, contained in a ceramic crucible, was preheated to a desired temperature, held for $30 \mathrm{~min}$, and then quickly transferred into a microwave oven $(2.45 \mathrm{MHz}, 1100 \mathrm{~W})$. Microwave power was turned on for several minutes. The results are shown in Table 2.3.

After conventional electric heating at $550^{\circ} \mathrm{C}$ for 30 minutes, the samples showed no sintering. Even heated at $600^{\circ} \mathrm{C}$ for 30 minutes, the sample was only slightly sintered.

The samples preheated at $500^{\circ} \mathrm{C}$ or below, followed by microwave heating for 5 minutes showed no physical changes. But after preheating at $550^{\circ} \mathrm{C}$ followed by microwave heating for 2.5 minutes, the samples began to melt. If microwave heating increased to 4 minutes, $90 \%$ of the sample was melted (Figure 2.6). After preheating at $600^{\circ} \mathrm{C}$, the sample started melting with 15 second microwave heating, induced red flame with 20 second microwave heating, and partially (about 1/3) melted with 60 second microwave heating. These phenomena showed that the fluoride becomes a strong microwave absorber above $550^{\circ} \mathrm{C}$.

\begin{tabular}{|c|c|c|}
\hline \multicolumn{3}{|c|}{ Table 2.3 Fluoride microwave absorption at elevated temperatures } \\
\hline $\begin{array}{c}\text { Preheating temperature } \\
{ }^{\mathbf{o}} \mathbf{C}\end{array}$ & $\begin{array}{c}\text { Surface features of samples after } \\
\text { preheating for 30 minutes }\end{array}$ & Under microwave irradiation \\
\hline 300 & No sintering & 5 minutes, no sintering \\
\hline 400 & No sintering & 5 minutes, no sintering \\
\hline 500 & No sintering & 5 minutes, no sintering \\
\hline 550 & No sintering & 2.5 minutes, begin to sinter \\
& Slightly sintered & 15 seconds, sintered \\
& & 20 seconds, red flame; \\
\hline 600 & 60 seconds, $1 / 3$ melted \\
\hline
\end{tabular}




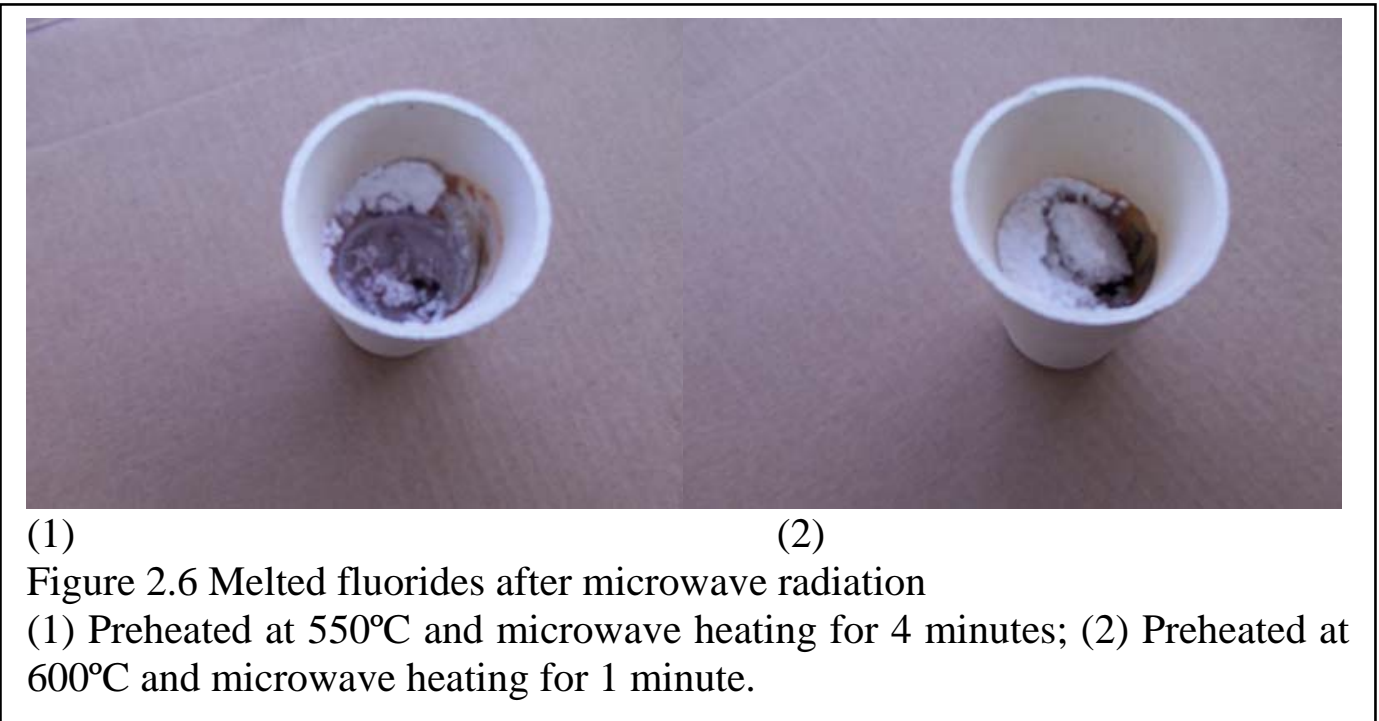

\subsection{Conclusion}

The commonly used fluorides for aluminum electrowinning: $\mathrm{MgF}_{2}, \mathrm{CaF}_{2}, \mathrm{AlF}_{3} .3 \mathrm{H}_{2} \mathrm{O}, \mathrm{NaF}$, and $\mathrm{LiF}$ are poor microwave absorption materials at room temperature. The eutectic composition of $63.66 \mathrm{wt} \% \mathrm{AlF}_{3}$ and $36.34 \mathrm{wt} \% \mathrm{NaF}$ is also a poor microwave absorption material at room temperature, but becomes an excellent microwave absorption material at temperatures above $550^{\circ} \mathrm{C}$. 


\section{Design and Fabrication of Microwave Assisted Electrolytic Cell}

One objective of this research was to design and fabricate a bench top microwave assisted aluminum electrolytic cell which can be used to conduct primary aluminum electrowinning tests in our laboratory. This type of apparatus is totally new and has never been built before. To carry out the design, we collected and reviewed literature, consulted with the industry collaborators, defined the technical requirements, discussed potential problems, and developed the detailed design. The apparatus was fabricated jointly by Michigan Tech and a local company.

The original plan was to design and fabricate the microwave electrolytic cell with a superalloy inert anode and a superalloy wetted cathode. The funding agency (Department of Energy) wished to concentrate on the effect of microwave irradiation on aluminum electrowinning. By agreement, we decided to still use a graphite anode along with a superalloy cathode for the apparatus.

\subsection{Basic technical requirements and features}

The basic technical requirement for this apparatus is to imitate the current production of primary aluminum with the same operating principles and similar operating conditions to current industrial baths with additional microwave irradiation. This apparatus has the following features:

- graphite anode,

- superalloy cathode,

- working temperature $750-1000^{\circ} \mathrm{C}$ with a fluoride electrolyte,

- 100 amps cell current, 5 volts, 0.8 amps $/ \mathrm{cm}^{2}$ current density, and

- 1.75 inches between anode and cathode.

The selected superalloy was "Inco Alloy HX Nickel” produced by Special Metals Corporation, containing $47.5 \%$ nickel, $21.8 \%$ chromium, $18.5 \%$ iron and 9\% molybdenum, with outstanding weldability and oxidation resistance. This alloy can be used in highly corrosive environments and in temperatures up to $1200^{\circ} \mathrm{C}$.

The microwave energy was supplied by MCR200, which was manufactured by Wavemat Inc., Plymouth, Michigan. This microwave system was originally designated for ceramic sintering experiments but utilized for this project. MCR200 has a good control system which can control the microwave output up to $3 \mathrm{~kW}$, adjust the antenna and the tuner to minimize reflection, and indicate forward and reflected powers and temperature.

\subsection{Potential problems}

We expected to face several potential problems which we had to consider in the design. These problems included:

- working condition at high temperature;

- introduction, distribution and screen of microwave;

- insulation of electric current among anode, cathode, waveguide, and thermocouple;

- accuracy of temperature measurement in the microwave field; 
- prevention of volatilization and erosion of fluoride;

- prevention of oxidation and burning of graphite electrode;

- maintaining a constant distance between anode and cathode, while (or after) the electrodes were consumed;

- preheating electrolyte sample from room temperature to melting point;

- loading and removing samples;

- thermal insulation of the bath cavity; and

- operation safety.

\subsection{Design considerations}

(1) Anode Design: For the purpose of obtaining evenly-distributed thermal and microwave fields, efficacious temperature measurement and simplicity of manufacture, the anode shape was a cylinder and the shape of cathode was correspondingly circular. The bottom surface area of the anode faced to the cathode was determined to be not less than $125 \mathrm{~cm}^{2}$ (19.38 square inch), based on the total power of direct current of $100 \mathrm{~A}$ and current density of $0.8 \mathrm{~A} / \mathrm{cm}^{2}$. The anode was 8 inches in diameter and 12 inches in length. There was a groove cut on the cylindrical surface of the anode for insertion of two half rings to hold the anode on the pot cover.

(2) Cathode Design: The cathode was made of $1 / 4$ " thick Inco Alloy HX Nickel plate with the shape of a pot. The cathode was mounted on the top cover of a large cylindrical steel shell with a mica sheet in between as an electric insulator. The top cover and the cylindrical shell were made of 3/16" thick steel. Underneath the cathode pot, an electric heater was installed for preheating the electrolyte in the pot to its melting point. Alumina fiber filled in between the cathode and the cylindrical shell for thermal insulation.

(3) Control of anode and cathode distance: The anode was held by the steel cover fixed on the cylindrical shell. The cathode was movable, up and down against the anode. The distance between the anode and cathode can be adjusted from 0 to 5.75 inches. If the anode is consumed for more than 3 inches, the anode will be replaced. A jack was used to support the cathode and move it up and down. The horizontal space between the anode and the cathode was much smaller than the vertical distance between the anode and the cathode. This design was to maximize the effective heating area, but it might cause local over current. A BN coating was applied on a part of the cathode side surface near the bottom.

(4) Introduction, distribution, screen and test of microwave field: We purchased a microwave generator (model MH1250S-211BA, 1250W, 2.45GHz) with a power supply, both made by Muegge Co., Germany. Later, we decided to replace this microwave generator with our existing MCR 200 microwave system because of better control and large power. According to the frequency of the microwave generator and industrial standards, the microwaves are transferred by a set of rectangular guide tubes with an internal size of $1-11 / 16$ by $3-6 / 16$ square inches. The isolator, directional coupler and tuner are installed to optimize the microwave delivery and protect the magnetron. To evenly distribute microwaves in the bath and into the sample, as well as for comparison with current industry processing, microwaves were introduced from the center of the graphite anode into the bath cavity. The microwave pathway through the anode is a vertical rectangle, so a straight microwave guide can be inserted appropriately. On the lower end 
of the anode, a cross slot (1 inch in width and 4 inches in depth) was cut so that microwaves can travel to everywhere in the bath cavity during electrowinning operations. The end of the waveguide was inserted 6 inches deep into the anode to prevent microwave leakage. In order to prevent microwave leakage from the periphery of the cylinder anode, the top of the pot cover consisted of two layers of steel plate and one layer of mica sheet. The mica was used to insulate the electrodes. The flange located at the top of the anode was 2 inches wider all around, and sandwiched with mica sheet to seal off microwave leakage and insulate the anode and waveguide. It also prevented fluoride vapor from getting into the waveguides. This flange was fastened by bolts and nuts with ceramic shells and cushions.

(5) Temperature measure: The bath temperature was measured with a thermocouple. There was a hole on the anode to insert a thermocouple vertically. Having a stainless steel sheath, the tip of thermocouple must be kept under the surface of the melted fluoride and at (or over) the surface of the lower end of the anode to prevent tip discharge. The location of the hole was close to the center of the fluoride bath.

(6) Initial method of preheating samples: Considering that it is difficult to install an electric heater to preheat electrolyte samples in the cathode, an electrolyte sample would be preheated and melted in another oven, then poured into the cathode bath. Before electrowinning operations, the cathode pot needs to be preheated to $300^{\circ} \mathrm{C}$ to reduce chilling to incoming melted samples (fluorite). The method of preheating would be to spray a thin layer of carbon powder on the bottom of the cathode and contact the anode and the cathode through the layer of carbon by raising the cathode. Direct voltage would be applied to the anode and cathode. By controlling the current and monitoring the temperature using the thermocouple, the cathode pot would be preheated to the desired temperature. The purpose of the thin layer of carbon powder was to provide an even contact between the anode and cathode and prevent arcing.

(7) Ventilation: There was a steel tube on the top of the pot cover for fluoride vapor escape. A fan was used to pull out the vapor. The experiments were done under a ventilating hood.

(8) Operation viewing: There was a viewing hole on the right top of the anode. The bath inside during an operation would be viewed through the hole and though a mirror mounted above the hole and inclined at $45^{\circ}$.

(9) Control panel: For a safe and convenient operation, the microwave power and electrowinning system would be integrated into one unit. The following functions were provided on the control panel: Cooling water switch, water meter, emergency switch, fuse indicator, thermocouple meter, AC (to magnetron head) indicator, AC switch, voltage and current meter for AC, DC (to bath) indicator, DC switch, voltage and current meter for DC, and microwave power supplier (microwave controller).

\subsection{Results}

The apparatus design is shown in Figure 3.1. During fabrication, installation and operations, some modifications have been made. Figures 3.2-3.11 show a few views of the fabricated unit. 


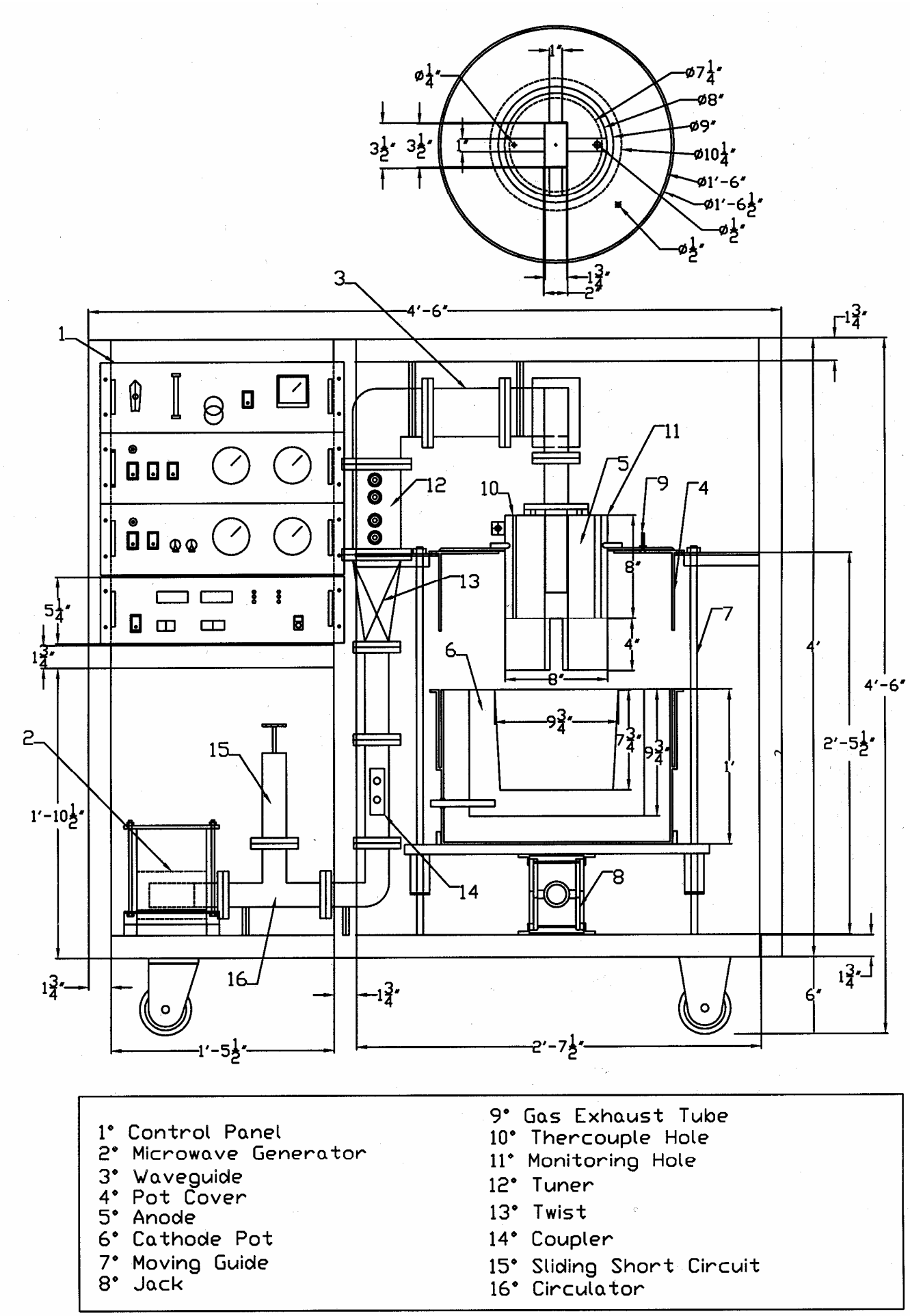

Figure 3.1 Microwave assisted electrolytic cell 

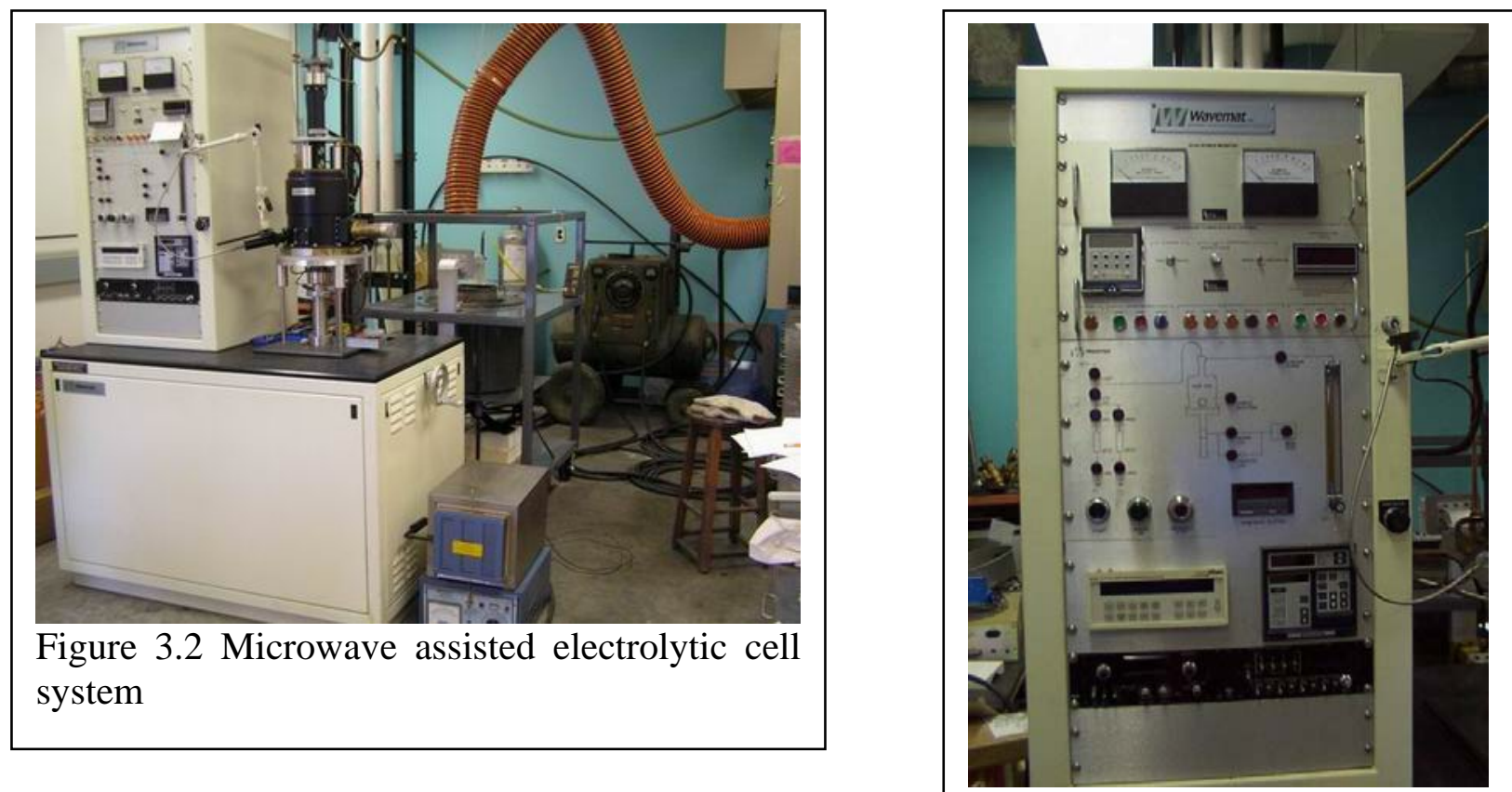

Figure 3.3 Control panel of microwave power (Microwave power is adjustable)

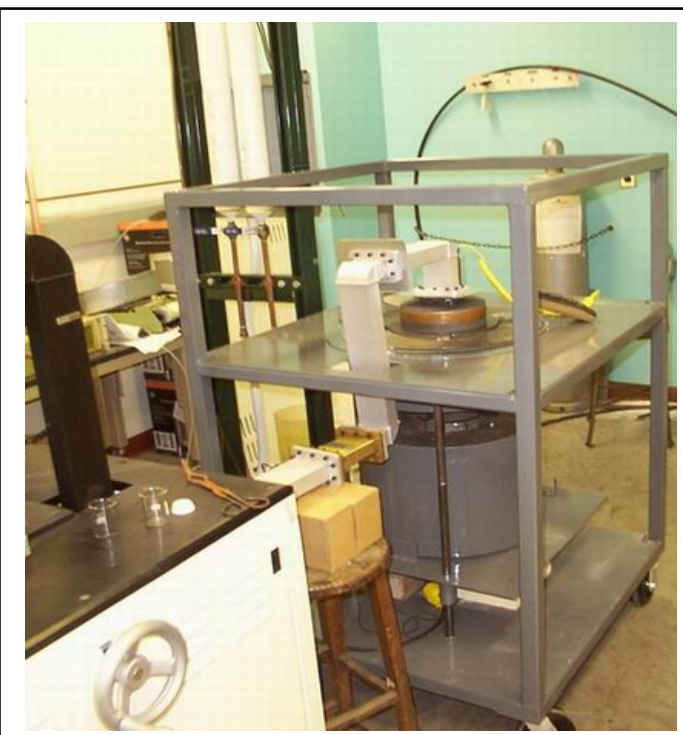

Figure3.4 Electrolyte cell

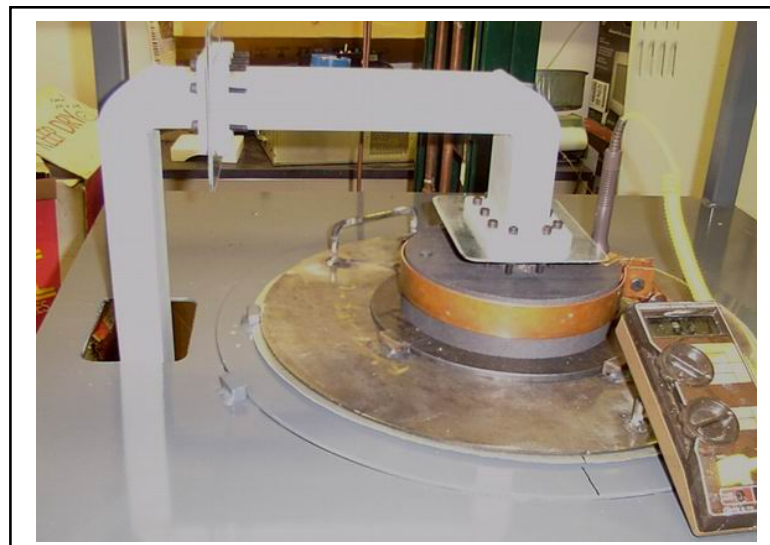

Figure 3.5 Waveguide and graphite anode 

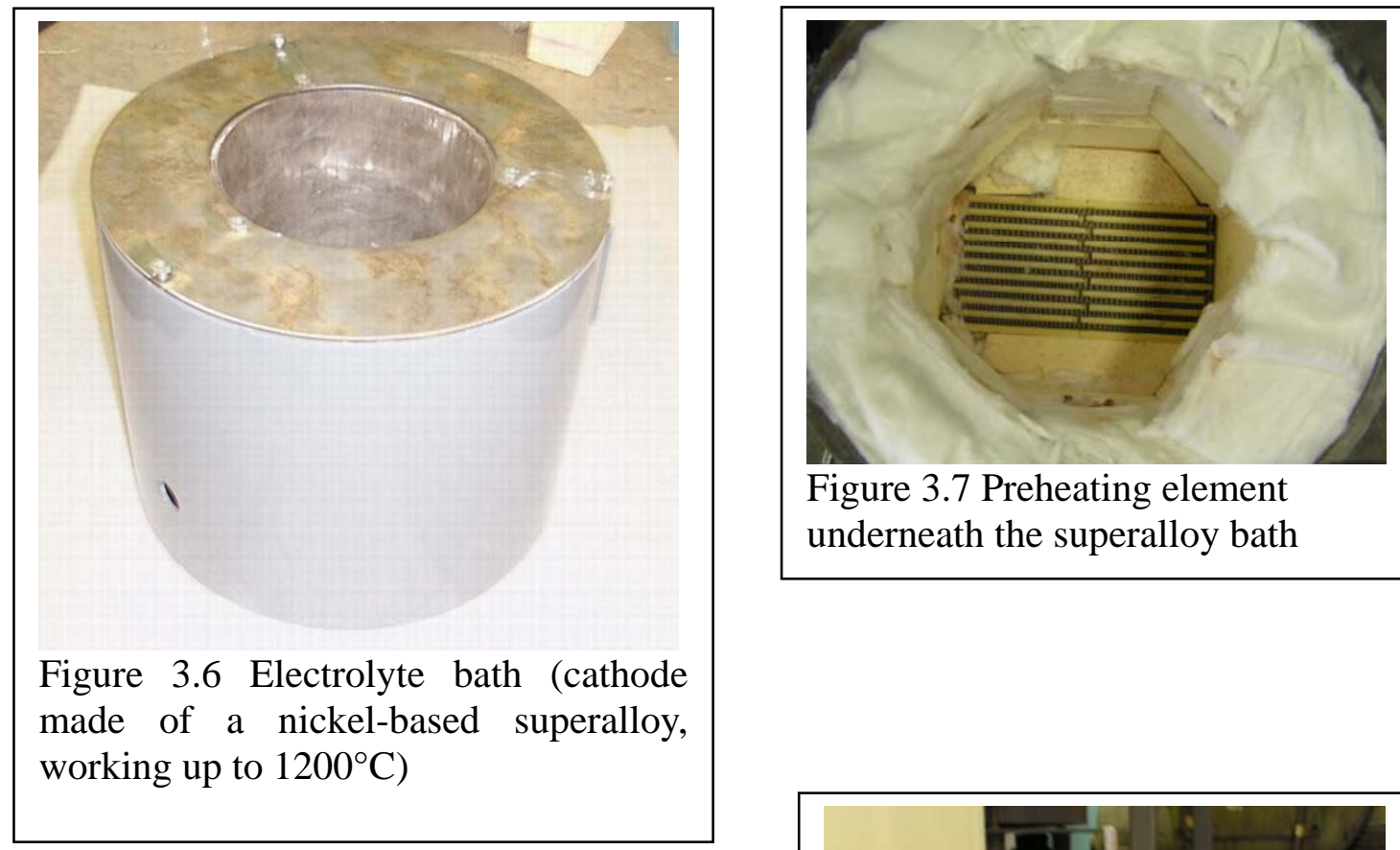

Figure 3.7 Preheating element underneath the superalloy bath

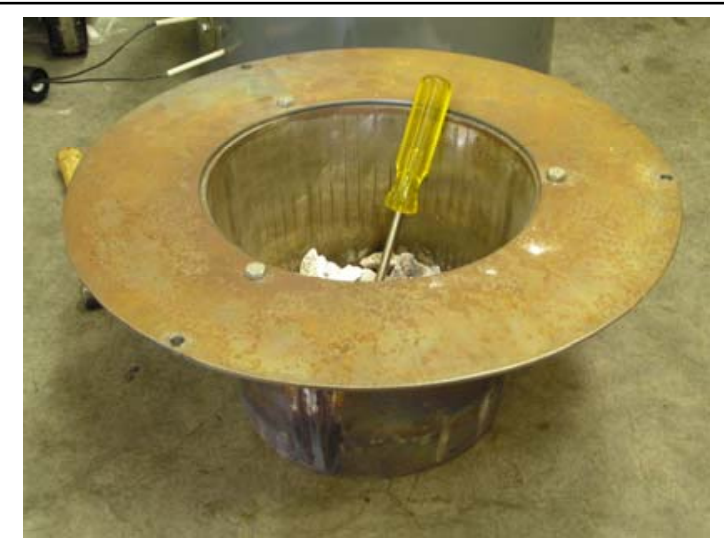

Figure 3.8 Nickel-based superalloy bath

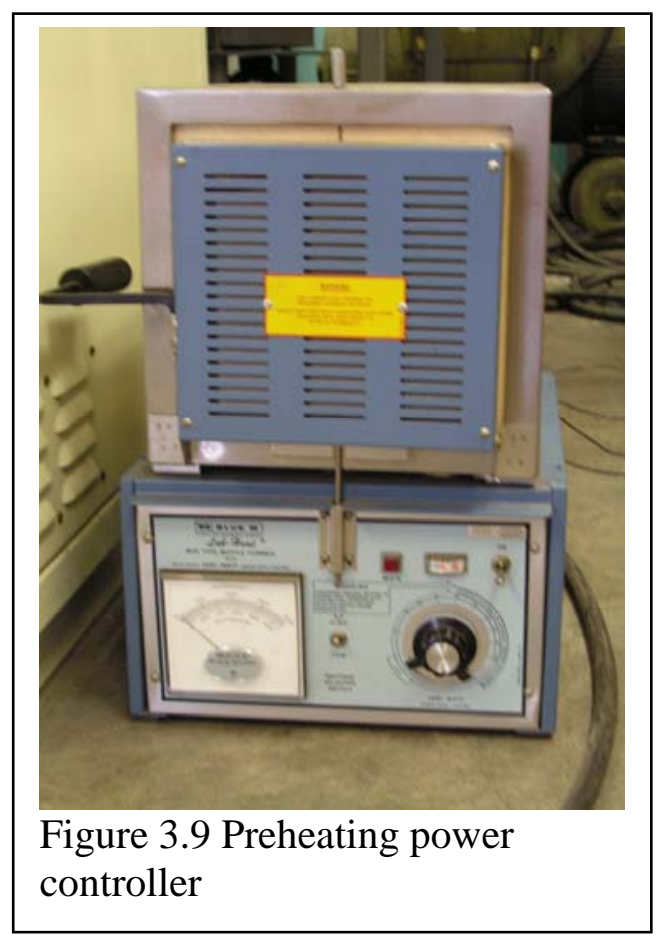



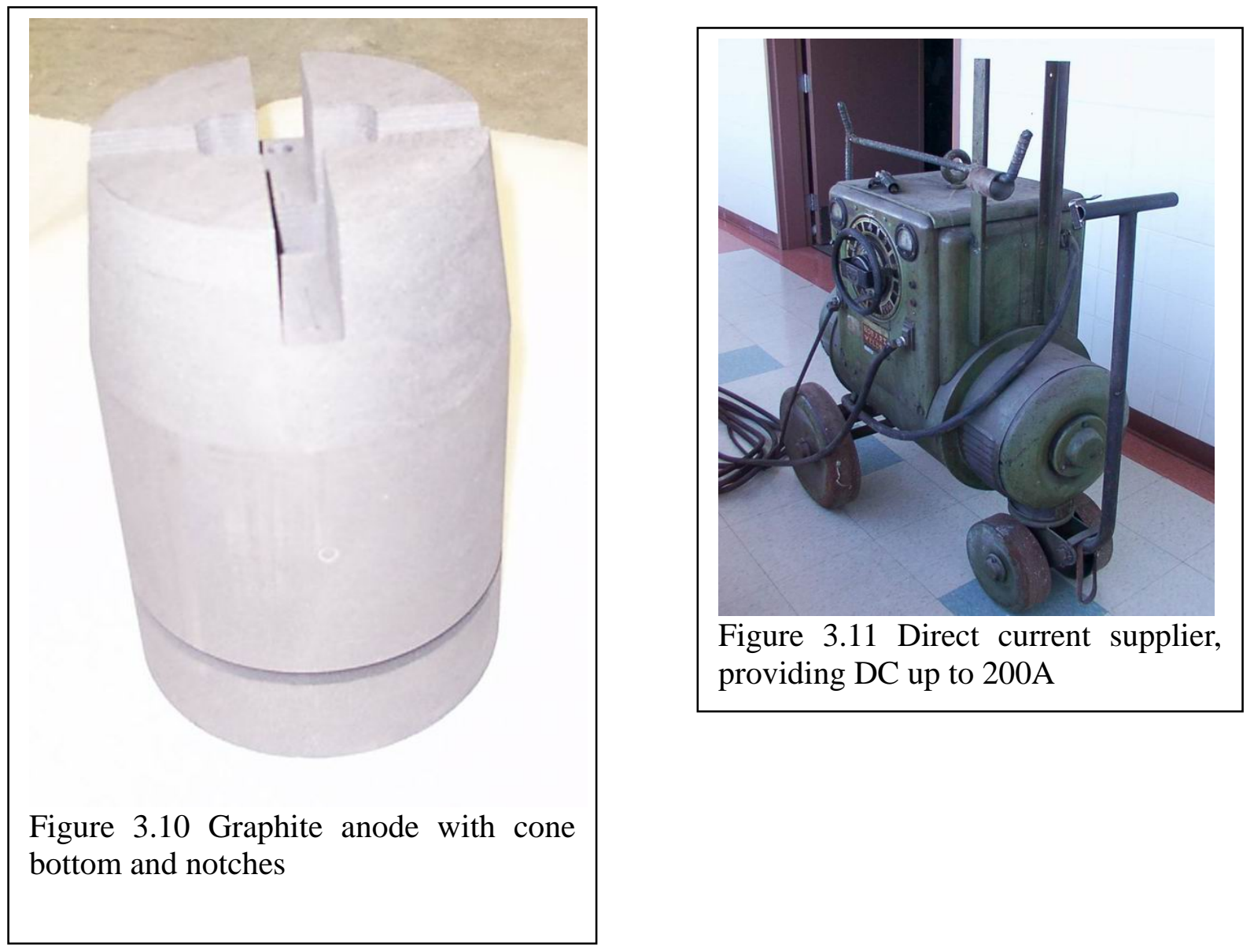


\section{Electrowinning Tests}

The purpose of this study is to find out the effect of microwave irradiation on aluminum electrowinning through basic comparison tests with and without microwave irradiation.

\subsection{Experiments}

\subsubsection{Electrolyte}

The electrolyte used in this study was provided by Century Aluminum Co. It is the same bath material used by Century Aluminum for daily production. This electrolyte is a mixture of aluminum fluoride, sodium fluoride, calcium fluoride and alumina. The received bath material was first crushed with a vibratory mill and passed through a 16 mesh screen. The composition of the bath material is $55.23 \mathrm{wt} \%$ aluminum fluoride, $34.42 \mathrm{wt} \%$ sodium fluoride, $5.66 \mathrm{wt} \%$ calcium fluoride, and $4.69 \mathrm{wt} \%$ alumina. The melting temperature of this compound is theoretically about $700^{\circ} \mathrm{C}$ (Figure 4.1).

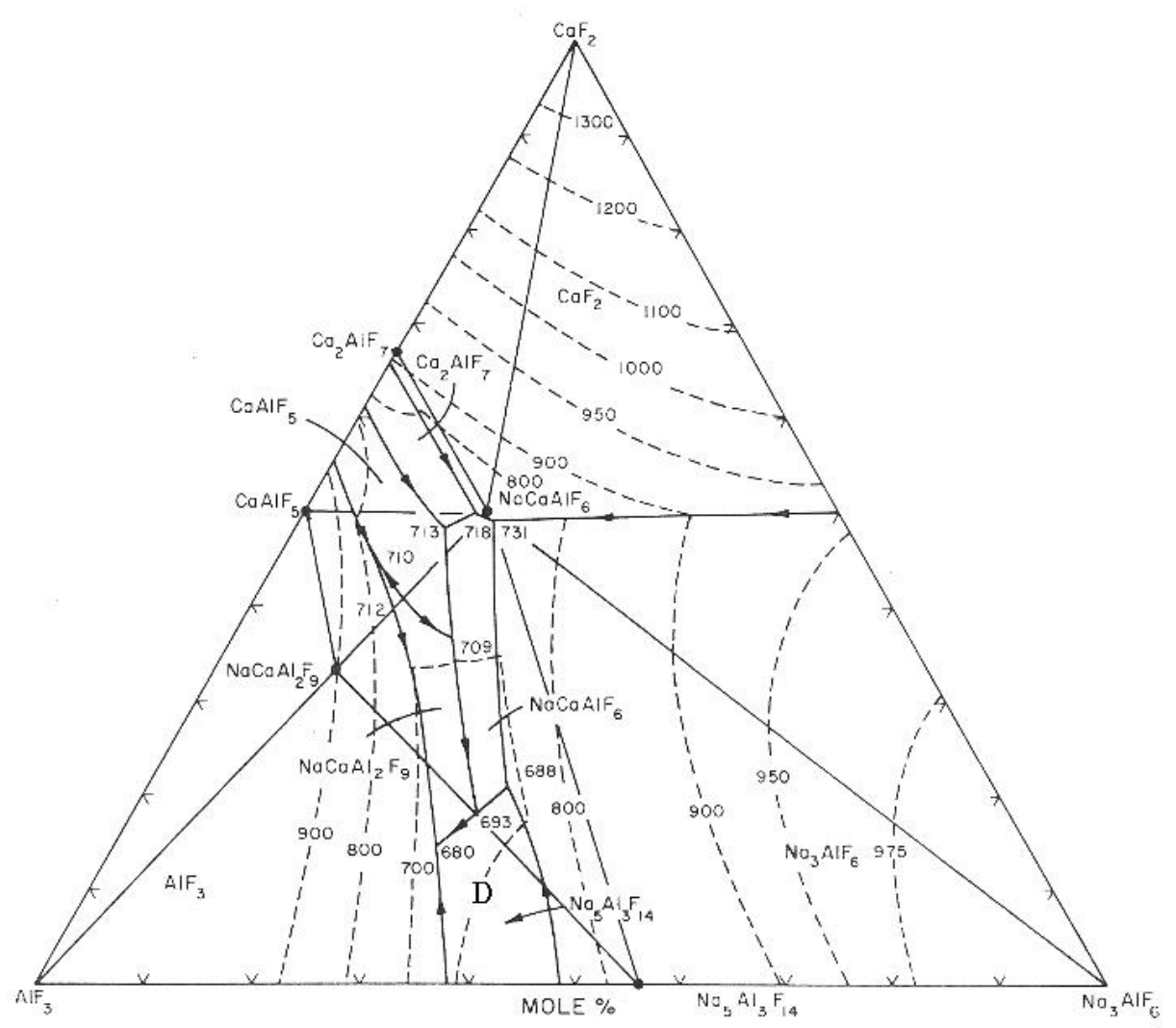

Figure 4.1 The melting temperature of the fluoride mixture is $700^{\circ} \mathrm{C}$ based on the $\mathrm{CaF}_{2}-\mathrm{AlF}_{3}-\mathrm{Na}_{3} \mathrm{AlF}_{6}$ phase diagram (Point $\mathrm{D}, \mathrm{CaF}_{2}-9.92 \mathrm{~mol} \%$, $\mathrm{AlaF}_{3}-52.66 \mathrm{~mol} \%$, $\mathrm{Na}_{3} \mathrm{AlF}_{6}-37.42 \mathrm{~mol} \%$ ) (Phase diagram cited from D.F.Craig and J.J.Brown, 1980) 
According to our XRD analysis, this material is made up of a major crystalline phase: chiolite $\left(\mathrm{Na}_{5} \mathrm{Al}_{3} \mathrm{~F}_{14}\right)$, and minor crystalline phases: sodium aluminum fluoride, cryolite $\left(\mathrm{Na}_{3} \mathrm{AlF}_{6}\right)$ and aluminum fluorite $\left(\mathrm{AlF}_{3}\right)$, as seen in Figure 4.2.

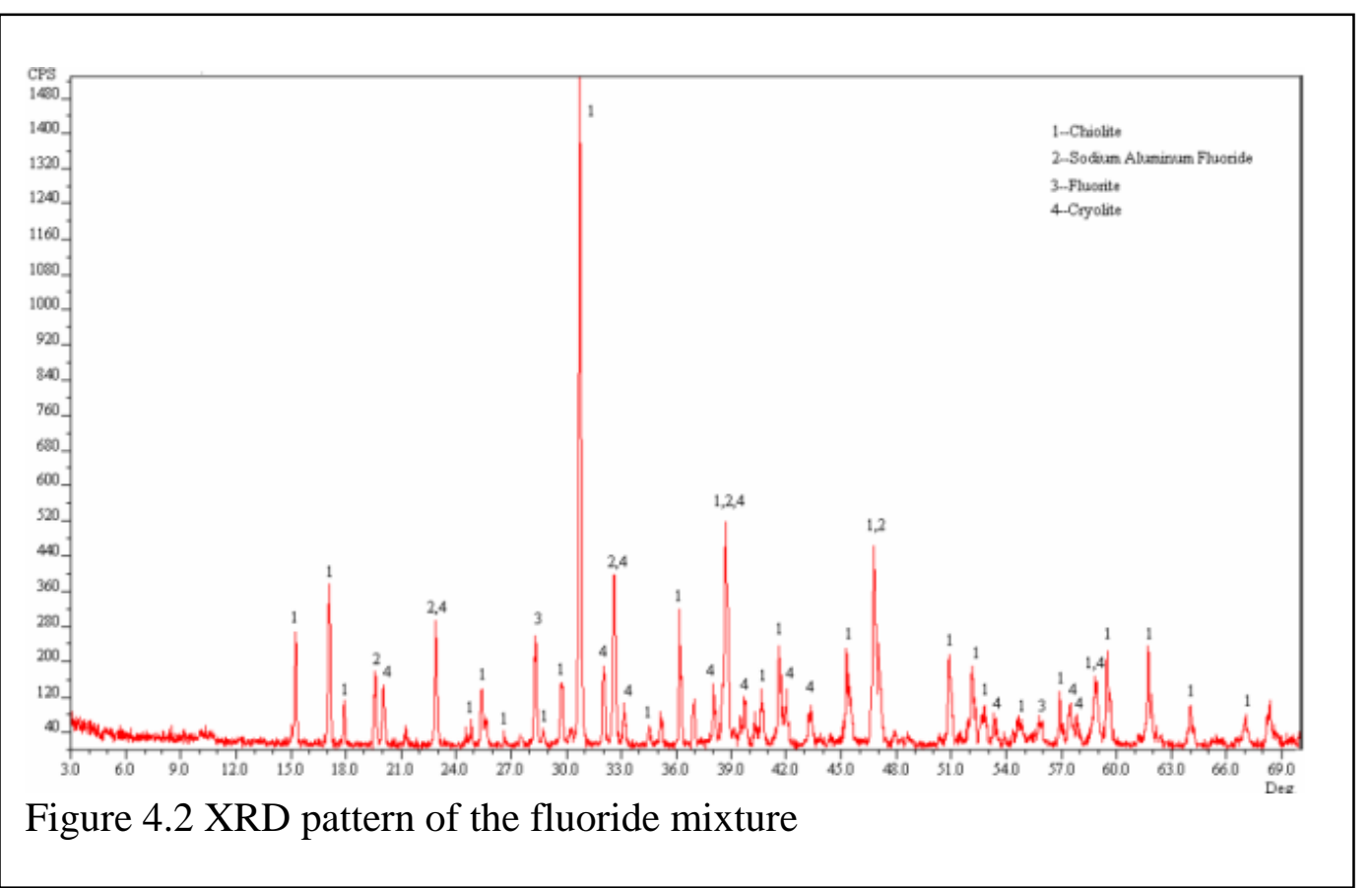

The weight of each sample for the electrowinning test was $2500 \mathrm{~g}$, which ensured the molten electrolyte adequately filled the space between the anode and cathode.

All electrowinning tests with and without assisted microwave irradiation followed the basic procedure below:

(1) Preheating an electrolyte sample in the cell to $650^{\circ} \mathrm{C}$ using the electric heater underneath the cell (This temperature was the sample surface temperature. The sample bottom temperature was in the range of 900 to $960^{\circ} \mathrm{C}$. At this condition, the electrolyte became molten and showed electric conduction).

(2) Adjusting the distance between anode and cathode to 1" $(2.54 \mathrm{~cm})$.

(3) Applying DC voltage to the anode and the cathode, and adjusting the direct current to 200A (The voltage meter showed about $5 \mathrm{~V}$ between the electrodes).

(4) Turning on the microwave power and delivering $1 \mathrm{~kW}$ microwave into the cell for microwave assisted electrowinning. (The reflection of microwave was controlled to be less than $0.05 \mathrm{~kW}$ ). This step was skipped for conventional electrowinning tests.

(5) Maintaining the preheating power, DC power and microwave power for 60 minutes.

(6) Shutting down the microwave power, DC power and preheating power.

(7) Recording the bottom and surface temperatures of the molten sample.

(8) Lowering the cathode and cooling the electrolyte to room temperature. 


\subsubsection{Product Characterization}

Each electrolytic product (slag) was broken into pieces after cooling. The cross sections of the broken samples were checked for structure and the presence of metallic aluminum.

XRD, SEM and EDS methods were employed to investigate the structures and the chemical compositions of the products.

The XRD instrument used for the characterization was a Scintag XDS2000 Powder Diffractometer. The operational parameters are: $\mathrm{CuK \alpha}$ target, slits to X-ray tube at 1 and $2 \mathrm{~mm}$, slits to detector at 0.3 and $0.5 \mathrm{~mm}$, step scan model, $0.02^{\circ}$ step size, and 0.48 second count time. The scan ranges were selected with $2 \theta=5-60^{\circ}$. All of the backgrounds of the peaks were removed with the "Manual Spline Curve Fitting" method of the DMSNT program.

The SEM instrument used for the characterization was JEOL 6400 Scanning Electronic Microscope. The acceleration voltage used was $20 \mathrm{kV}$. The elements including $\mathrm{Al}, \mathrm{Na}, \mathrm{Ca}, \mathrm{Mg}$, $\mathrm{Fe}, \mathrm{Si}, \mathrm{Cr}, \mathrm{Ni}$ and $\mathrm{F}$ were determined by the attached EDS system. The live time for signal collection was 100 seconds and the dead time was less than $30 \%$.

\subsection{Results and discussions}

\subsubsection{Layer structures of the slags}

Figure 4.3 shows the normal slag appearance after electrowinning. The solidified slags in the bath were 3.5$5 \mathrm{~cm}$ in thickness. Due to uneven shrinkage in the cooling process, the thickness at the center was less than at the edges. The slags had a multi-layer structure, both with and without microwave irradiation. Based on distinguishing features, a slag was divided into top and bottom sections. Furthermore, the upper section can be divided into three layers and the bottom

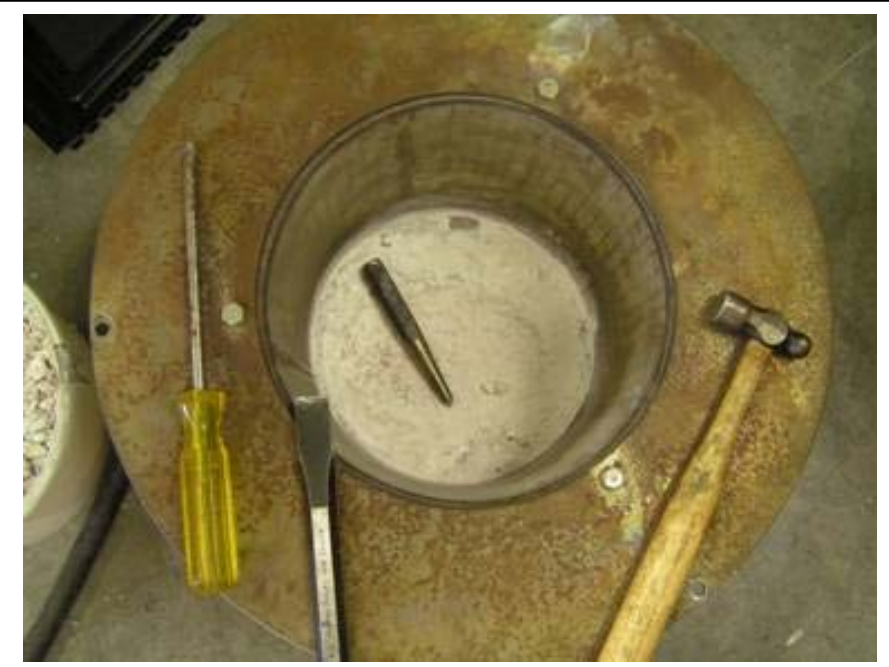

Figure 4.3 Normal appearance of slag after electrowinning section can be divided into two layers (Figure 4.4).

Upper section:

(1) Surface film: thin layer $(<1 \mathrm{~mm})$, white, solid, and microcrystalline-glass structure.

(2) Microcrystalline layer: white, hard solid and about $1 \mathrm{~cm}$ in thickness. Many pores can be seen. The pore sizes were less than $2 \mathrm{~mm}$. The porosity was less than $30 \%$.

(3) Porous layer: $1-2 \mathrm{~cm}$ thick and grey to dark-grey. The porosity was usually greater than $60 \%$. The composition was the same as the microcrystalline layer. 
Lower section:

(4) Dendrite crystal layer: $1-1.5 \mathrm{~cm}$ in thickness, light grey to grey, and fully crystallized with vertical dendrites.

(5) Coarser crystallized layer: $<1 \mathrm{~cm}$, white-grey, and solid coarse granular crystals. Metallic aluminum beads can be seen near the bottom of this layer.

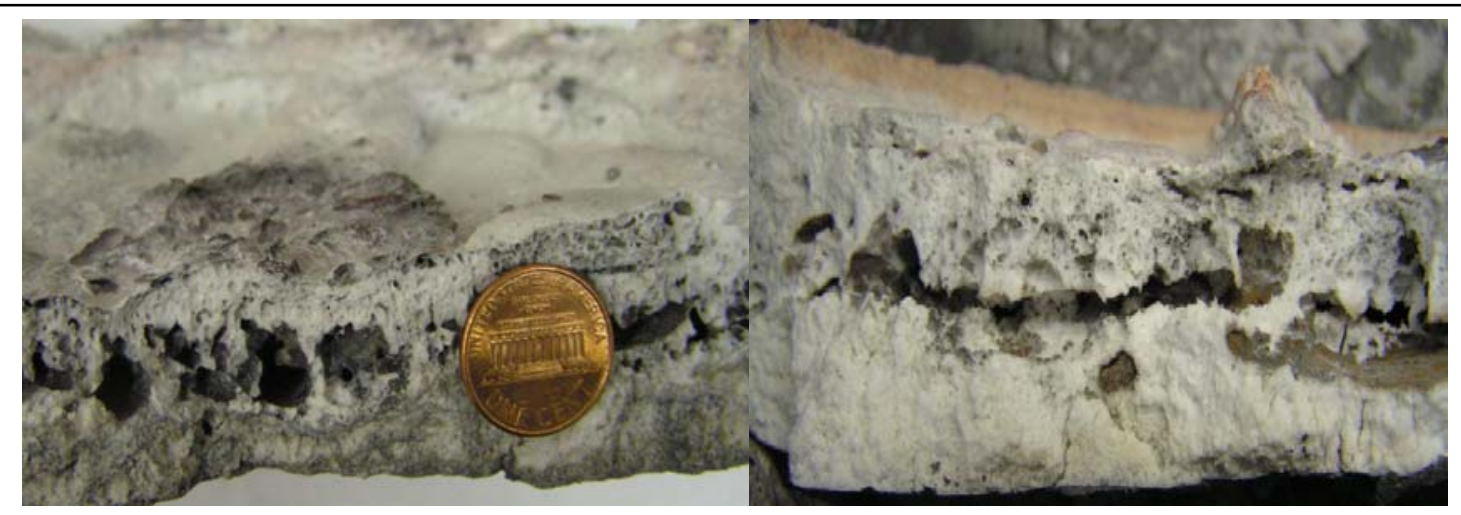

Figure 4.4 Multi-layer structures of solidified slags (with microwave irradiation) (Left): lower section shows gray color in one slag; (Right): lower section is white but denser in another slag.

In addition, numerous white dendrites can be seen on the bottom surface of the graphite anode. The thickness was in a range of 2 to $5 \mathrm{~mm}$ (Figure 4.5).

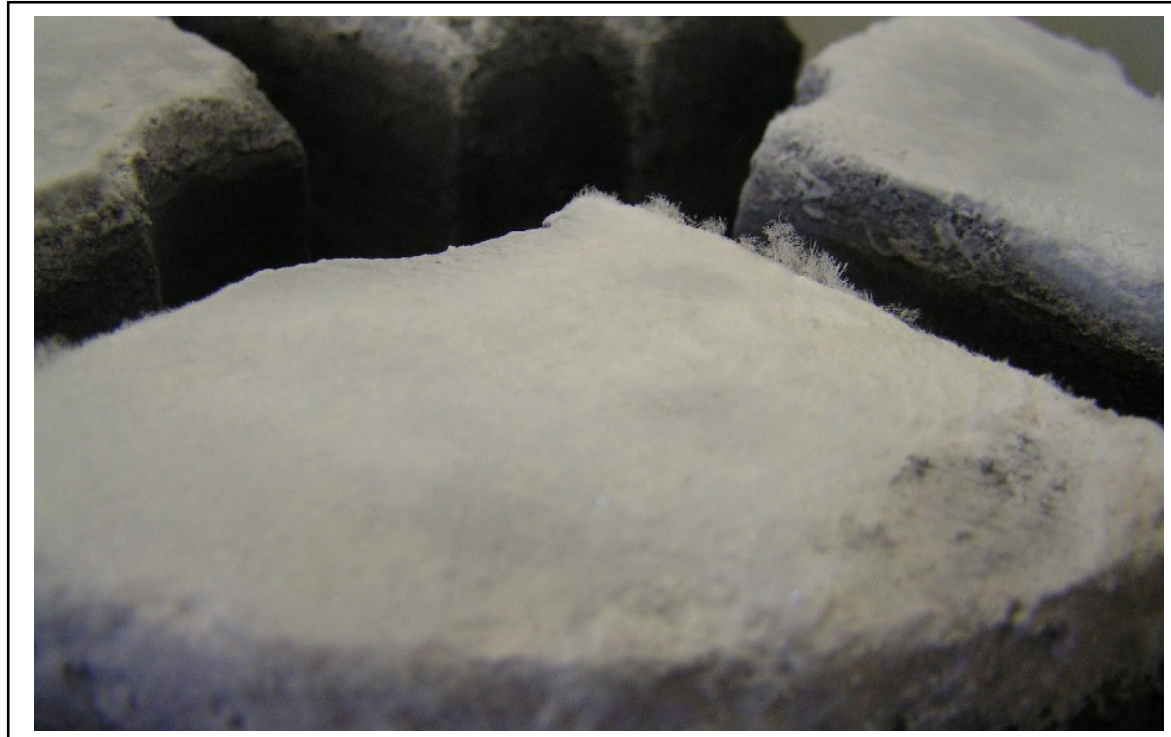

Figure 4.5 Dendrites on the bottom surface of graphite anode 
The major difference between the slag samples with and without microwave irradiation was the pore size and the quantity of aluminum beads in the porous layer.

Many aluminum beads have been found near the bottom of the slag samples without microwave irradiation. However, few aluminum beads can be seen in the slag samples with microwave irradiation. The yield of metallic aluminum was less than that without microwave irradiation.

\subsubsection{Crystalline phases}

The XRD analyses conducted on the slag samples indicated that the slags were highly crystalline compounds (Figures 4.6 and 4.7). It should be noted that the aluminum beads had been separated from the slag samples prior to these tests.

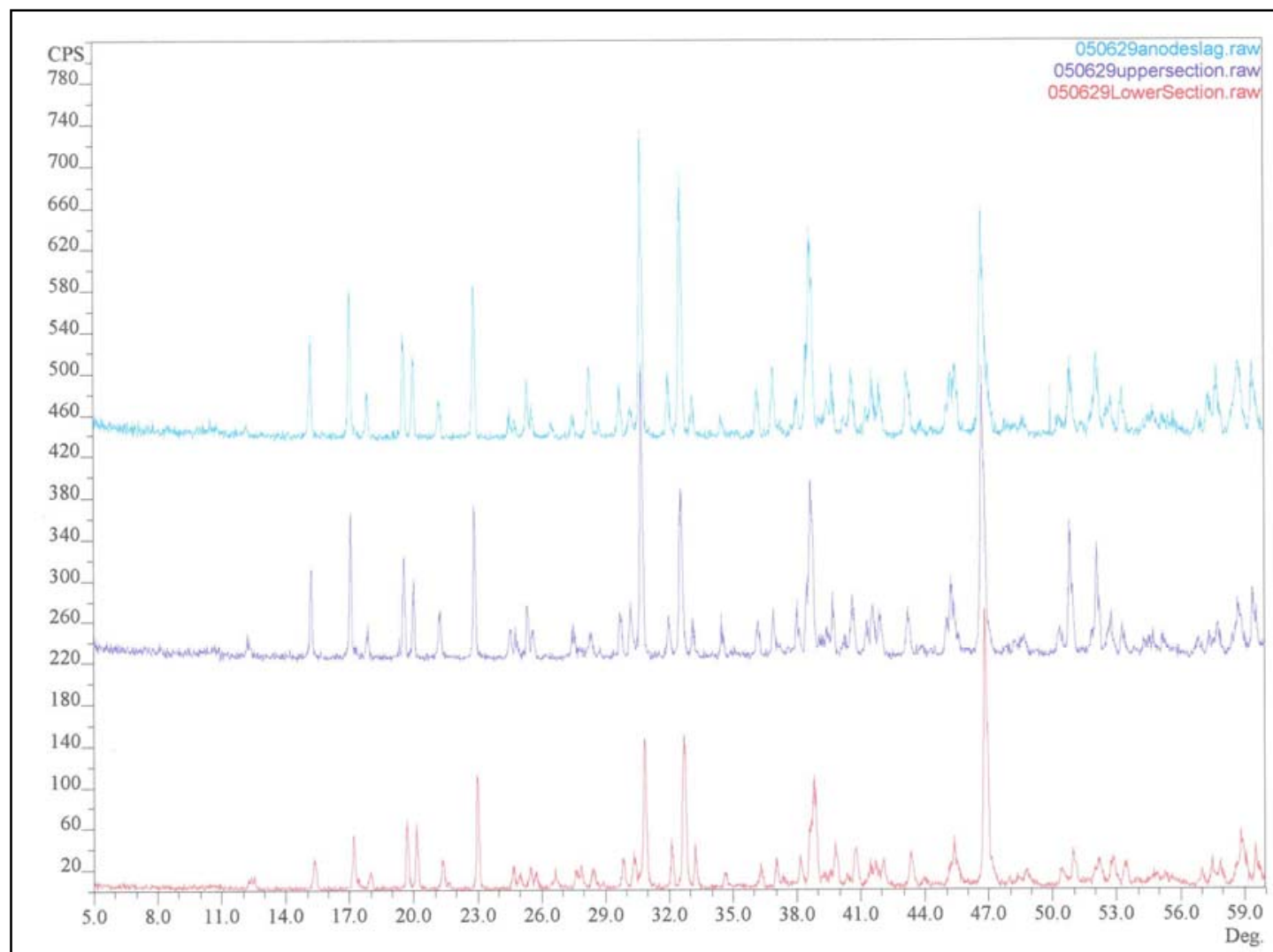

Figure 4.6 Comparison of XRD patterns of upper and lower section of the slag without microwave irradiation 


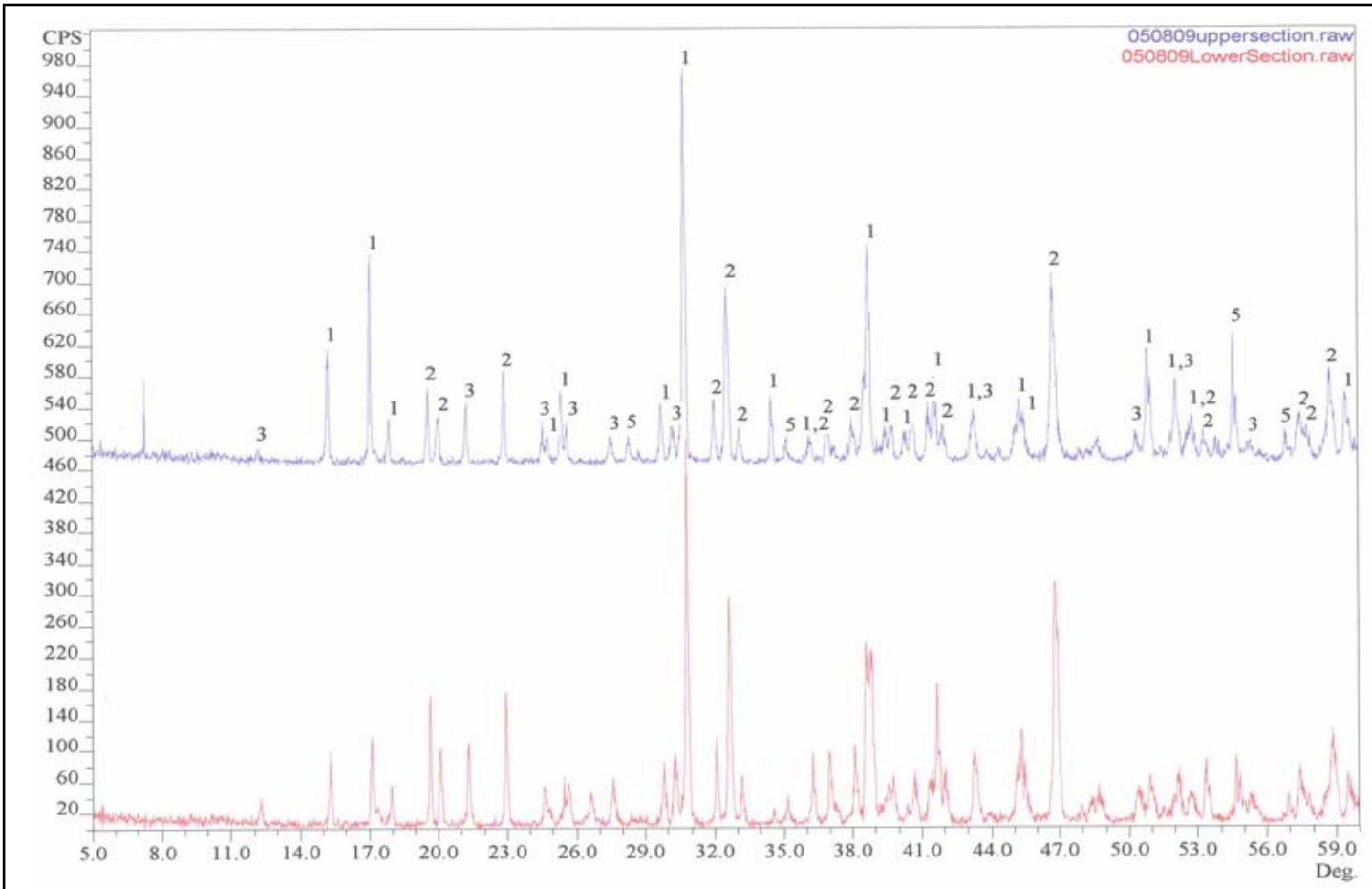

Figure 4.7 Comparison of XRD patterns of upper and lower section of the slag with microwave irradiation (1: chiolite, 2 : cryolite, 3 : sodium calcium aluminum fluoride)

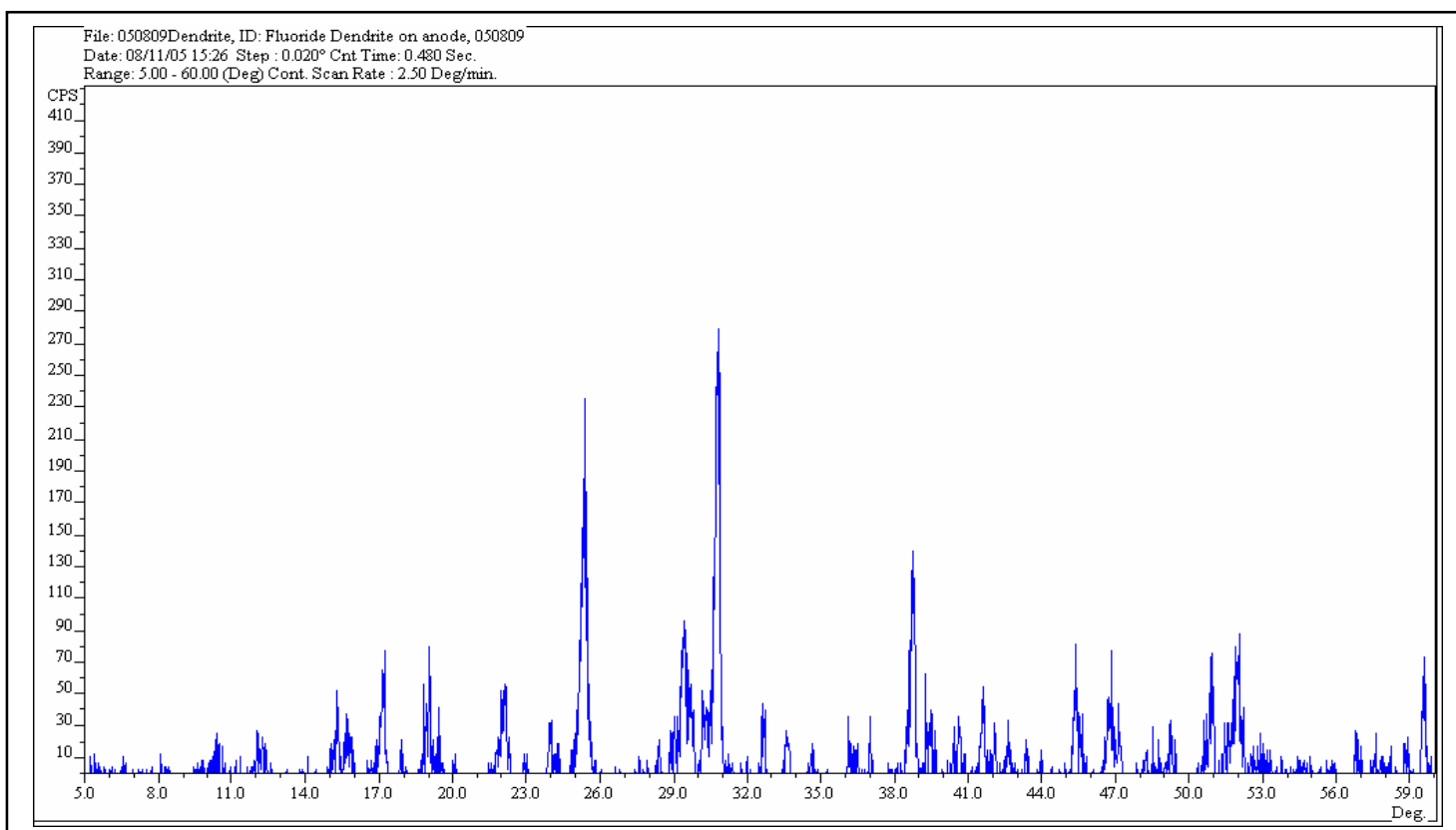

Figure 4.8 XRD pattern of dendrite on the surface of anode bottom 
The slags consisted of two major crystalline phases: chiolite $\left(\mathrm{Na}_{5} \mathrm{Al}_{3} \mathrm{~F}_{14}\right)$ and cryolite $\left(\mathrm{Na}_{3} \mathrm{AlF}_{6}\right)$, and a minor phase: sodium calcium aluminum fluoride $\left(\mathrm{Na}_{2} \mathrm{Ca}_{3} \mathrm{Al}_{2} \mathrm{~F}_{14}\right)$. These crystalline features were present in both the upper and lower regions of the slags with or without assisted microwave irradiation. However, there was iron oxide fluoride and an unknown phase present in the slags with microwave irradiation. Aluminum fluoride $\left(\mathrm{AlF}_{3}\right)$ occurred within the lower regions of the slag without microwave irradiation (Table 4.1). The comparison between the upper section and the lower section of a slag, including both with and without microwave, showed that the cryolite in the lower section was always more than that of the upper section. Cryolite became the major phase in the lower section without microwave irradiation (Figures 4.6 and 4.7). This may imply that the aluminum compounded with or dissolved in the fluorides of the lower section was less than that of the aluminum in the fluorides of the upper section due to the more extraction of metallic aluminum in the lower section by electrowinning.

The alumina phase can be identified from the XRD patterns, which means alumina was over saturated in the fluorides.

Although metallic aluminum was seen in the lower section of a slag, it did not show on the XRD pattern of the lower section sample. This indicated that all metallic aluminum was separated from the slag sample by crushing and screening and there were no tiny aluminum particles in the slag. The aluminum phase can also not be seen on the XRD pattern of the samples from the slag upper section.

The dendrites on the anode bottom surface mostly consisted of chiolite and aluminum fluoride. There was more cryolite in the dendrites than that in the slags (Figure 4.8).

\begin{tabular}{|l|l|l|}
\hline \multicolumn{2}{|c|}{ Table 4.1 Phases in the slags identified by XRD } \\
\hline Locations & With microwave irradiation (629) & Without microwave irradiation(809) \\
\hline Slag stuck on anode bottom & $\begin{array}{l}\text { Major phases: } \\
\text { (1)Chiolite } \\
\text { (2)Cryolite } \\
\text { Minor phases: } \\
\text { Sodium calcium aluminum fluoride }\end{array}$ & \\
\hline \multirow{3}{*}{$\begin{array}{l}\text { Dendrite on anode side } \\
\text { surface }\end{array}$} & & $\begin{array}{l}\text { Major phases: } \\
\text { Chiolite }\end{array}$ \\
& & Aluminum fluoride \\
& & $\begin{array}{l}\text { Minor phases: } \\
\text { Cryolite } \\
\text { Sodium iron fluoride }\end{array}$ \\
\hline Slag surface film & & $\begin{array}{l}\text { Major phases: } \\
\text { (1) a unknown phase } \\
\end{array}$ \\
& & Minor phases: \\
& & (1) Chiolite \\
& & (2) Villiaumite \\
\hline
\end{tabular}




\begin{tabular}{|c|c|c|}
\hline \multicolumn{3}{|c|}{ Table 4.1 Phases in the slags identified by XRD } \\
\hline Locations & With microwave irradiation (629) & Without microwave irradiation(809) \\
\hline Upper section of slag & $\begin{array}{l}\text { Major phases: } \\
\text { (1)Chiolite } \\
\text { (2)Cryolite } \\
\text { Minor phases: } \\
\text { Sodium calcium aluminum fluoride }\end{array}$ & $\begin{array}{l}\text { Major phases: } \\
\text { (1)Chiolite } \\
\text { (2)Cryolite } \\
\text { Minor phases: } \\
\text { (1)a unknown phase } \\
\text { (2)Sodium calcium aluminum fluoride } \\
\text { (3) Iron oxide fluoride }\end{array}$ \\
\hline Lower section of slag & $\begin{array}{l}\text { Major phases: } \\
\text { (1)Cryolite } \\
\text { (2)Chiolite } \\
\text { Minor phases: } \\
\text { Fluorite }\end{array}$ & $\begin{array}{l}\text { Major phases: } \\
\text { (1)Chiolite } \\
\text { (2)Cryolite } \\
\text { Minor phases: } \\
\text { (1)Sodium calcium aluminum fluoride } \\
\text { (2)Iron oxide fluoride } \\
\text { (3)a unknown phase }\end{array}$ \\
\hline Bath bottom & & $\begin{array}{l}\text { Major phase: } \\
\text { Sodium calcium aluminum fluoride } \\
\text { Minor phases: } \\
\text { Cryolite } \\
\text { Aluminum (?) }\end{array}$ \\
\hline
\end{tabular}

It should be noted that no ternary compounds were identified by XRD.

\subsubsection{Metallic aluminum obtained by electrowinning}

All of the metallic aluminum obtained in this study was spherical in shape. The particles presented on the bottom of the bath next to the cathode. The spherical shape of aluminum may result from the surface tension. The liquid aluminum has a higher surface tension than that of the liquid electrolyte and the liquid aluminum has a high contact angle to the graphite surface.

(1) Without microwave irradiation

Many aluminum beads can be seen at the bottom of solidified electrolyte without microwave irradiation. The size of most beads was in the range of 1-3 $\mathrm{mm}$. The largest bead was about 5 $\mathrm{mm}$ (Figure 4.9). Some aluminum beads can be seen in the porous layer (Figure 4.10) 


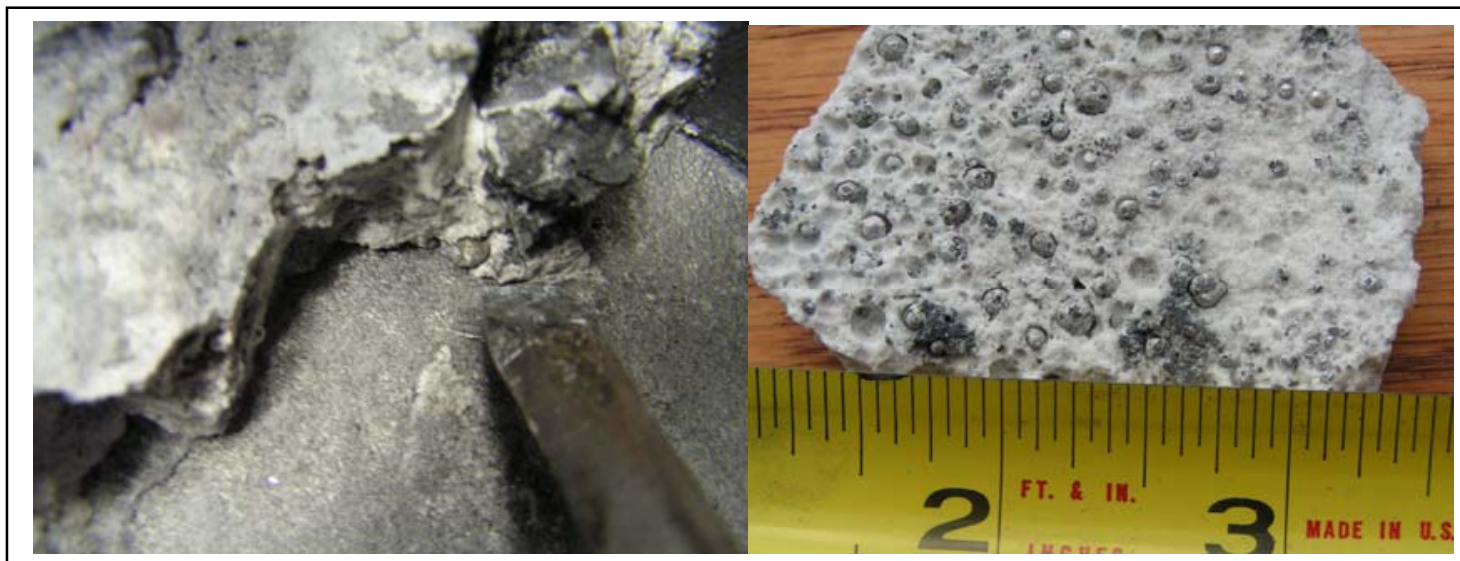

Figure 4.9 Aluminum beads

(Left): aluminum beads at the bottom of the bath

(Right): aluminum beads on the surface of solidified electrolyte at the bath bottom

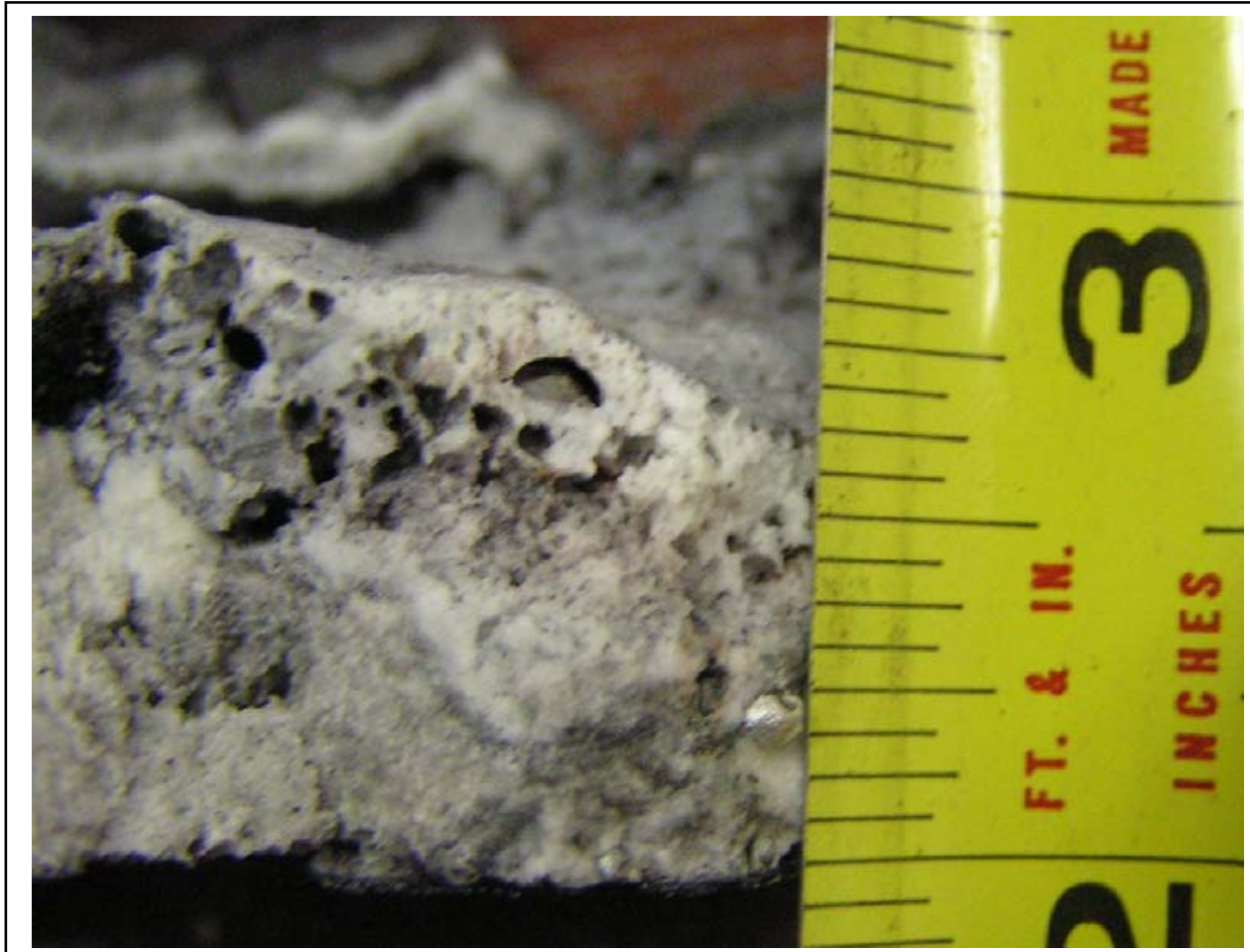

Figure 4.10 Aluminum beads in the porous layer 


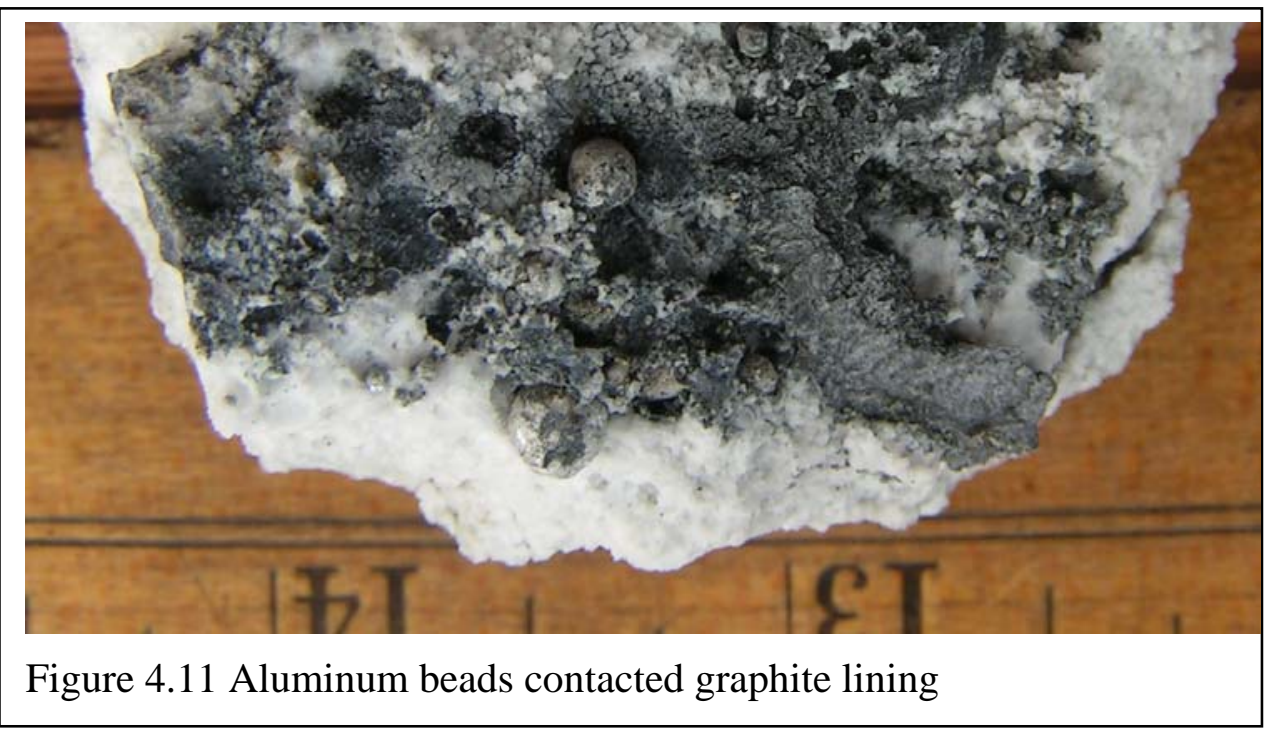

Molten aluminum was not wetted to the graphite lining as seen in Figure 4.11. The total metallic aluminum obtained in most experiments was about 20-25 grams.

(2) With microwave irradiation

The multi-layer structure and aluminum beads also can be seen in the slags produced with assisted microwave irradiation (Figure 4.12). The difference from the slags produced without microwave irradiation were larger pore size in porous layer, higher porosity and larger size of aluminum beads (up to $10 \mathrm{~mm}$ ). But the yield of metallic aluminum was less. This reason is not clear. It may be caused by lower reaction temperature. The slag surface was not flat after solidification (Figure 4.13), which is an indication of lower bath temperature.

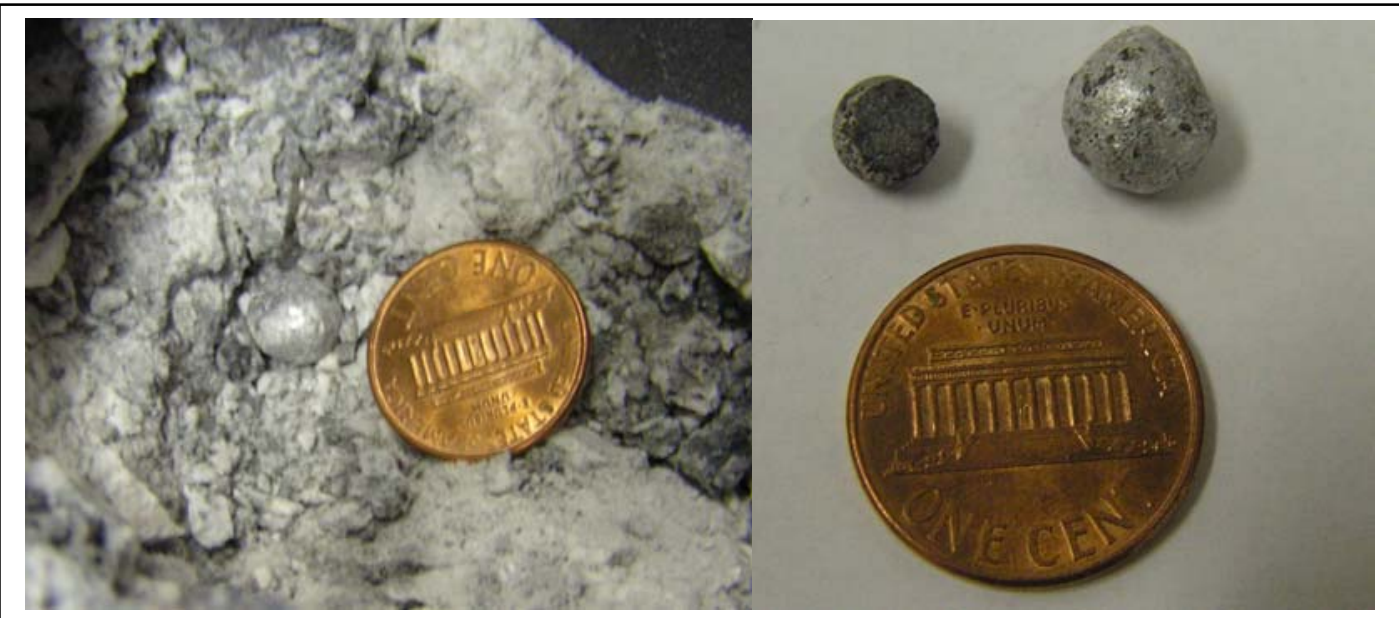

Figure 4.12 Size of the aluminum beads increased with microwave irradiation (the largest aluminum bead: about $10 \mathrm{~mm}$ in diameter) 


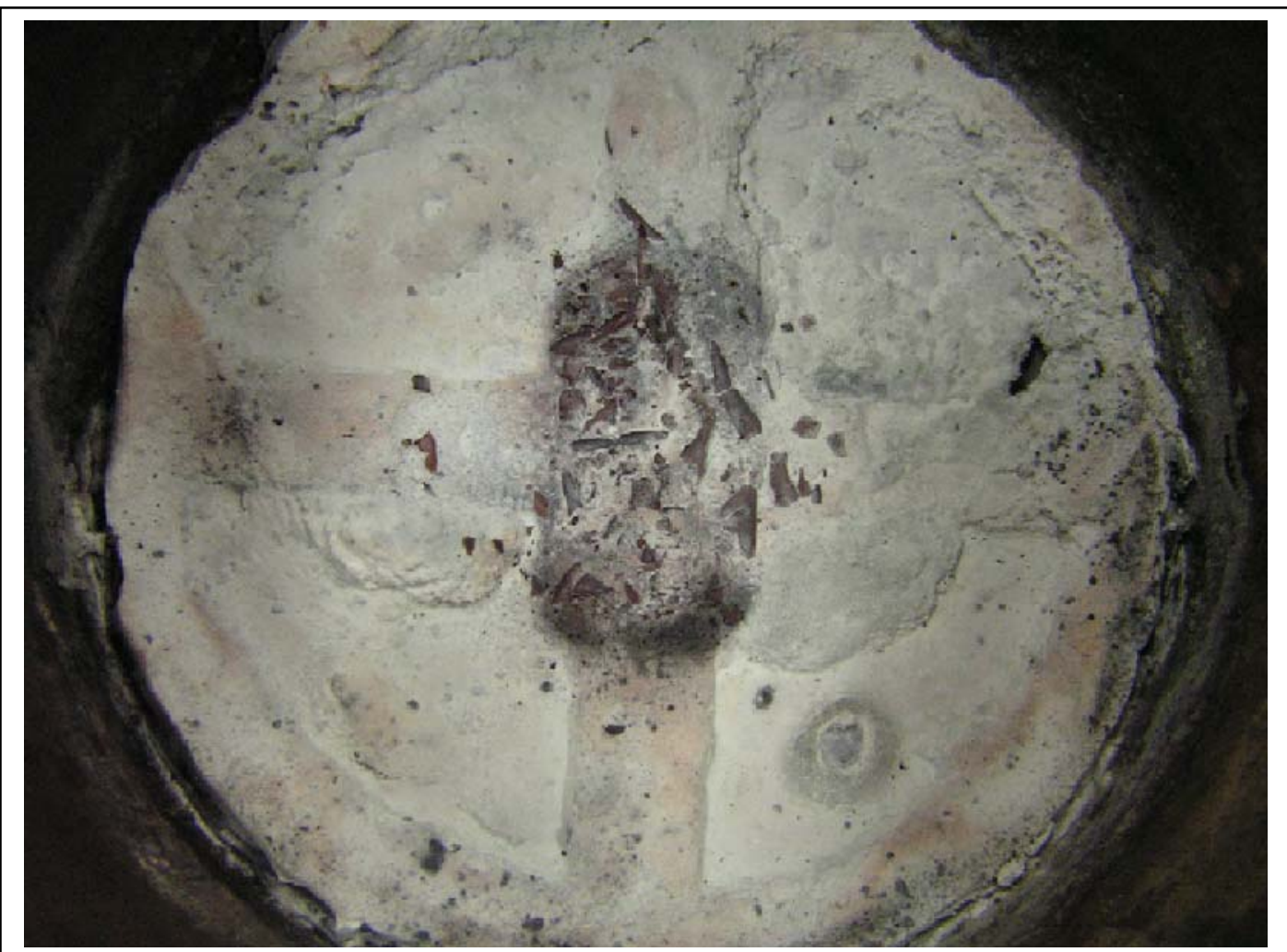

Figure 4.13 The solidified slag surface is not flat

\subsubsection{Features of slags without microwave irradiation}

(1) Upper section

The upper section of the slags without microwave irradiation has a complicated microstructure. Identified by SEM, the near surface region of this section can be divided into 4 sublayers downward from the top (Figure 4.14):
a. Surface film
b. Microcrystalline sublayer
c. Spherical-septum-crystalline sublayer
d. Spherical particles sublayer

However, there are no obvious boundaries between these sublayers.

(a) Microcrystalline sublayer

The microcrystalline sublayer is a porous and uniform layer with a glass-like feature (Figure 4.15). According to the quantitative composition analysis using EDS, the composition is mainly $\mathrm{CaF}_{2}$ with minor $\mathrm{NaF}$ and $\mathrm{AlF}_{3}$ (Table 4.2). 


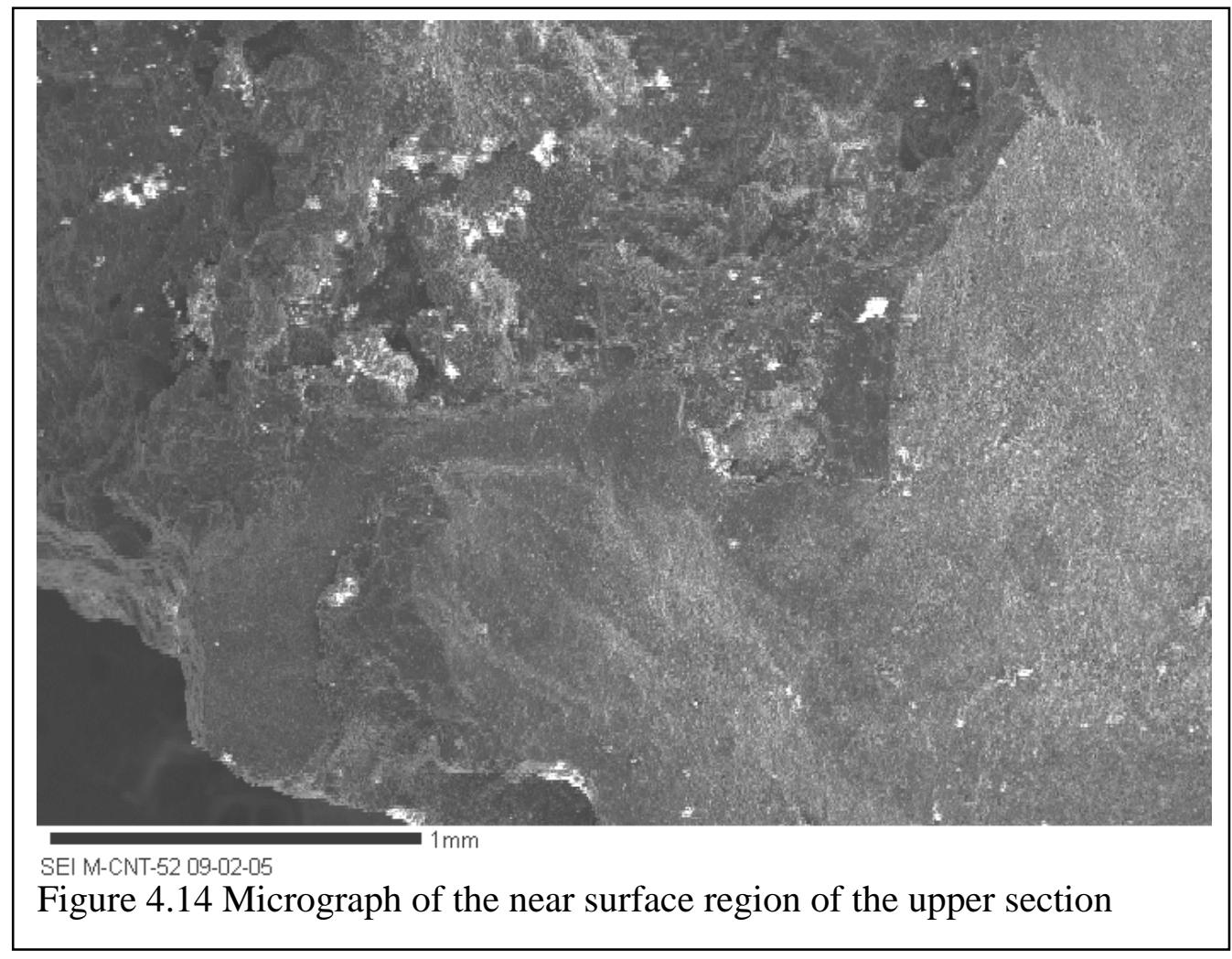

\begin{tabular}{|c|c|c|c|c|c|c|c|c|c|c|}
\hline \multicolumn{11}{|c|}{ Table 4.2 Composition of Microcrystalline sublayer } \\
\hline \multirow[b]{2}{*}{$\begin{array}{l}\text { Test } \\
\text { points }\end{array}$} & \multicolumn{4}{|c|}{ Atom \%, tested } & \multicolumn{2}{|c|}{ Atomic ratio } & \multicolumn{4}{|c|}{ Mol \%, calculated } \\
\hline & $\mathrm{Na}$ & $\mathrm{Ca}$ & $\mathrm{Al}$ & $\mathrm{F}$ & $\mathrm{Na} / \mathrm{Ca} / \mathrm{Al}$ & $\mathrm{Ca} / \mathrm{Na}$ & $\mathrm{NaF}$ & $\mathrm{CaF}_{2}$ & $\mathrm{AlF}_{3}$ & $\begin{array}{c}\mathrm{Al}\left(\mathrm{Al}_{2} \mathrm{O}_{3}\right. \\
\text { included })\end{array}$ \\
\hline 1 & 3.37 & 15.90 & 10.15 & 39.13 & $0.33 / 1.57 / 1.00$ & 4.72 & 11.45 & 54.04 & 4.49 & 30.01 \\
\hline 2 & 2.93 & 15.97 & 10.06 & 39.98 & $0.29 / 1.59 / 1.00$ & 5.45 & 10.12 & 55.15 & 5.88 & 28.86 \\
\hline 3 & 2.17 & 16.34 & 8.10 & 43.00 & $0.27 / 2.02 / 1.00$ & 7.53 & 8.15 & 61.41 & 10.21 & 20.23 \\
\hline 4 & 0.83 & 24.45 & 4.66 & 48.29 & $0.18 / 5.25 / 1.00$ & 29.46 & 2.77 & 81.66 & -1.66 & 17.17 \\
\hline 5 & 4.21 & 16.52 & 10.86 & 43.40 & $0.39 / 1.52 / 1.00$ & 3.92 & 13.33 & 52.30 & 6.49 & 27.89 \\
\hline 6 & 2.48 & 28.09 & 4.02 & 51.89 & $0.62 / 6.99 / 1.00$ & 11.33 & 13.33 & 52.30 & 6.49 & 27.89 \\
\hline 7 & 0.72 & 24.67 & 3.79 & 50.42 & $0.19 / 6.51 / 1.00$ & 34.26 & 7.17 & 81.21 & -6.52 & 18.15 \\
\hline 8 & 6.65 & 17.00 & 8.25 & 48.48 & $0.81 / 2.06 / 1.00$ & 2.56 & 2.47 & 84.54 & 0.41 & 12.58 \\
\hline 9 & 0.76 & 20.89 & 2.73 & 55.31 & $0.28 / 7.65 / 1.00$ & 27.49 & 20.85 & 53.29 & 8.56 & 17.30 \\
\hline
\end{tabular}



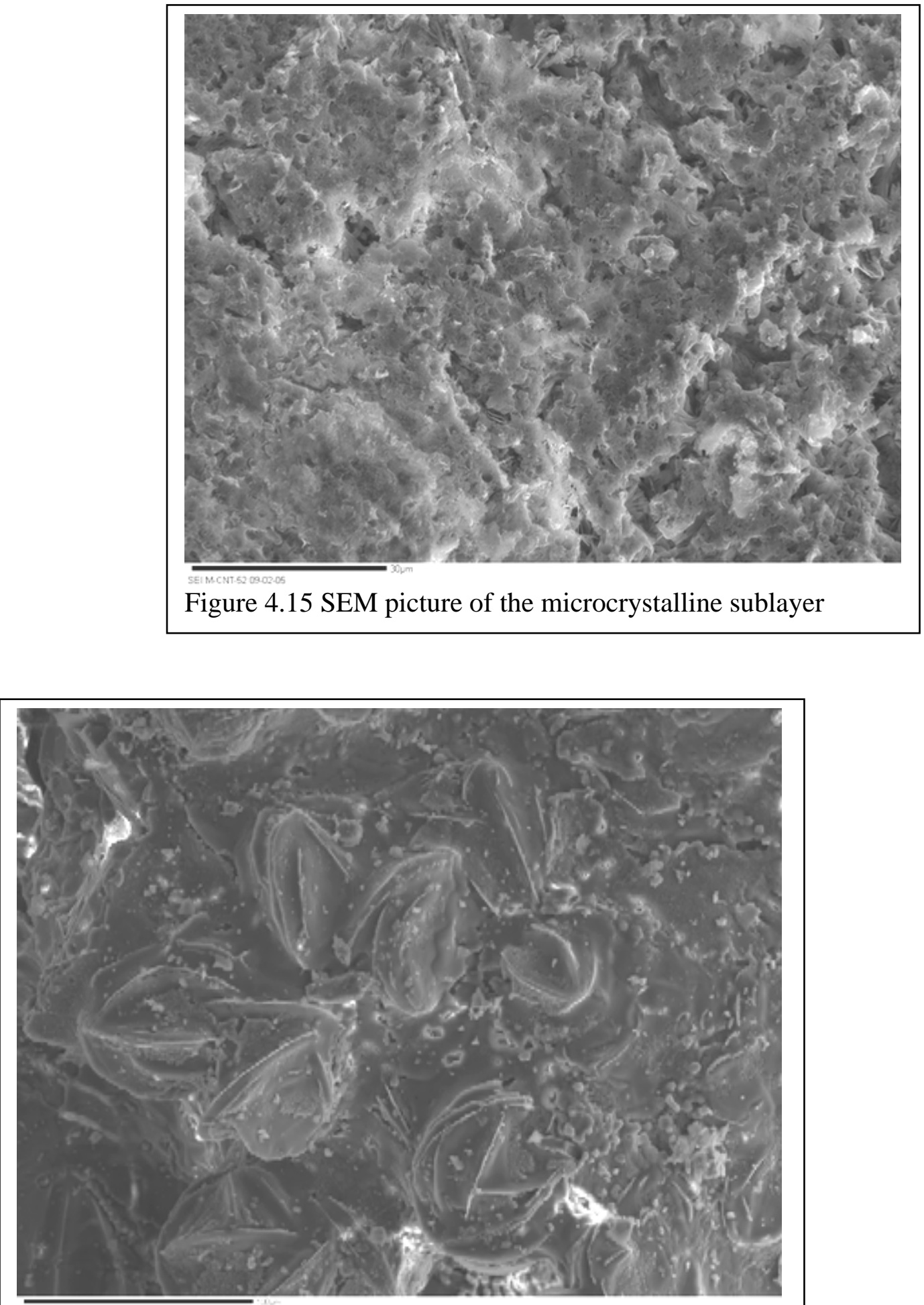

Figure 4.16 Spherical crystalline with septum-shaped single crystals 


\section{(b) Spherical-septum-crystalline sublayer}

Spherical-septum-crystalline sublayer has multiple spherical crystals which consist of septumshaped single crystals (Figure 4.16). The spheres are 30-80 microns in diameter. The septumshaped crystal is 30-70 microns in length and 1 micron in thickness. Their compositions are shown in Table 4.3.

\begin{tabular}{|c|c|c|c|c|c|c|c|c|c|c|}
\hline \multicolumn{9}{|c|}{ Table 4.3 Composition of septum crystals } \\
\hline $\begin{array}{c}\text { Test } \\
\text { point }\end{array}$ & \multicolumn{3}{|c|}{ Atom \%, tested } & \multicolumn{2}{c|}{ Atomic ratio } & \multicolumn{5}{c|}{ Mol \%, calculated } \\
\cline { 2 - 12 } & $\mathrm{Na}$ & $\mathrm{Ca}$ & $\mathrm{Al}$ & $\mathrm{F}$ & $\mathrm{Na} / \mathrm{Ca} / \mathrm{Al}$ & $\mathrm{Ca} / \mathrm{Na}$ & $\mathrm{NaF}$ & $\mathrm{CaF}_{2}$ & $\mathrm{AlF}_{3}$ & $\begin{array}{c}\mathrm{Al}^{(}\left(\mathrm{Al}_{2} \mathrm{O}_{3}\right. \\
\text { included })\end{array}$ \\
\hline 1 & 23.30 & 0.78 & 15.90 & 47.80 & $1.47 / 0.05 / 1.00$ & 0.03 & 58.28 & 1.95 & 19.13 & 20.64 \\
\hline 2 & 23.11 & 1.01 & 20.56 & 42.67 & $1.12 / 0.05 / 1.00$ & 0.04 & 58.72 & 2.26 & 13.09 & 32.93 \\
\hline 3 & 25.20 & 0.96 & 13.85 & 51.36 & $1.82 / 0.07 / 1.00$ & 0.04 & 62.98 & 2.40 & 20.19 & 14.42 \\
\hline 4 & 32.32 & 0.22 & 18.56 & 39.38 & $1.74 / 0.01 / 1.00$ & 0.01 & 63.25 & 0.43 & 4.32 & 32.00 \\
\hline
\end{tabular}

Table 4.3 shows that the septum-shaped crystal is mainly a compound of $\mathrm{NaF}$ and $\mathrm{AlF}_{3}$. Its composition is similar to that of chiolite.

The composition of the matrix hosting the septum-shaped crystals is shown in Table 4.4. It has higher $\mathrm{NaF}$ and lower $\mathrm{CaF}_{2}$ than the septum-shaped crystals.

\begin{tabular}{|c|c|c|c|c|c|c|c|c|c|c|}
\hline \multicolumn{7}{|c|}{ Table 4.4 Composition of the matrix hosting septum-shaped crystals } \\
\hline \multirow{3}{*}{$\begin{array}{c}\text { Test } \\
\text { point }\end{array}$} & $\mathrm{Na}$ & $\mathrm{Ca}$ & $\mathrm{Al}$ & $\mathrm{F}$ & $\mathrm{Na} / \mathrm{Ca} / \mathrm{Al}$ & $\mathrm{Ca} / \mathrm{Na}$ & $\mathrm{NaF}$ & $\mathrm{CaF}_{2}$ & $\mathrm{AlF}_{3}$ & $\begin{array}{c}\mathrm{Al}^{(}\left(\mathrm{Al}_{2} \mathrm{O}_{3}\right. \\
\text { included }\end{array}$ \\
\cline { 2 - 12 } & $\mathrm{N}$ & & & & & & \multicolumn{3}{c|}{ Atomic ratio } & \multicolumn{3}{c|}{ \%ol calculated } \\
\hline 1 & 31.45 & 0.10 & 12.19 & 51.36 & $2.58 / 0.01 / 1.00$ & 0 & 71.90 & 0.23 & 15.02 & 12.85 \\
\hline 2 & 38.66 & 0.12 & 10.90 & 45.69 & $3.55 / 0.01 / 1.00$ & 0 & 77.82 & 0.24 & 4.56 & 17.38 \\
\hline 3 & 37.11 & 0.04 & 12.45 & 46.19 & $2.98 / 0 / 1.00$ & 0 & 74.82 & 0.08 & 6.05 & 19.05 \\
\hline 4 & 39.47 & 0.05 & 11.95 & 44.10 & $3.30 / 0 / 1.00$ & 0 & 76.69 & 0.10 & 2.93 & 20.28 \\
\hline 5 & 36.46 & 0.08 & 12.76 & 46.67 & $2.86 / 0.01 / 1.00$ & 0 & 73.96 & 0.16 & 6.80 & 19.09 \\
\hline
\end{tabular}

In the sublayer, many aluminum oxide particles can be seen (Figure 4.17). The alumina particles are porous and irregular in shape. They contain about $13-20 \mathrm{~mol} \%$ of $\mathrm{NaF}$ and a small percent of $\mathrm{AlF}_{3}$ and $\mathrm{CaF}_{2}(<2 \mathrm{~mol} \%)$. 


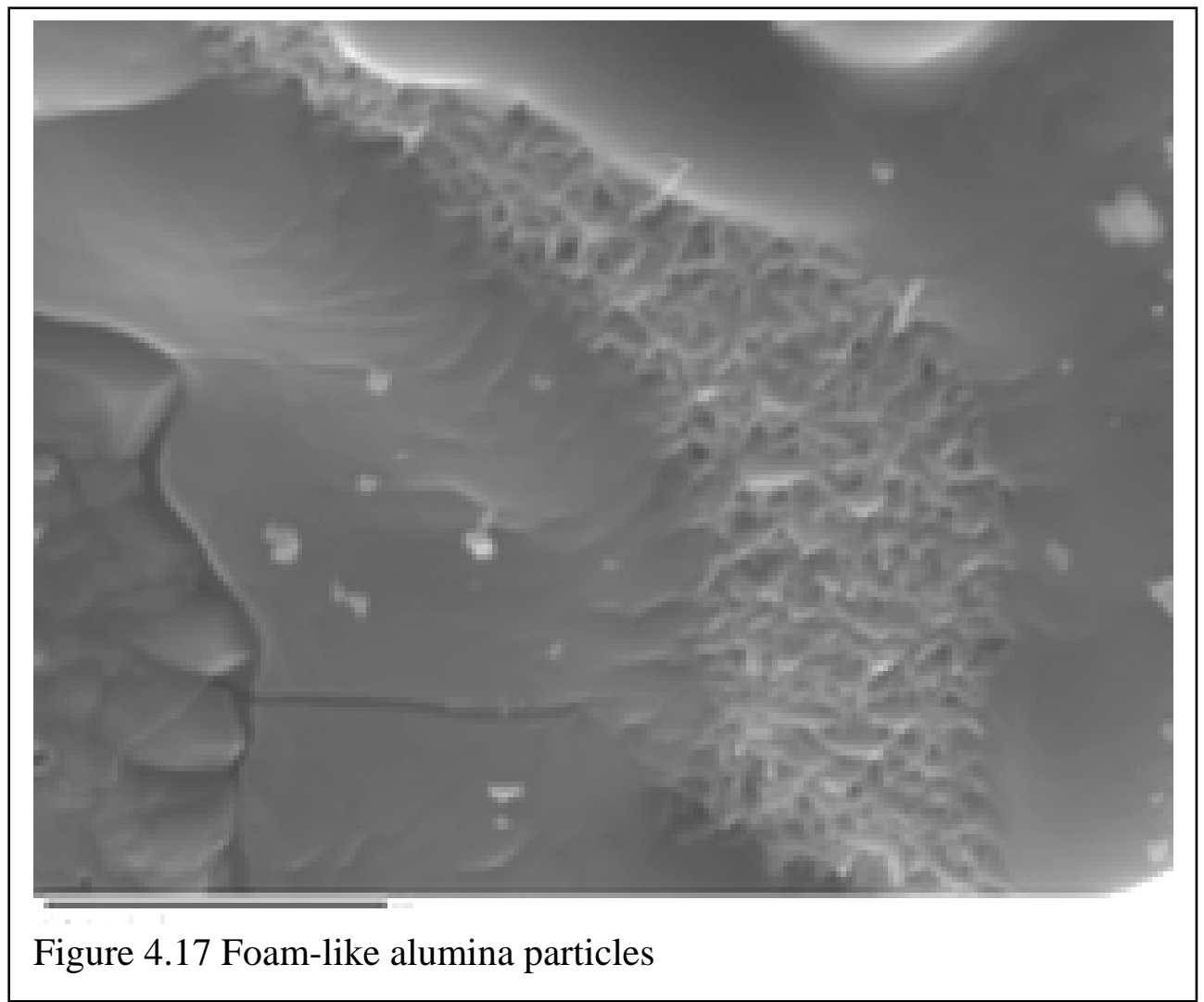

\begin{tabular}{|c|c|c|c|c|c|c|c|c|c|c|}
\hline & & & ole 4.5 & Comp & ition of the fo & Im-like & lumin & particl & & \\
\hline \multirow[b]{2}{*}{$\begin{array}{l}\text { Test } \\
\text { point }\end{array}$} & \multicolumn{4}{|c|}{ Atom \%, tested } & \multicolumn{2}{|c|}{ Atomic ratio } & \multicolumn{4}{|c|}{ Mol \%, calculated } \\
\hline & $\mathrm{Na}$ & $\mathrm{Ca}$ & $\mathrm{Al}$ & $\mathrm{F}$ & $\mathrm{Na} / \mathrm{Ca} / \mathrm{Al}$ & $\mathrm{Ca} / \mathrm{Na}$ & $\mathrm{NaF}$ & $\mathrm{CaF}_{2}$ & $\mathrm{AlF}_{3}$ & $\begin{array}{c}\mathrm{Al}\left(\mathrm{Al}_{2} \mathrm{O}_{3}\right. \\
\text { included })\end{array}$ \\
\hline 1 & 5.86 & 0.37 & 35.90 & 20.32 & $0.16 / 0.01 / 1.00$ & 0.06 & 13.91 & 0.88 & 10.86 & 74.36 \\
\hline 2 & 7.95 & 0.19 & 31.40 & 15.42 & $0.25 / 0.01 / 1.00$ & 0.02 & 20.11 & 0.48 & 5.98 & 73.44 \\
\hline 3 & 8.09 & 0.79 & 33.99 & 15.61 & $0.24 / 0.02 / 1.00$ & 0.10 & 18.87 & 1.84 & 4.62 & 74.67 \\
\hline
\end{tabular}

\section{(c) Spherical particle sublayer}

This sublayer features spheres dispersed in the matrix phase. The sphere size is generally in a range of 2-4 microns (Figure 4.18). These spherical particles are insufficient in calcium fluoride, but have higher aluminum and sodium contents. The $\mathrm{Na} / \mathrm{Al}$ ratio is $0.21-0.48$. The $\mathrm{Ca} / \mathrm{Al}$ ratio is 0-0.03 (Table 4.6). However, their sodium content is less than that of the matrix $(\mathrm{Na} / \mathrm{Al}$ ratio 2.60-3.70). Hence these particles are a mixture of sodium with aluminum fluoride, aluminum metal or remaining alumina.

The matrix in this sublayer is non-crystalline. Its composition is the same as that of the septumshaped crystal sublayer. It has lower aluminum concentration. 


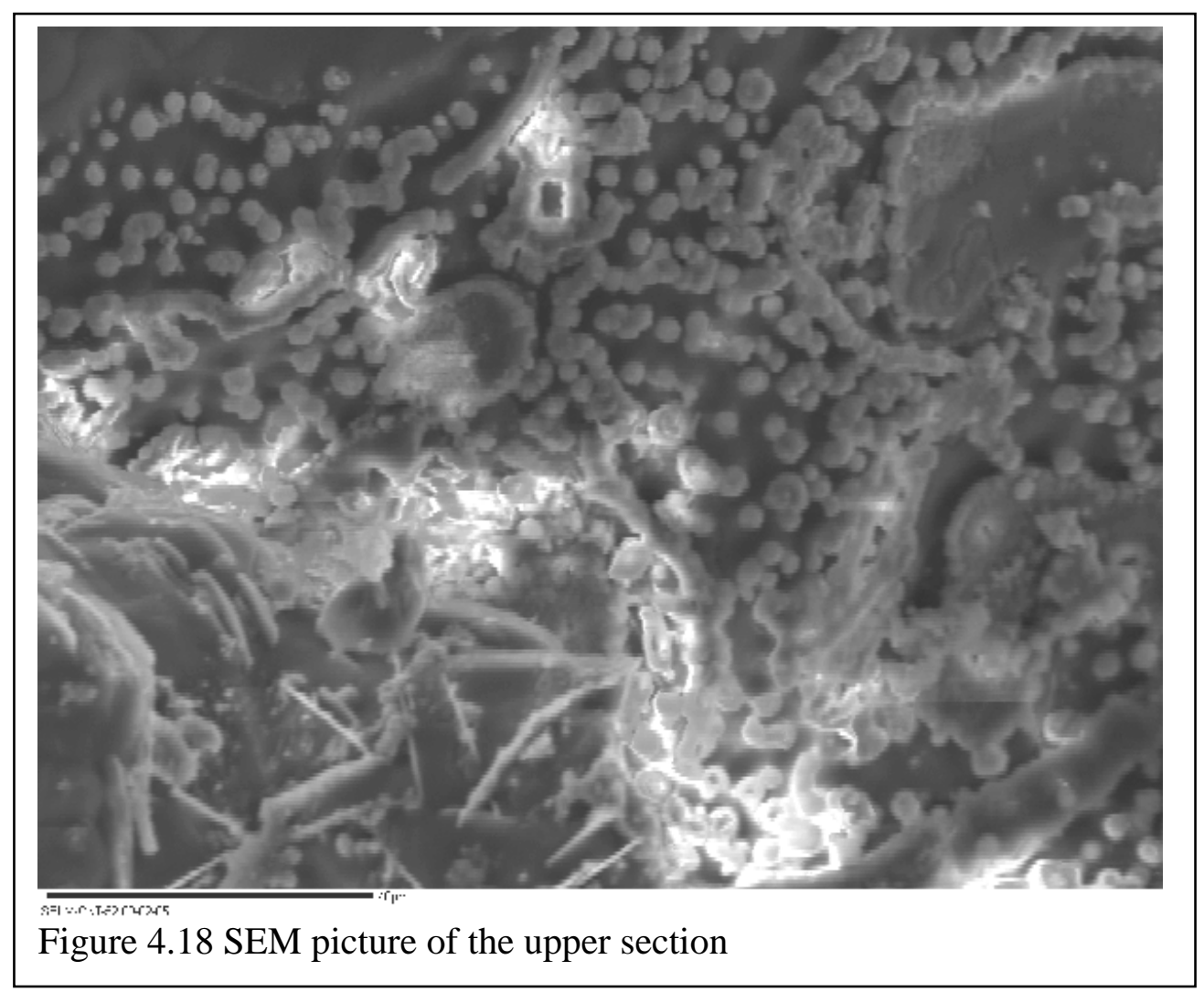

\begin{tabular}{|c|c|c|c|c|c|c|c|c|c|c|}
\hline \multicolumn{9}{|c|}{ Table 4.6 Composition of spherical particles } \\
\hline \multirow{2}{*}{$\begin{array}{c}\text { Test } \\
\text { point }\end{array}$} & \multicolumn{3}{|c|}{ Atom \%, tested } & \multicolumn{2}{c|}{ Atomic ratio } & \multicolumn{4}{c|}{ Mol \%, calculated } \\
\cline { 2 - 11 } & $\mathrm{Na}$ & $\mathrm{Ca}$ & $\mathrm{Al}$ & $\mathrm{F}$ & $\mathrm{Na} / \mathrm{Ca} / \mathrm{Al}$ & $\mathrm{Ca} / \mathrm{Na}$ & $\mathrm{NaF}$ & $\mathrm{CaF}_{2}$ & $\mathrm{AlF}_{3}$ & $\begin{array}{c}\mathrm{Al}_{\left(\mathrm{Al}_{2} \mathrm{O}_{3}\right.} \\
\text { included })\end{array}$ \\
\hline 1 & 9.21 & 0.09 & 27.88 & 26.57 & $0.33 / 0 / 1.00$ & 0.01 & 24.77 & 0.24 & 15.40 & 59.58 \\
\hline 2 & 12.79 & 0.67 & 26.70 & 24.93 & $0.48 / 0.03 / 1.00$ & 0.05 & 31.85 & 1.67 & 8.96 & 57.52 \\
\hline 3 & 11.44 & 0.25 & 26.87 & 29.45 & $0.43 / 0.01 / 1.00$ & 0.02 & 29.67 & 0.65 & 15.14 & 54.55 \\
\hline 4 & 5.97 & 0.12 & 29.05 & 20.28 & $0.21 / 0 / 1.00$ & 0.02 & 16.99 & 0.34 & 13.35 & 69.32 \\
\hline
\end{tabular}

\section{(2) Lower section}

The lower section consists of fully developed crystals. It always consists of chains or rows of plate-like fluoride (cryolite and chiolite) (Figure 4.19). Usually, the crystal particle size is between 50 and 100 microns, much greater than that in the upper section. The crystals have smooth surfaces but are closely packed to one another. These fluoride particles are mainly compounds of aluminum fluoride and sodium fluoride (Table 4.7). On surfaces and between intergranulates of these particles, the calcium fluoride is greatly increased and the sodium fluoride is decreased, but the aluminum concentration remains stable (Table 4.8). 


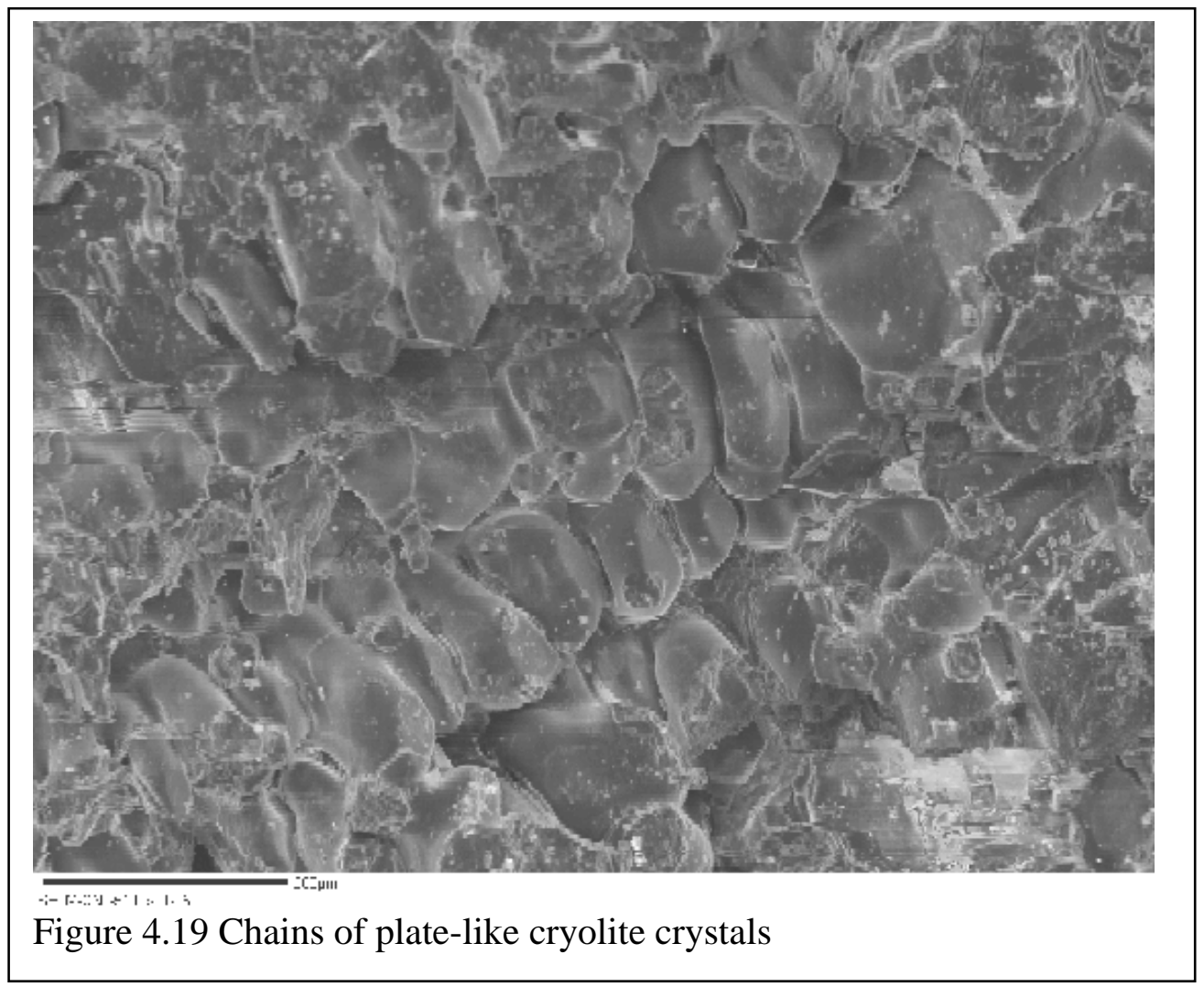

\begin{tabular}{|c|c|c|c|c|c|c|c|c|c|c|}
\hline \multicolumn{8}{|c|}{ Table 4.7 Composition of the cryolite crystal chains } \\
\hline \multirow{2}{*}{$\begin{array}{c}\text { Test } \\
\text { point }\end{array}$} & \multicolumn{3}{|c|}{ Atom \%, tested } & \multicolumn{3}{c|}{ Atomic ratio } & \multicolumn{4}{c|}{ Mol \%, calculated } \\
\cline { 2 - 12 } & $\mathrm{Na}$ & $\mathrm{Al}$ & $\mathrm{F}$ & $\mathrm{Na} / \mathrm{Ca} / \mathrm{Al}$ & $\mathrm{Ca} / \mathrm{Na}$ & $\mathrm{NaF}$ & $\mathrm{CaF}_{2}$ & $\mathrm{AlF}_{3}$ & $\begin{array}{c}\mathrm{Al}_{\left(\mathrm{Al}_{2} \mathrm{O}_{3}\right.} \\
\text { included })\end{array}$ \\
\hline 1 & 44.16 & 0.28 & 14.85 & 40.71 & $2.97 / 0.02 / 1.00$ & 0.01 & 74.48 & 0.47 & -2.25 & 27.30 \\
\hline 2 & 41.19 & 0.18 & 14.62 & 44.01 & $2.82 / 0.01 / 1.00$ & 0 & 73.57 & 0.32 & 1.46 & 24.65 \\
\hline 3 & 34.61 & 0.24 & 13.17 & 51.98 & $2.63 / 0.02 / 1.00$ & 0.01 & 72.07 & 0.50 & 11.72 & 15.70 \\
\hline 4 & 34.60 & 0.14 & 13.00 & 52.26 & $2.66 / 0.01 / 1.00$ & 0 & 72.48 & 0.29 & 12.14 & 15.10 \\
\hline 5 & 33.22 & 0.12 & 12.61 & 54.05 & $2.63 / 0.01 / 1.00$ & 0 & 72.30 & 0.26 & 14.94 & 12.51 \\
\hline 6 & 34.97 & 0.08 & 12.48 & 52.46 & $2.80 / 0.01 / 1.00$ & 0 & 73.57 & 0.17 & 12.15 & 14.10 \\
\hline 7 & 35.31 & 0.05 & 13.66 & 50.98 & $2.58 / 0 / 1.00$ & 0 & 72.03 & 0.10 & 10.59 & 17.28 \\
\hline
\end{tabular}




\begin{tabular}{|c|c|c|c|c|c|c|c|c|c|c|}
\hline & Table & $4.8 \mathrm{Cc}$ & mposi & of of & e intergranula & es beth & en cry & lite cry & al cha & \\
\hline \multirow[b]{2}{*}{$\begin{array}{l}\text { Test } \\
\text { point }\end{array}$} & \multicolumn{4}{|c|}{ Atom \%, tested } & \multicolumn{2}{|c|}{ Atomic ratio } & \multicolumn{4}{|c|}{ Mol \%, calculated } \\
\hline & $\mathrm{Na}$ & $\mathrm{Ca}$ & $\mathrm{Al}$ & $\mathrm{F}$ & $\mathrm{Na} / \mathrm{Ca} / \mathrm{Al}$ & $\mathrm{Ca} / \mathrm{Na}$ & $\mathrm{NaF}$ & $\mathrm{CaF}_{2}$ & $\mathrm{AlF}_{3}$ & $\begin{array}{c}\mathrm{Al}\left(\mathrm{Al}_{2} \mathrm{O}_{3}\right. \\
\text { included })\end{array}$ \\
\hline 1 & 16.82 & 14.16 & 7.80 & 61.22 & $2.16 / 1.82 / 1.00$ & 0.84 & 4.37 & 36.51 & 13.82 & 6.29 \\
\hline 2 & 16.37 & 13.74 & 7.98 & 61.91 & $2.05 / 1.72 / 1.00$ & 0.84 & 42.98 & 36.07 & 15.80 & 5.15 \\
\hline 3 & 17.96 & 9.94 & 15.40 & 56.70 & $1.17 / 0.65 / 1.00$ & 0.55 & 41.48 & 22.96 & 14.52 & 21.05 \\
\hline 4 & 13.93 & 12.32 & 12.23 & 61.52 & $1.14 / 1.01 / 1.00$ & 0.88 & 36.20 & 32.02 & 19.88 & 11.90 \\
\hline
\end{tabular}

The aluminum beads in the lower section of the bath are usually spherical and greater than $1 \mathrm{~mm}$ in diameter (Figure 4.20, Table 4.9).

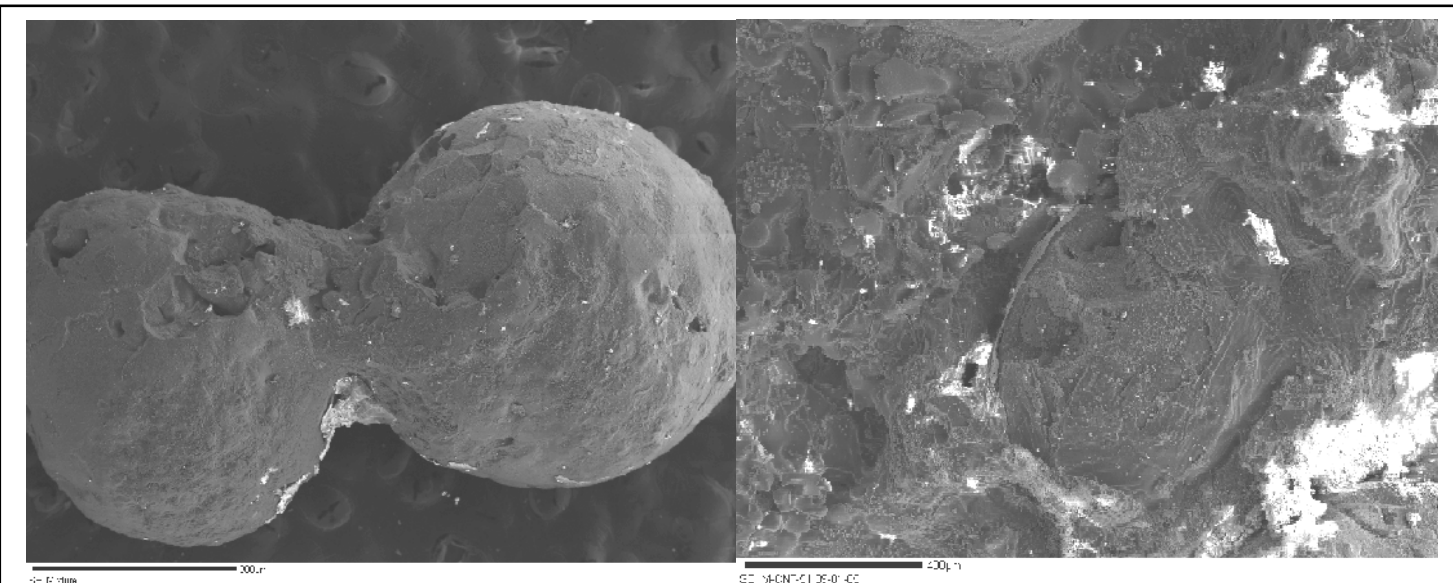

Figure 4.20 Aluminum beads, (Left): two aluminum beads in contact with each other; (Right): a thin metallic aluminum shell on the surface of an aluminum bead.

\begin{tabular}{|c|c|c|c|c|c|c|c|c|c|c|}
\hline \multicolumn{11}{|c|}{ Table 4.9 Composition of the aluminum bead surface (No eroded) } \\
\hline \multirow[b]{2}{*}{$\begin{array}{l}\text { Test } \\
\text { point }\end{array}$} & \multicolumn{4}{|c|}{ Atom \%, tested } & \multicolumn{2}{|c|}{ Atomic ratio } & \multicolumn{4}{|c|}{ Mol \%, calculated } \\
\hline & $\mathrm{Na}$ & $\mathrm{Ca}$ & $\mathrm{Al}$ & $\mathrm{F}$ & $\mathrm{Na} / \mathrm{Ca} / \mathrm{Al}$ & $\mathrm{Ca} / \mathrm{Na}$ & $\mathrm{NaF}$ & $\mathrm{CaF}_{2}$ & $\mathrm{AlF}_{3}$ & $\begin{array}{c}\mathrm{Al}\left(\mathrm{Al}_{2} \mathrm{O}_{3}\right. \\
\text { included })\end{array}$ \\
\hline 1 & 2.53 & 0.18 & 79.75 & 17.55 & $0.03 / 0 / 1.00$ & 0.07 & 3.06 & 0.21 & 5.93 & 90.79 \\
\hline 2 & 0.98 & 0.60 & 91.88 & 6.53 & $0.01 / 0.01 / 1.00$ & 0.61 & 1.05 & 0.64 & 1.55 & 96.75 \\
\hline 3 & 3.85 & 0.15 & 72.74 & 23.25 & $0.05 / 0 / 1.00$ & 0.04 & 5.02 & 0.20 & 8.29 & 86.49 \\
\hline 4 & 1.07 & 0.22 & 87.25 & 11.45 & $0.01 / 0 / 1.00$ & 0.20 & 1.21 & 0.25 & 3.74 & 94.80 \\
\hline 5 & 9.84 & 0.68 & 59.41 & 30.80 & $0.17 / 0.01 / 1.00$ & 0.07 & 14.07 & 0.97 & 9.00 & 75.96 \\
\hline 6 & 9.56 & 0.61 & 59.48 & 30.35 & $0.16 / 0.01 / 1.00$ & 0.06 & 13.72 & 0.88 & 9.36 & 76.04 \\
\hline 7 & 10.77 & 0.57 & 56.47 & 32.20 & $0.19 / 0.01 / 1.00$ & 0.05 & 15.88 & 0.84 & 9.98 & 73.31 \\
\hline 8 & 10.81 & 1.16 & 55.61 & 32.42 & $0.19 / 0.02 / 1.00$ & 0.11 & 15.99 & 1.72 & 9.52 & 72.77 \\
\hline
\end{tabular}


The silicon atoms are always concentrated on the surface of the aluminum beads. Usually, it is inversely relative to concentration of the sodium atoms. The lower the sodium atomic content is, the higher the silicon atoms. At other sites of the bath, silicon is only a trace element.

The surface of the beads are usually covered by crystalline fluoride (Their compositions vary, mostly a mixture of aluminum fluoride and sodium aluminum fluoride). These fluorides always lack calcium fluoride. The fluoride compounds are coherent to aluminum beads. On the surface of aluminum beads, remaining alumina can be found (Figure 4.21). Table 4.10 shows the compositions of the fluoride compound on the aluminum bead surfaces. Sometimes, the needlelike aluminum fluoride can be seen inside pores. A thin shell consisting of metallic aluminum and aluminum fluoride can be seen outside the beads (Figure 4.20 (Right)).

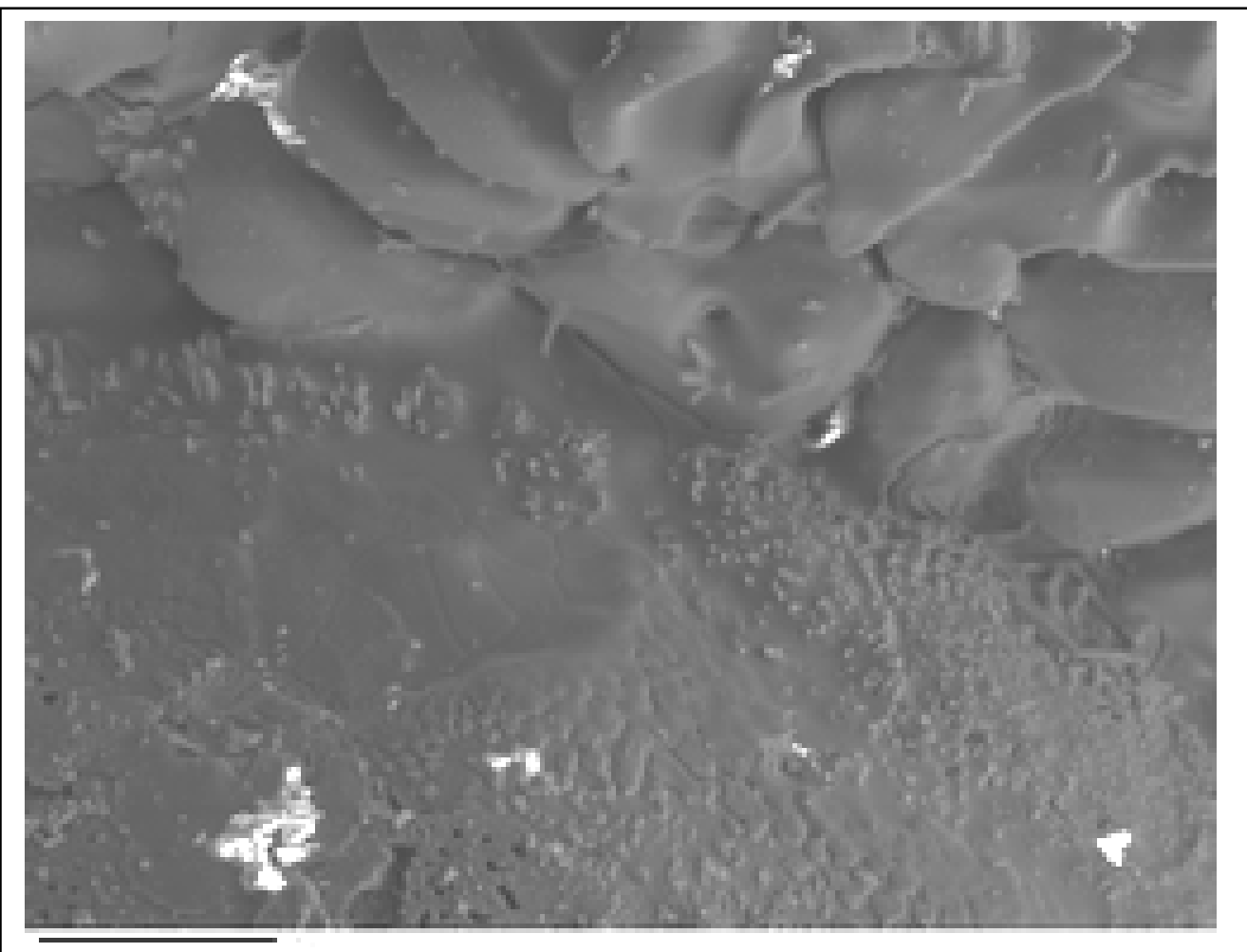

Figure 4.21 Fluoride particles (upper) coherent to the aluminum beads (lower), many alumina particles remained on the surface of aluminum beads 


\begin{tabular}{|c|c|c|c|c|c|c|c|c|c|c|}
\hline \multicolumn{11}{|c|}{$\begin{array}{l}\text { Table } 4.10 \text { Composition of the fluoride compound on the aluminum bead surfaces } \\
\text { (No eroded, No. 1-5: sodium aluminum fluoride; No. 6-8: needle-like aluminum fluoride } \\
\text { crystals) }\end{array}$} \\
\hline \multirow[b]{2}{*}{$\begin{array}{l}\text { Test } \\
\text { point }\end{array}$} & \multicolumn{4}{|c|}{ Atom \%, tested } & \multicolumn{2}{|c|}{ Atomic ratio } & \multicolumn{4}{|c|}{ Mol \%, calculated } \\
\hline & $\mathrm{Na}$ & $\mathrm{Ca}$ & $\mathrm{Al}$ & F & $\mathrm{Na} / \mathrm{Ca} / \mathrm{Al}$ & $\mathrm{Ca} / \mathrm{Na}$ & $\mathrm{NaF}$ & $\mathrm{CaF}_{2}$ & $\mathrm{AlF}_{3}$ & $\begin{array}{c}\mathrm{Al}\left(\mathrm{Al}_{2} \mathrm{O}_{3}\right. \\
\text { included) }\end{array}$ \\
\hline 1 & 19.37 & 0.64 & 28.69 & 51.30 & 0.68/0.02/1.00 & 0.03 & 39.78 & 1.31 & 20.98 & 37.93 \\
\hline 2 & 17.02 & 0.96 & 29.84 & 52.18 & $0.57 / 0.03 / 1.00$ & 0.06 & 35.59 & 2.01 & 23.71 & 39.23 \\
\hline 3 & 19.11 & 0.81 & 27.60 & 52.47 & $0.69 / 0.03 / 1.00$ & 0.04 & 40.21 & 1.71 & 22.25 & 35.82 \\
\hline 4 & 22.64 & 1.07 & 20.00 & 56.29 & $1.13 / 0.05 / 1.00$ & 0.05 & 51.80 & 2.45 & 24.02 & 21.73 \\
\hline 5 & 19.14 & 2.66 & 32.60 & 45.61 & $0.59 / 0.08 / 1.00$ & 0.14 & 35.18 & 4.88 & 12.96 & 46.97 \\
\hline 6 & 7.04 & 1.97 & 59.71 & 31.28 & $0.12 / 0.03 / 1.00$ & 0.28 & 10.24 & 2.87 & 9.85 & 77.04 \\
\hline 7 & 14.44 & 1.17 & 38.59 & 45.80 & $0.37 / 0.03 / 1.00$ & 0.08 & 26.24 & 2.17 & 17.84 & 53.35 \\
\hline 8 & 12.86 & 0.75 & 34.43 & 51.96 & $0.37 / 0.02 / 1.00$ & 0.06 & 26.76 & 1.57 & 26.09 & 45.58 \\
\hline
\end{tabular}

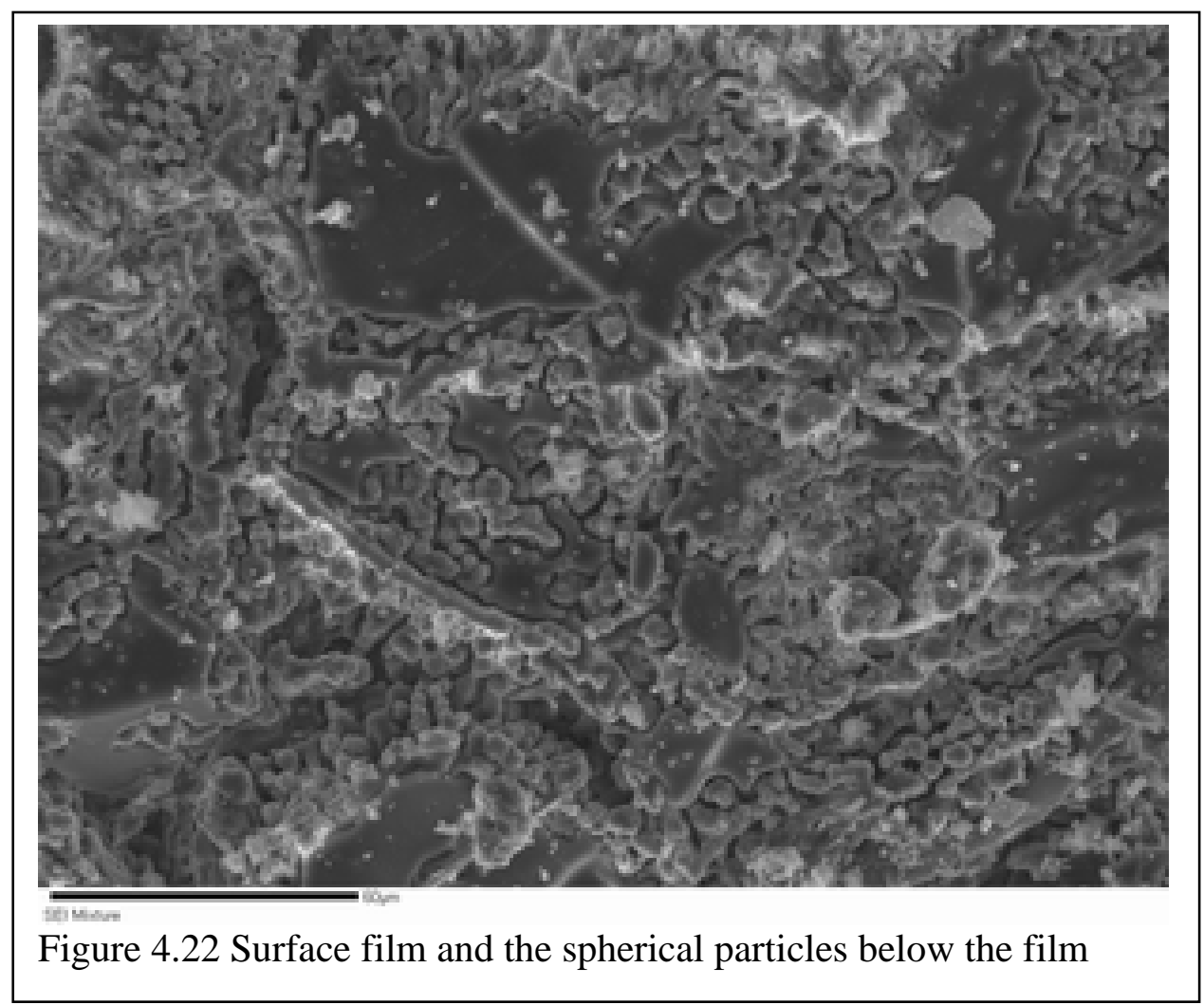

At the bottom of the bath, there is no significant difference from the lower section. 


\subsubsection{Features of the slags with microwave irradiation}

(1) Surface and near surface region of the upper section

According to SEM micrographs, the near surface portion of the upper section with microwave also can be divided into 3 sublayers downward from the surface:
a. Surface film
b. Radiating crystal sublayer
c. Spherical particle sublayer

They are located on the surface of the upper section. The thickness of the surface film is about 1 $\mathrm{mm}$. The radiating crystal sublayer is a thin sheet, which is only 10-30 microns in thickness and always stuck on the surface film.

Figure 4.22 showed the surface film and the spherical particle sublayer.

(a) Surface film

The surface film is smooth. It consists of sodium fluoride and aluminum fluoride. The atomic ratio of sodium vs. aluminum is around 1.5/1 (Table 4.11). This ratio is lower than that both in the pure chiolite (1.67) and cryolite (3). From a XRD analysis, there is villiaumite existing in this layer. This implies that there is additional aluminum fluoride or alumina except chiolite.

\begin{tabular}{|c|c|c|c|c|c|c|c|c|c|c|}
\hline \multicolumn{9}{|c|}{ Table 4.11 Composition of surface film } \\
\hline \multirow{2}{*}{$\begin{array}{c}\text { Test } \\
\text { point }\end{array}$} & $\mathrm{Na}$ & $\mathrm{Ca}$ & $\mathrm{Al}$ & $\mathrm{F}$ & $\mathrm{Na} / \mathrm{Ca} / \mathrm{Al}$ & $\mathrm{Ca} / \mathrm{Na}$ & $\mathrm{NaF}$ & $\mathrm{CaF}_{2}$ & $\mathrm{AlF}_{3}$ & $\begin{array}{c}\mathrm{Al}_{(}\left(\mathrm{Al}_{2} \mathrm{O}_{3}\right. \\
\text { included })\end{array}$ \\
\cline { 2 - 12 } & & & & & & & \multicolumn{3}{c|}{ Atomic ratio } & \multicolumn{3}{c|}{ Mol \%, calculated } \\
\hline 1 & 22.33 & 0.30 & 15.08 & 62.29 & $1.48 / 0.02 / 1.00$ & 0.01 & 59.21 & 0.80 & 34.79 & 5.20 \\
\hline 2 & 21.64 & 0.10 & 15.47 & 62.78 & $1.40 / 0.01 / 1.00$ & 0 & 58.16 & 0.28 & 36.66 & 4.90 \\
\hline 3 & 23.17 & 0.18 & 15.99 & 60.67 & $1.45 / 0.01 / 1.00$ & 0.01 & 58.90 & 0.45 & 31.48 & 9.17 \\
\hline 4 & 24.05 & 0.17 & 20.46 & 55.32 & $1.18 / 0.01 / 1.00$ & 0.01 & 53.84 & 0.38 & 23.08 & 22.71 \\
\hline 5 & 26.28 & 0.15 & 15.95 & 57.62 & $1.65 / 0.01 / 1.00$ & 0.01 & 62.01 & 0.35 & 24.43 & 13.21 \\
\hline 6 & 24.80 & 0.12 & 16.19 & 58.90 & $1.53 / 0.01 / 1.00$ & 0 & 60.33 & 0.28 & 27.47 & 11.92 \\
\hline
\end{tabular}

(b) Radiating crystal sublayer

This sublayer is made up of radiating fluoride fibers. Usually, the fiber is 3-5 microns in length and 0.2-0.3 microns in diameter (Figure 4.23). As Table 4.12 demonstrates, these fibers are insufficient in sodium and calcium fluoride, and mainly consist of aluminum fluoride. 


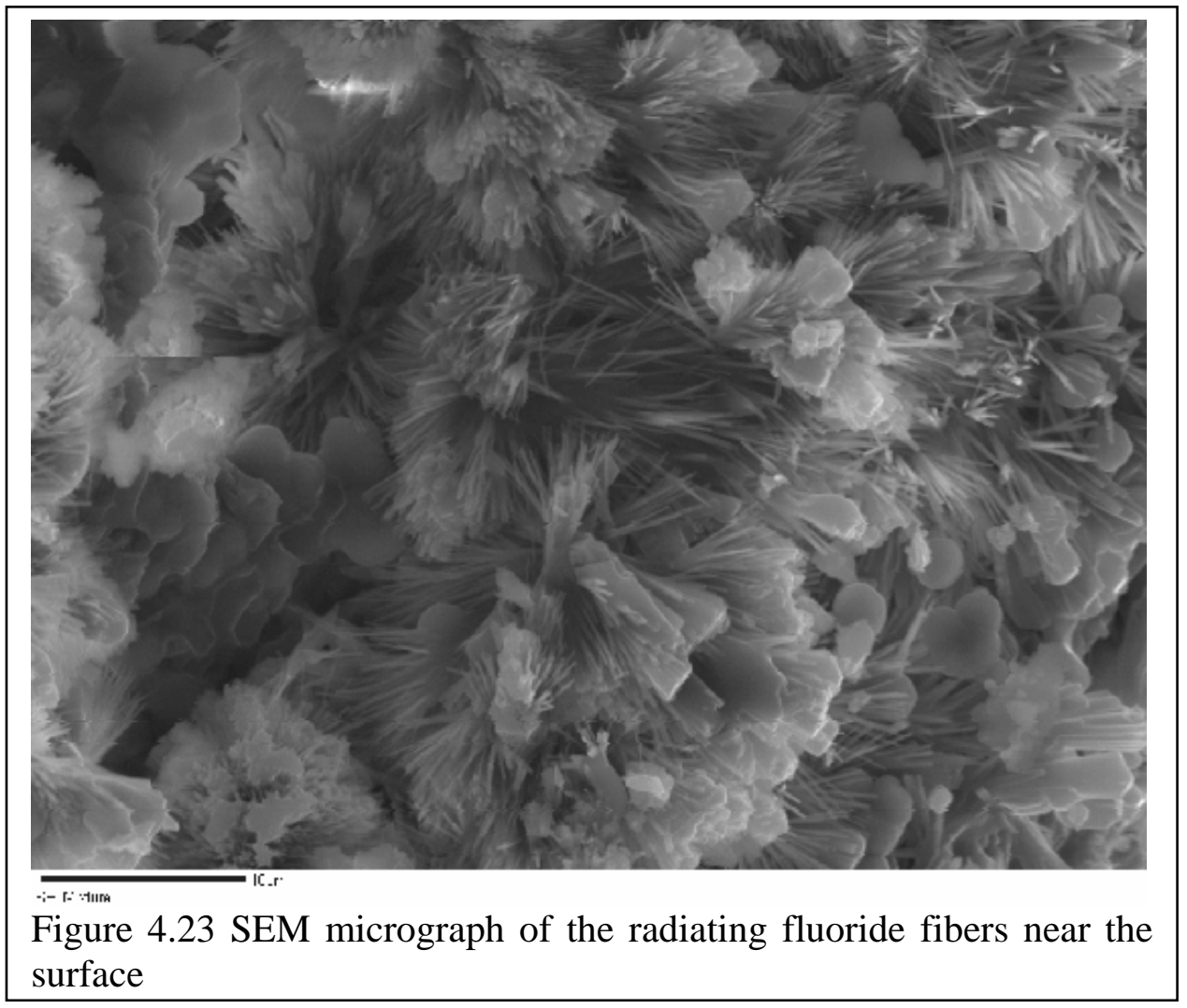

\begin{tabular}{|c|c|c|c|c|c|c|c|c|c|c|}
\hline \multirow[b]{2}{*}{$\begin{array}{l}\text { Test } \\
\text { point }\end{array}$} & \multicolumn{4}{|c|}{ Atom \%, tested } & \multicolumn{2}{|c|}{ Atomic ratio } & \multicolumn{4}{|c|}{ Mol \%, calculated } \\
\hline & $\mathrm{Na}$ & $\mathrm{Ca}$ & $\mathrm{Al}$ & $\mathrm{F}$ & $\mathrm{Na} / \mathrm{Ca} / \mathrm{Al}$ & $\mathrm{Ca} / \mathrm{Na}$ & $\mathrm{NaF}$ & $\mathrm{CaF}_{2}$ & $\mathrm{AlF}_{3}$ & $\begin{array}{c}\mathrm{Al}\left(\mathrm{Al}_{2} \mathrm{O}_{3}\right. \\
\text { included) }\end{array}$ \\
\hline 1 & 9.34 & 2.90 & 63.02 & 24.74 & $0.15 / 0.05 / 1.00$ & 0.31 & 12.42 & 3.85 & 4.25 & 79.78 \\
\hline 2 & 13.42 & 2.06 & 54.89 & 29.63 & $0.24 / 0.04 / 1.00$ & 0.15 & 19.07 & 2.93 & 5.72 & 72.28 \\
\hline
\end{tabular}

(c) Spherical particle sublayer

The spherical particles are mostly 2-3 microns in diameter. They are loosely packed with pointpoint contacts. With similar composition to the fibers above, these particles mainly consist of aluminum fluoride (Table 4.13). 


\begin{tabular}{|c|c|c|c|c|c|c|c|c|c|c|}
\hline \multicolumn{11}{|c|}{ Table 4.13 Composition of spherical particles } \\
\hline \multirow[b]{2}{*}{$\begin{array}{l}\text { Test } \\
\text { point }\end{array}$} & \multicolumn{4}{|c|}{ Atom \%, tested } & \multicolumn{2}{|c|}{ Atomic ratio } & \multicolumn{4}{|c|}{ Mol \%, calculated } \\
\hline & $\mathrm{Na}$ & Ca & $\mathrm{Al}$ & $\mathrm{F}$ & $\mathrm{Na} / \mathrm{Ca} / \mathrm{Al}$ & $\mathrm{Ca} / \mathrm{Na}$ & $\mathrm{NaF}$ & $\mathrm{CaF}_{2}$ & $\mathrm{AlF}_{3}$ & 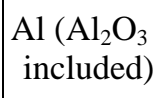 \\
\hline 1 & 6.99 & 0.21 & 76.23 & 16.57 & 0.09/0/1.00 & 0.03 & 8.38 & 0.25 & 3.66 & 87.71 \\
\hline 2 & 11.93 & 0.14 & 62.75 & 25.18 & $0.19 / 0 / 1.00$ & 0.01 & 15.94 & 0.19 & 5.78 & 78.09 \\
\hline 3 & 8.83 & 0.22 & 76.01 & 14.94 & $0.12 / 0 / 1.00$ & 0.02 & 10.38 & 0.25 & 2.23 & 87.14 \\
\hline 4 & 19.98 & 0.88 & 24.41 & 54.74 & $0.83 / 0.04 / 1.00$ & 0.04 & 44.13 & 1.94 & 24.31 & 29.62 \\
\hline 5 & 28.61 & 0.33 & 26.76 & 44.30 & $1.07 / 0.01 / 1.00$ & 0.01 & 51.36 & 0.59 & 9.00 & 39.05 \\
\hline 6 & 16.29 & 2.64 & 35.02 & 46.05 & $0.47 / 0.08 / 1.00$ & 0.16 & 30.20 & 4.89 & 15.12 & 49.79 \\
\hline
\end{tabular}

In most cases, the fluoride particles near the bath surface have fibrous shapes whereas the particles are spherical in the center of the bath.

\section{(2) Upper section}

The upper section is a dense solid. The broken surface is glass-like (Figure 4.24). This section is mainly consists of sodium fluoride and aluminum fluoride with minor calcium fluoride. The atomic ratio of sodium to aluminum is $1.35-1.58 / 1.00$, while the ratio of calcium to aluminum is 0.02-0.14/1.00 (Table 4.14)

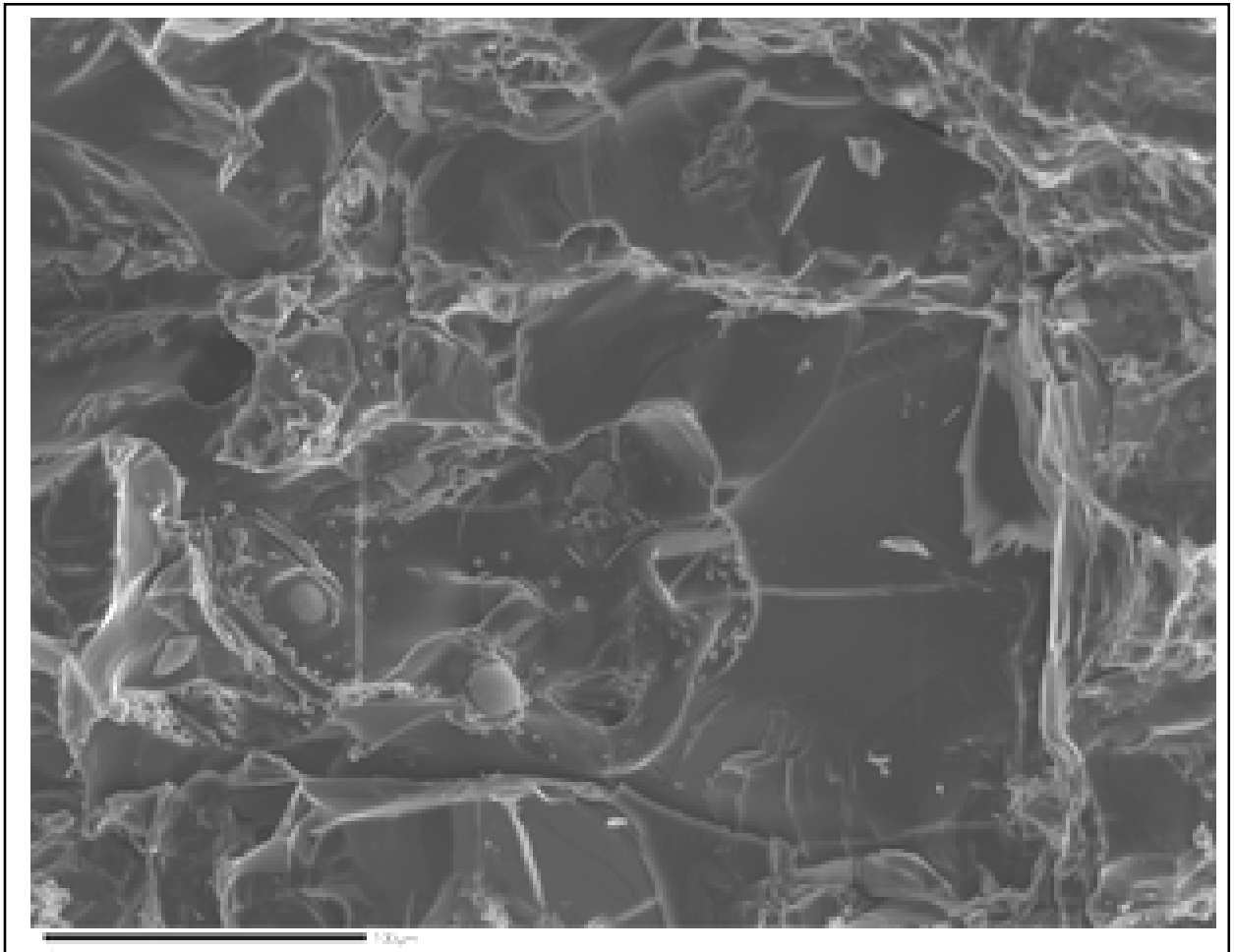

Figure 4.24 SEM picture of broken surface of upper section 


\begin{tabular}{|c|c|c|c|c|c|c|c|c|c|c|}
\hline \multicolumn{11}{|c|}{ Table 4.14 Composition of matrix in upper section } \\
\hline \multirow[b]{2}{*}{$\begin{array}{l}\text { Test } \\
\text { point }\end{array}$} & \multicolumn{4}{|c|}{ Atom \%, tested } & \multicolumn{2}{|c|}{ Atomic ratio } & \multicolumn{4}{|c|}{ Mol \%, calculated } \\
\hline & $\mathrm{Na}$ & $\mathrm{Ca}$ & $\mathrm{Al}$ & $\mathrm{F}$ & $\mathrm{Na} / \mathrm{Ca} / \mathrm{Al}$ & $\mathrm{Ca} / \mathrm{Na}$ & $\mathrm{NaF}$ & $\mathrm{CaF}_{2}$ & $\mathrm{AlF}_{3}$ & $\begin{array}{c}\mathrm{Al}\left(\mathrm{Al}_{2} \mathrm{O}_{3}\right. \\
\text { included })\end{array}$ \\
\hline 1 & 23.69 & 0.85 & 16.80 & 58.66 & $1.41 / 0.05 / 1.00$ & 0.04 & 57.31 & 2.06 & 26.83 & 13.80 \\
\hline 2 & 23.30 & 0.76 & 16.06 & 59.88 & $1.45 / 0.05 / 1.00$ & 0.03 & 58.08 & 1.89 & 29.13 & 10.90 \\
\hline 3 & 23.53 & 0.39 & 16.91 & 59.17 & $1.39 / 0.02 / 1.00$ & 0.02 & 57.63 & 0.96 & 28.46 & 12.96 \\
\hline 4 & 23.71 & 0.86 & 17.61 & 57.82 & $1.35 / 0.05 / 1.00$ & 0.04 & 56.21 & 2.04 & 25.59 & 16.16 \\
\hline 5 & 24.60 & 1.80 & 15.56 & 58.03 & $1.58 / 0.12 / 1.00$ & 0.07 & 58.63 & 4.29 & 23.69 & 13.39 \\
\hline 6 & 24.23 & 2.13 & 15.46 & 58.18 & $1.57 / 0.14 / 1.00$ & 0.09 & 57.94 & 5.09 & 23.66 & 13.31 \\
\hline 7 & 22.30 & 0.35 & 16.34 & 61.00 & $1.36 / 0.02 / 1.00$ & 0.02 & 57.19 & 0.89 & 32.48 & 9.43 \\
\hline 8 & 25.00 & 0.23 & 16.38 & 58.39 & $1.53 / 0.01 / 1.00$ & 0.01 & 60.08 & 0.55 & 26.37 & 13.00 \\
\hline 9 & 22.13 & 0.35 & 17.41 & 60.11 & $1.27 / 0.02 / 1.00$ & 0.02 & 55.47 & 0.87 & 31.17 & 12.49 \\
\hline
\end{tabular}

In this section, there are many remaining alumina particles. These particles are spherical or irregular, and surrounded by dense matrix (Figure 4.25). They have over saturated aluminum concentration (is above the content in $\mathrm{AlF}_{3}$ ) (Table 4.15). The size is about 10 microns in diameter. The particle surfaces are quite rough. This indicates that the fluoride was eroding and dissolving alumina particles.

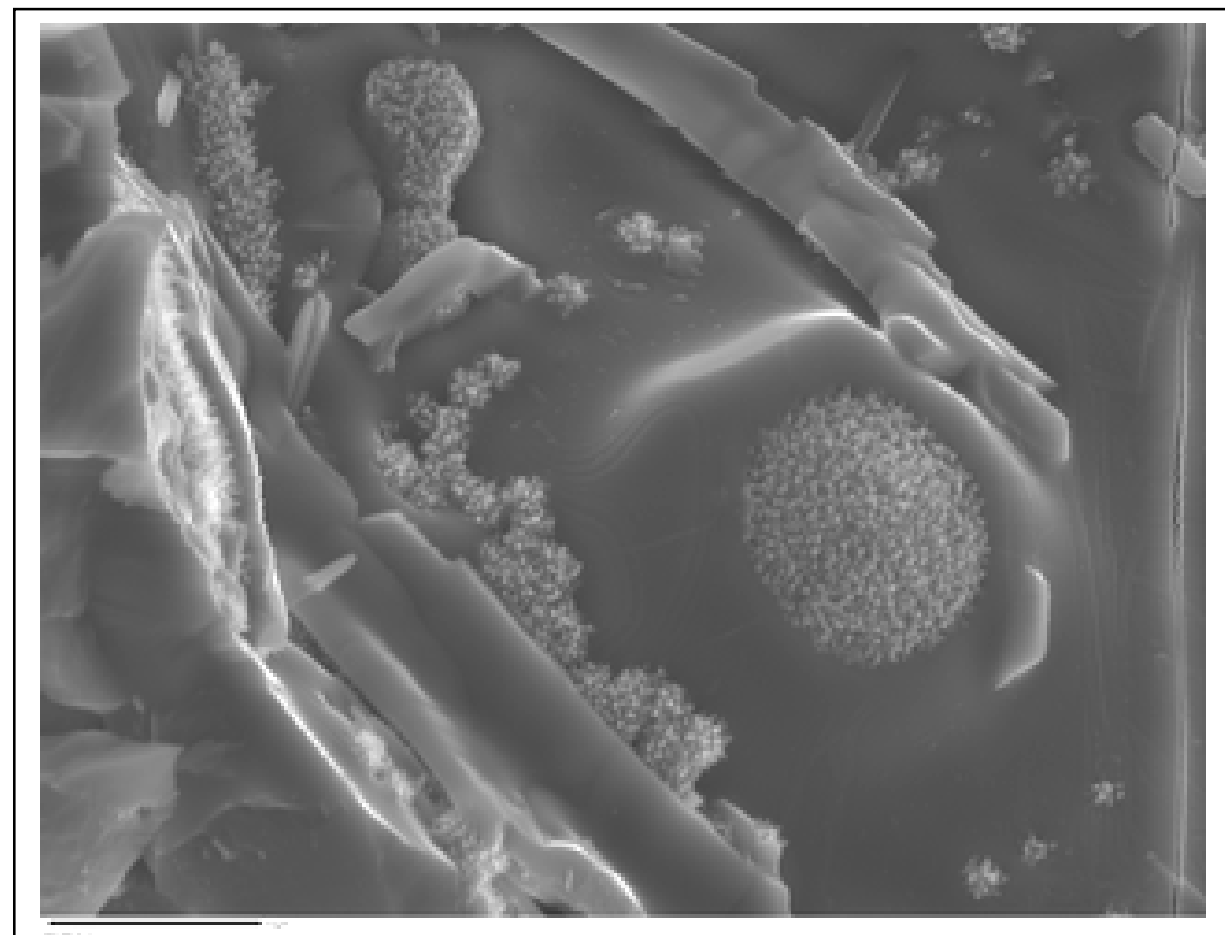

Figure 4.25 Remaining alumina particle surrounded by fluoride matrix 


\begin{tabular}{|c|c|c|c|c|c|c|c|c|c|c|}
\hline \multirow[b]{2}{*}{$\begin{array}{l}\text { Test } \\
\text { point }\end{array}$} & \multicolumn{4}{|c|}{ Atom \%, tested } & \multicolumn{2}{|c|}{ Atomic ratio } & \multicolumn{4}{|c|}{ Mol \%, calculated } \\
\hline & $\mathrm{Na}$ & $\mathrm{Ca}$ & $\mathrm{Al}$ & $\mathrm{F}$ & $\mathrm{Na} / \mathrm{Ca} / \mathrm{Al}$ & $\mathrm{Ca} / \mathrm{Na}$ & $\mathrm{NaF}$ & $\mathrm{CaF}_{2}$ & $\mathrm{AlF}_{3}$ & $\begin{array}{c}\mathrm{Al}\left(\mathrm{Al}_{2} \mathrm{O}_{3}\right. \\
\text { included) }\end{array}$ \\
\hline 1 & 2.95 & 0.77 & 57.39 & 38.89 & $0.05 / 0.01 / 1.00$ & 0.26 & 4.83 & 1.26 & 18.77 & 75.14 \\
\hline 2 & 2.60 & 0.65 & 57.77 & 38.99 & $0.04 / 0.01 / 1.00$ & 0.25 & 4.26 & 1.06 & 19.17 & 75.51 \\
\hline 3 & 2.82 & 0.65 & 53.91 & 42.62 & $0.05 / 0.01 / 1.00$ & 0.23 & 4.91 & 1.14 & 22.37 & 71.59 \\
\hline 4 & 2.75 & 1.17 & 47.09 & 48.99 & $0.06 / 0.02 / 1.00$ & 0.43 & 5.40 & 2.30 & 28.68 & 63.63 \\
\hline 5 & 2.97 & 0.60 & 54.84 & 41.58 & $0.05 / 0.01 / 1.00$ & 0.20 & 5.09 & 1.03 & 21.34 & 72.54 \\
\hline 6 & 3.31 & 0.68 & 56.47 & 39.54 & $0.06 / 0.01 / 1.00$ & 0.21 & 5.47 & 1.13 & 19.22 & 74.18 \\
\hline
\end{tabular}

Many rod-shaped particles also can be seen inside the matrix (Figure 4.25). These rod-shaped particles have a higher content of calcium fluoride (Table 4.16).

\begin{tabular}{|c|c|c|c|c|c|c|c|c|c|c|}
\hline \multicolumn{11}{|c|}{ Table 4.16 Composition of rod-shaped particles } \\
\hline \multirow[b]{2}{*}{$\begin{array}{l}\text { Test } \\
\text { point }\end{array}$} & \multicolumn{4}{|c|}{ Atom \%, tested } & \multicolumn{2}{|c|}{ Atomic ratio } & \multicolumn{4}{|c|}{ Mol \%, calculated } \\
\hline & $\mathrm{Na}$ & $\mathrm{Ca}$ & $\mathrm{Al}$ & $\mathrm{F}$ & $\mathrm{Na} / \mathrm{Ca} / \mathrm{Al}$ & $\mathrm{Ca} / \mathrm{Na}$ & $\mathrm{NaF}$ & $\mathrm{CaF}_{2}$ & $\mathrm{AlF}_{3}$ & $\begin{array}{c}\mathrm{Al}\left(\mathrm{Al}_{2} \mathrm{O}_{3}\right. \\
\text { included })\end{array}$ \\
\hline 1 & 9.23 & 11.09 & 18.56 & 61.12 & $0.50 / 0.60 / 1.00$ & 1.20 & 23.73 & 28.53 & 25.47 & 22.27 \\
\hline 2 & 14.86 & 6.16 & 14.95 & 64.03 & $0.99 / 0.41 / 1.00$ & 0.41 & 41.32 & 17.13 & 34.15 & 7.40 \\
\hline
\end{tabular}

It was noted that the upper section just underneath the outlet of the waveguide was more crystallized than other parts of this section. The spherical crystal grains are as large as 300 microns in diameter (Figure 4.26). These crystal grains have similar composition as that of the dense matrix (Table 4.17). Comparing the compositions to other parts of this section, the calcium fluoride is less, but the sodium fluoride is obviously more. 


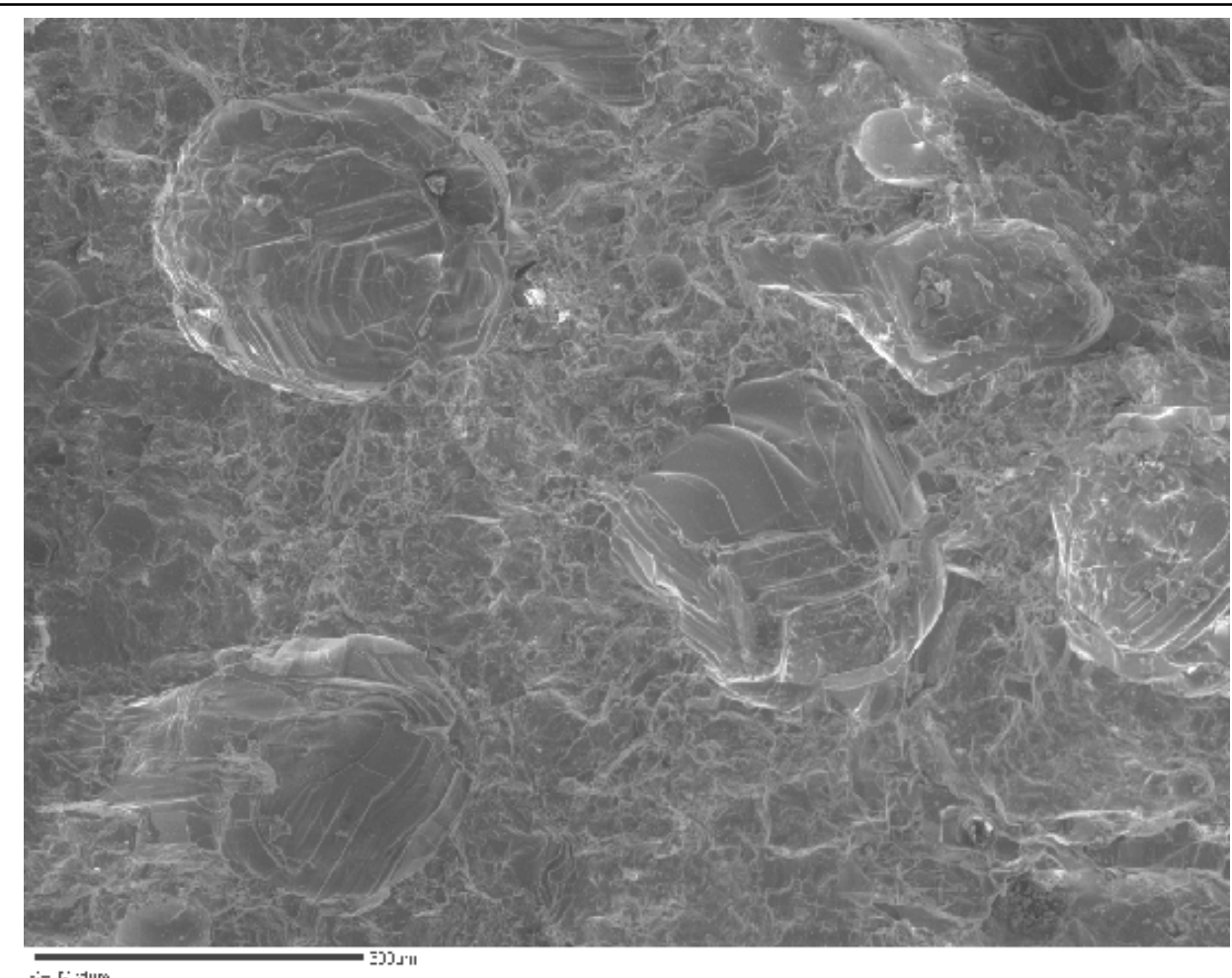

Figure 4.26 Fluoride particles in center of the upper section

\begin{tabular}{|c|c|c|c|c|c|c|c|c|c|c|}
\hline \multirow[b]{2}{*}{$\begin{array}{l}\text { Test } \\
\text { point }\end{array}$} & \multicolumn{4}{|c|}{ Atom \%, tested } & \multicolumn{2}{|c|}{ Atomic ratio } & \multicolumn{4}{|c|}{ Mol \%, calculated } \\
\hline & $\mathrm{Na}$ & $\mathrm{Ca}$ & $\mathrm{Al}$ & $\mathrm{F}$ & $\mathrm{Na} / \mathrm{Ca} / \mathrm{Al}$ & $\mathrm{Ca} / \mathrm{Na}$ & $\mathrm{NaF}$ & $\mathrm{CaF}_{2}$ & $\mathrm{AlF}_{3}$ & $\begin{array}{c}\mathrm{Al}\left(\mathrm{Al}_{2} \mathrm{O}_{3}\right. \\
\text { included })\end{array}$ \\
\hline \multicolumn{11}{|c|}{ Solid matrix } \\
\hline 1 & 24.01 & 1.27 & 13.58 & 61.14 & $1.77 / 0.09 / 1.00$ & 0.05 & 61.79 & 3.27 & 29.66 & 5.27 \\
\hline 2 & 25.59 & 1.71 & 13.79 & 58.91 & $1.86 / 0.12 / 1.00$ & 0.07 & 62.29 & 4.16 & 24.25 & 9.30 \\
\hline 3 & 23.28 & 0.12 & 14.92 & 61.69 & $1.56 / 0.01 / 1.00$ & 0 & 60.76 & 0.30 & 33.22 & 5.72 \\
\hline 4 & 22.91 & 0.19 & 14.68 & 62.22 & $1.56 / 0.01 / 1.00$ & 0.01 & 60.64 & 0.50 & 34.34 & 4.51 \\
\hline \multicolumn{11}{|c|}{ Spherical crystals } \\
\hline 5 & 25.96 & 1.04 & 14.99 & 58.01 & $1.73 / 0.07 / 1.00$ & 0.04 & 61.83 & 2.47 & 23.78 & 11.92 \\
\hline 6 & 26.57 & 0.17 & 15.20 & 58.07 & $1.75 / 0.01 / 1.00$ & 0.01 & 63.35 & 0.39 & 24.78 & 11.48 \\
\hline 7 & 27.44 & 0.86 & 16.76 & 54.93 & $1.64 / 0.05 / 1.00$ & 0.03 & 60.89 & 1.92 & 19.05 & 18.14 \\
\hline \multicolumn{11}{|c|}{ Matrix of crystal } \\
\hline 8 & 23.87 & 1.12 & 13.99 & 61.02 & $1.71 / 0.08 / 1.00$ & 0.05 & 61.24 & 2.87 & 29.86 & 6.03 \\
\hline 9 & 33.12 & 1.43 & 10.52 & 54.94 & $3.15 / 0.14 / 1.00$ & 0.04 & 73.49 & 3.18 & 14.02 & 9.31 \\
\hline
\end{tabular}




\section{(3) Lower section}

The structural feature of the lower section of the slags with microwave irradiation is similar to that without microwave irradiation. But there are many spherical particles with higher calcium fluoride content (Figure 4.27). The typical particle size is 150-200 microns.

These particles are mainly a compound of sodium fluoride and aluminum fluoride containing little calcium fluoride. The atomic ratio of sodium to aluminum is generally 1.30-1.60/1.00, whereas the ratio of calcium to aluminum is $0.20-1.65 / 1.00$ (Table 4.18). Comparing to the ratio of the corresponding section without microwave irradiation, this section has lower content of sodium fluoride and higher calcium fluoride.

The composition in the area between particles is similar to the particle composition except calcium content. The calcium content is sharply decreased (Figure 4.28).

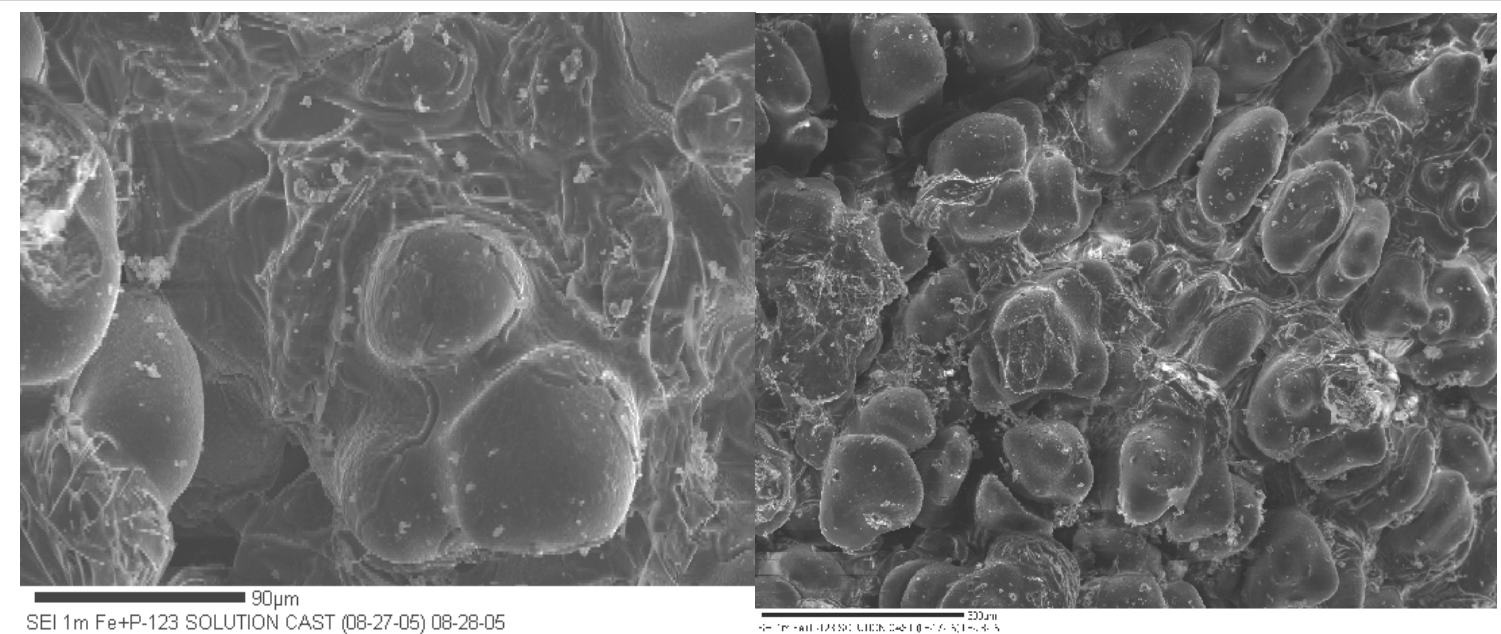

Figure 4.27 Spherical particles with high calcium fluoride content 


\begin{tabular}{|c|c|c|c|c|c|c|c|c|c|c|}
\hline \multicolumn{11}{|c|}{ Table 4.18 Composition of the spherical particles in the lower section } \\
\hline \multirow[b]{2}{*}{$\begin{array}{l}\text { Test } \\
\text { point }\end{array}$} & \multicolumn{4}{|c|}{ Atom \%, tested } & \multicolumn{2}{|c|}{ Atomic ratio } & \multicolumn{4}{|c|}{ Mol \%, calculated } \\
\hline & $\mathrm{Na}$ & $\mathrm{Ca}$ & $\mathrm{Al}$ & $\mathrm{F}$ & $\mathrm{Na} / \mathrm{Ca} / \mathrm{Al}$ & $\mathrm{Ca} / \mathrm{Na}$ & $\mathrm{NaF}$ & $\mathrm{CaF}_{2}$ & $\mathrm{AlF}_{3}$ & $\begin{array}{c}\mathrm{Al}\left(\mathrm{Al}_{2} \mathrm{O}_{3}\right. \\
\text { included })\end{array}$ \\
\hline \multicolumn{11}{|c|}{ Spherical crystals } \\
\hline 1 & 22.03 & 3.39 & 15.80 & 58.78 & $1.39 / 0.21 / 1.00$ & 0.15 & 53.44 & 8.22 & 24.24 & 14.10 \\
\hline 2 & 23.07 & 3.47 & 15.69 & 57.77 & $1.47 / 0.22 / 1.00$ & 0.15 & 54.63 & 8.22 & 21.91 & 15.24 \\
\hline 3 & 16.91 & 12.99 & 9.22 & 60.88 & $1.83 / 1.41 / 1.00$ & 0.77 & 43.23 & 33.21 & 15.34 & 8.23 \\
\hline 4 & 14.17 & 20.10 & 12.16 & 53.57 & $1.17 / 1.65 / 1.00$ & 1.42 & 30.53 & 43.29 & 0.57 & 26.76 \\
\hline 5 & 20.13 & 6.02 & 13.81 & 60.04 & $1.46 / 0.44 / 1.00$ & 0.30 & 50.38 & 15.07 & 23.25 & 11.31 \\
\hline 6 & 14.41 & 11.70 & 14.08 & 60.41 & $1.02 / 0.79 / 1.00$ & 0.77 & 36.40 & 28.04 & 20.04 & 15.53 \\
\hline 7 & 22.02 & 2.49 & 15.89 & 59.60 & $1.39 / 0.16 / 1.00$ & 0.11 & 54.50 & 6.16 & 26.90 & 12.43 \\
\hline 8 & 23.12 & 2.51 & 15.49 & 58.88 & $1.49 / 0.16 / 1.00$ & 0.11 & 56.23 & 6.10 & 24.92 & 12.75 \\
\hline 9 & 18.38 & 6.90 & 13.17 & 61.55 & $1.40 / 0.52 / 1.00$ & 0.38 & 47.80 & 17.95 & 25.46 & 8.79 \\
\hline 10 & 22.61 & 4.24 & 14.03 & 59.12 & $1.61 / 0.30 / 1.00$ & 0.19 & 55.31 & 10.37 & 22.85 & 11.47 \\
\hline 11 & 17.82 & 7.46 & 13.68 & 61.04 & $1.30 / 0.55 / 1.00$ & 0.42 & 45.74 & 29.15 & 24.21 & 10.90 \\
\hline \multicolumn{11}{|c|}{ Intersphericals } \\
\hline 1 & 22.67 & 0.07 & 23.91 & 53.29 & $0.95 / 0 / 1.00$ & 0 & 48.53 & 0.15 & 21.74 & 29.57 \\
\hline 2 & 21.88 & 3.01 & 38.88 & 36.23 & $0.56 / 0.08 / 1.00$ & 0.14 & 34.31 & 4.72 & 4.35 & 56.61 \\
\hline 3 & 22.99 & 0.36 & 15.40 & 61.25 & $1.49 / 0.02 / 1.00$ & 0.02 & 59.33 & 0.93 & 32.29 & 7.45 \\
\hline
\end{tabular}

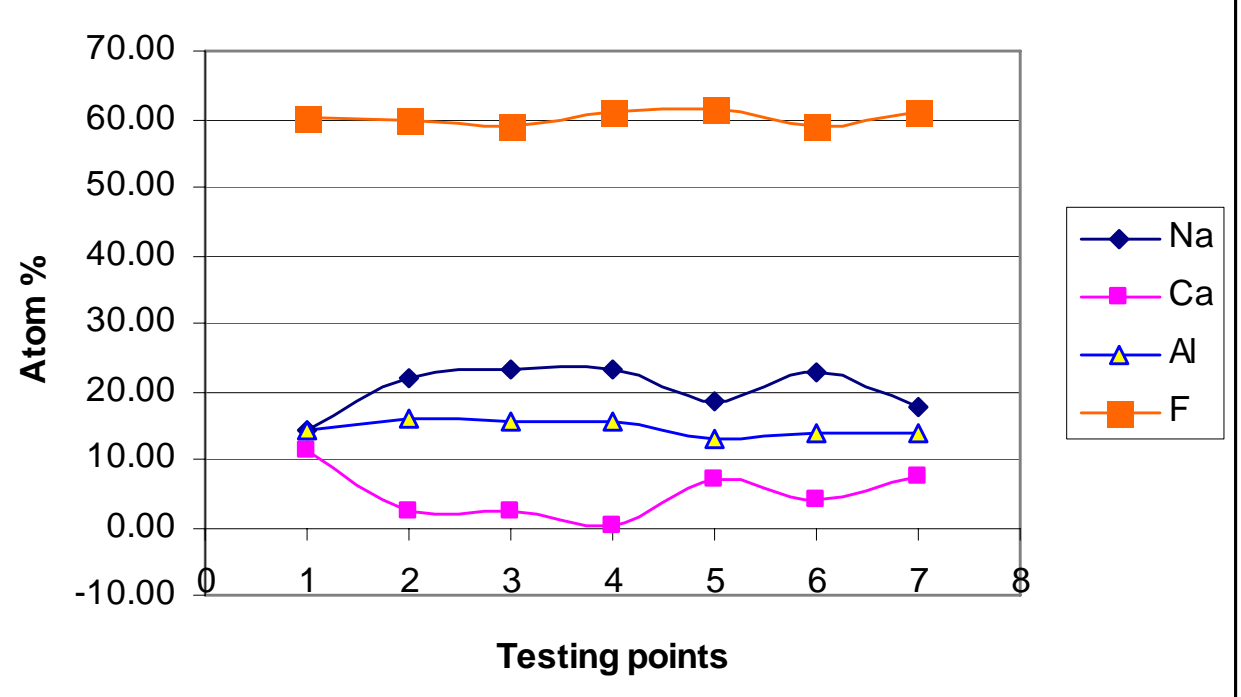

Figure 4.28 Atomic composition of cross section from the center of a particle (Point 1) to another (point 7) including inter-particle matrix (point 4) 
The lower section part just below the outlet of the waveguide is full crystallized. The size of crystalline particles is similar to other areas, 150-200 microns, but the dimension of the particles is uniform, and the crystalline grains are crowded together (Figure 4.29). The chemical composition in this area is similar to that of other areas (Table 4.19).

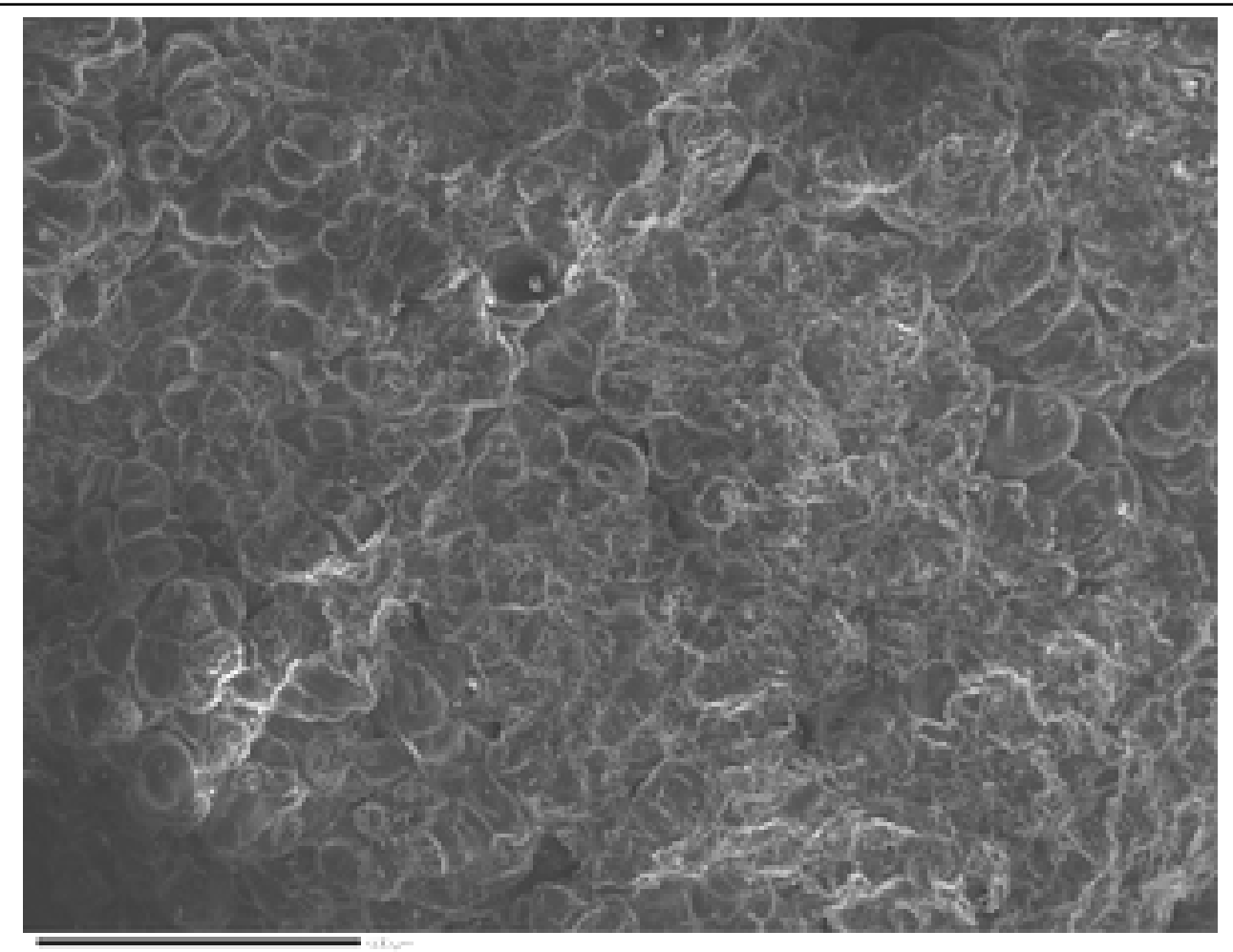

Figure 4.29 Fully crystallized structure below the outlet of the waveguide

\begin{tabular}{|c|c|c|c|c|c|c|c|c|c|c|}
\hline \multirow[b]{2}{*}{$\begin{array}{l}\text { Test } \\
\text { point }\end{array}$} & \multicolumn{4}{|c|}{ Atom \%, tested } & \multicolumn{2}{|c|}{ Atomic ratio } & \multicolumn{4}{|c|}{ Mol \%, calculated } \\
\hline & $\mathrm{Na}$ & $\mathrm{Ca}$ & $\mathrm{Al}$ & $\mathrm{F}$ & $\mathrm{Na} / \mathrm{Ca} / \mathrm{Al}$ & $\mathrm{Ca} / \mathrm{Na}$ & $\mathrm{NaF}$ & $\mathrm{CaF}_{2}$ & $\mathrm{AlF}_{3}$ & $\begin{array}{c}\mathrm{Al}\left(\mathrm{Al}_{2} \mathrm{O}_{3}\right. \\
\text { included })\end{array}$ \\
\hline 1 & 23.90 & 1.17 & 14.75 & 60.18 & $1.62 / 0.08 / 1.00$ & 0.05 & 60.03 & 2.93 & 28.42 & 8.63 \\
\hline 2 & 24.86 & 1.21 & 14.36 & 59.56 & $1.73 / 0.08 / 1.00$ & 0.05 & 61.49 & 3.00 & 26.60 & 8.91 \\
\hline
\end{tabular}

At the bottom of the bath, many stringed beads of fluoride crystal can be seen (Figure 4.30). Most of the crystal particles have over saturated aluminum concentration. In comparison with other areas of the section, the bottom area has less calcium fluoride and more sodium fluoride (Table 4.20). Aluminum beads can be found in this region. 


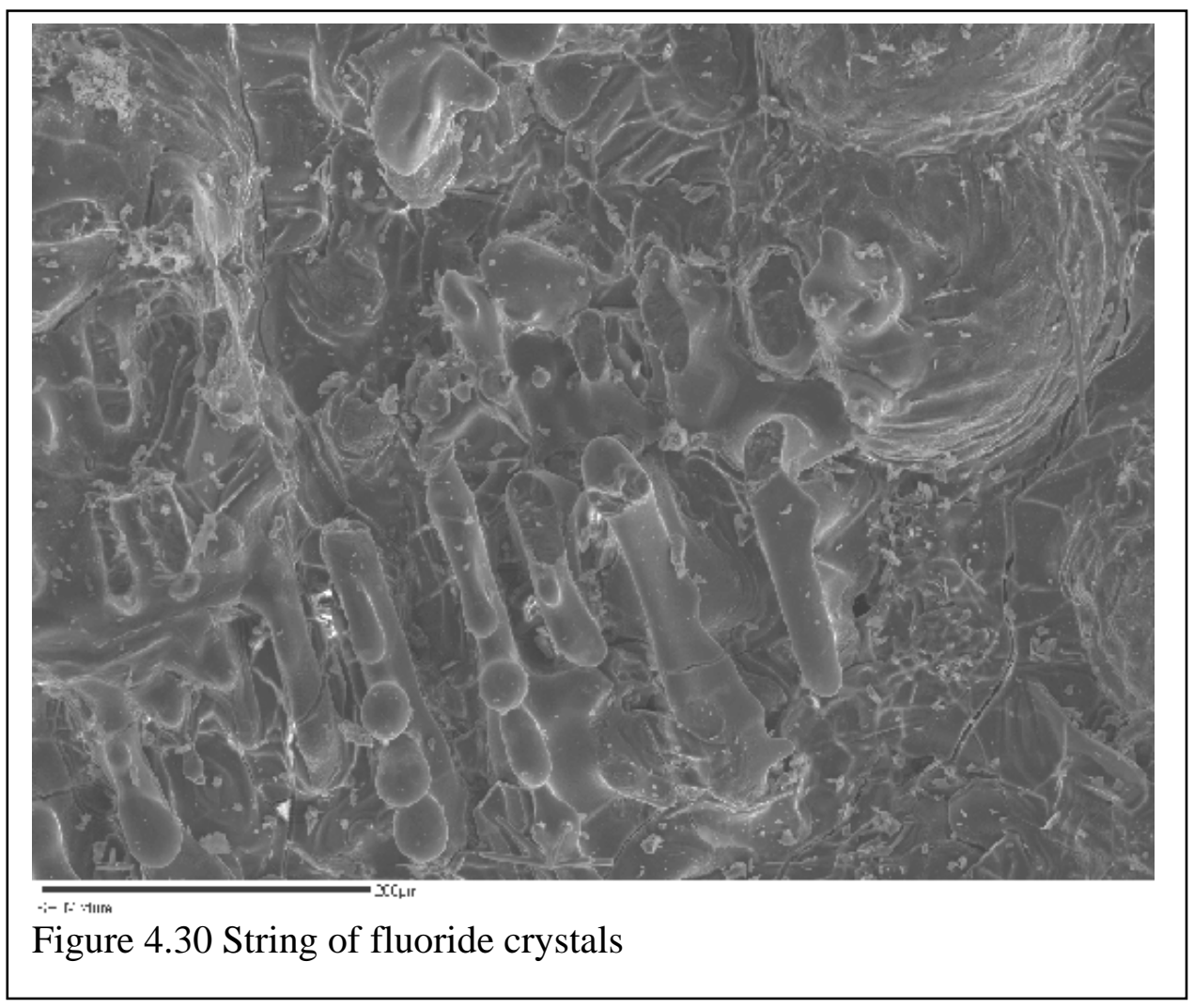

\begin{tabular}{|c|c|c|c|c|c|c|c|c|c|c|}
\hline \multicolumn{11}{|c|}{ Table 4.20 Composition of the slag at the bath bottom } \\
\hline \multirow[b]{2}{*}{$\begin{array}{l}\text { Test } \\
\text { point }\end{array}$} & \multicolumn{4}{|c|}{ Atom \%, tested } & \multicolumn{2}{|c|}{ Atomic ratio } & \multicolumn{4}{|c|}{ Mol \%, calculated } \\
\hline & $\mathrm{Na}$ & $\mathrm{Ca}$ & $\mathrm{Al}$ & F & $\mathrm{Na} / \mathrm{Ca} / \mathrm{Al}$ & $\mathrm{Ca} / \mathrm{Na}$ & $\mathrm{NaF}$ & $\mathrm{CaF}_{2}$ & $\mathrm{AlF}_{3}$ & $\begin{array}{c}\mathrm{Al}\left(\mathrm{Al}_{2} \mathrm{O}_{3}\right. \\
\text { included })\end{array}$ \\
\hline 1 & 19.22 & 8.08 & 15.53 & 57.17 & $1.24 / 0.52 / 1.00$ & 0.42 & 44.88 & 18.07 & 16.95 & 19.30 \\
\hline 2 & 48.87 & 0.12 & 13.01 & 38.00 & $3.76 / 0.01 / 1.00$ & 0 & 78.83 & 0.19 & -5.98 & 26.95 \\
\hline 3 & 42.17 & 0.20 & 12.61 & 45.01 & $3.34 / 0.02 / 1.00$ & 0 & 76.70 & 0.36 & 1.48 & 21.46 \\
\hline 4 & 27.04 & 1.51 & 14.63 & 56.82 & $1.85 / 0.10 / 1.00$ & 0.06 & 62.63 & 3.50 & 20.65 & 13.22 \\
\hline 5 & 44.49 & 0.27 & 12.31 & 42.92 & $3.61 / 0.02 / 1.00$ & 0.01 & 77.96 & 0.47 & -1.23 & 22.80 \\
\hline 6 & 43.00 & 0.21 & 13.11 & 43.68 & $3.28 / 0.02 / 1.00$ & 0 & 76.35 & 0.37 & 0.15 & 23.12 \\
\hline 7 & 28.94 & 0.81 & 17.56 & 52.69 & $1.65 / 0.05 / 1.00$ & 0.03 & 61.16 & 1.71 & 15.60 & 21.53 \\
\hline 8 & 29.30 & 0.79 & 18.15 & 51.76 & $1.61 / 0.04 / 1.00$ & 0.03 & 60.73 & 1.64 & 14.43 & 23.20 \\
\hline 9 & 29.37 & 0.82 & 18.50 & 51.31 & $1.59 / 0.04 / 1.00$ & 0.03 & 60.31 & 1.68 & 13.90 & 24.10 \\
\hline
\end{tabular}

Between the upper and the lower sections, there are many pores distributed horizontally. The pore internal surfaces are irregular (Figure 4.31). The composition of the pore internal surface indicates it is mainly a compound of $\mathrm{NaF}_{-} \mathrm{AlF}_{3}$ with little iron. 


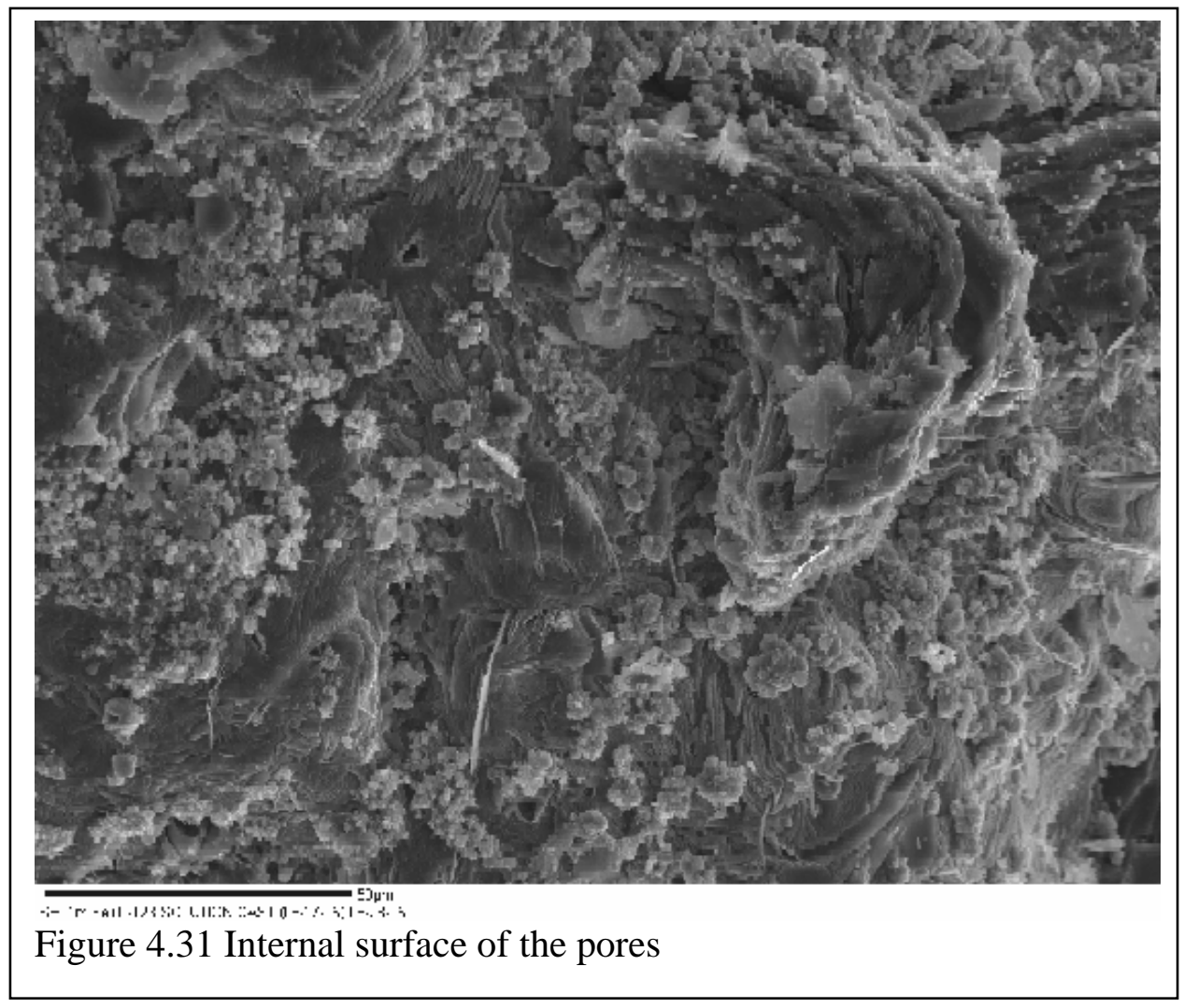

\subsubsection{Dendrites on anode end surfaces}

Various dendrites on the end of the anode can be clearly seen using SEM (Figure 4.32). The dendrites usually are 10-20 microns in diameter and 500-800 microns in length. The longest dendrite is approximately $2 \mathrm{~mm}$.

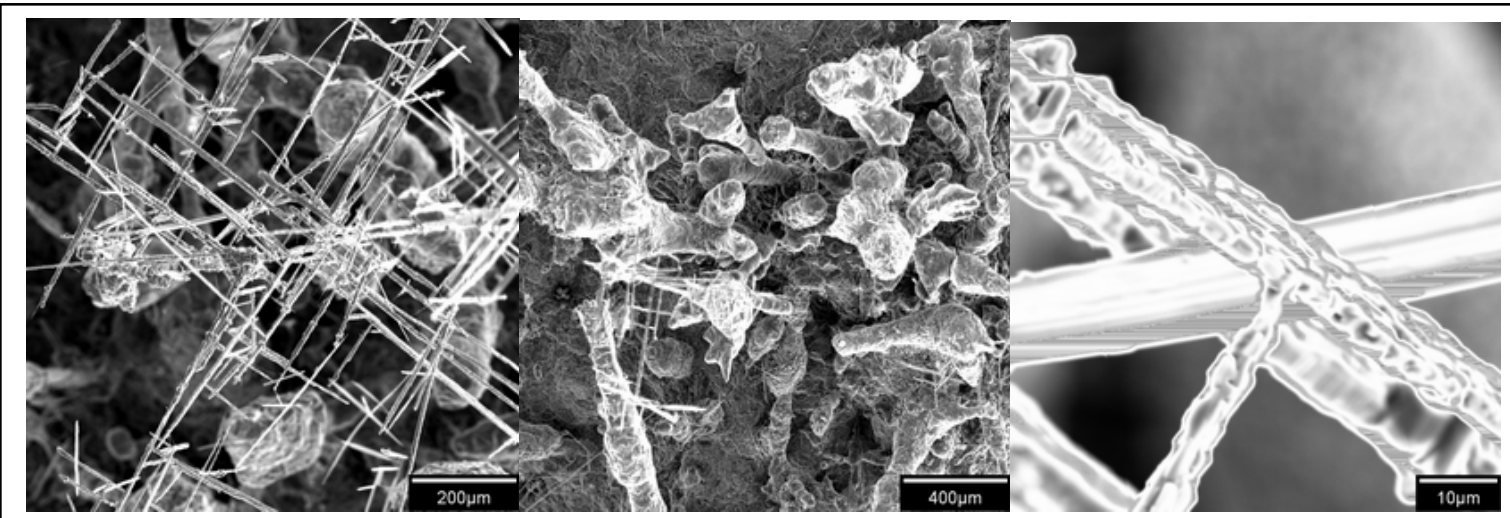

Figure 4.32 Dendrite crystals of aluminum fluoride on the anode end 
The composition of the dendrite crystals shows they lack in calcium fluoride and are low in sodium fluoride (Table 4.21). According to the XRD analytic result, the crystalline phases of dendrites are chiolite and aluminum fluoride. Table 4.21 indicates that the molar ratio of chiolite to aluminum fluoride is about 1:3.

\begin{tabular}{|c|c|c|c|c|c|c|c|c|c|c|}
\hline \multicolumn{11}{|c|}{ Table 4.21 Composition of the dendrite crystals } \\
\hline \multirow[b]{2}{*}{$\begin{array}{l}\text { Test } \\
\text { point }\end{array}$} & \multicolumn{4}{|c|}{ Atom \%, tested } & \multicolumn{2}{|c|}{ Atomic ratio } & \multicolumn{4}{|c|}{ Mol \%, calculated } \\
\hline & $\mathrm{Na}$ & $\mathrm{Ca}$ & $\mathrm{Al}$ & $\mathrm{F}$ & $\mathrm{Na} / \mathrm{Ca} / \mathrm{Al}$ & $\mathrm{Ca} / \mathrm{Na}$ & $\mathrm{NaF}$ & $\mathrm{CaF}_{2}$ & $\mathrm{AlF}_{3}$ & $\begin{array}{c}\mathrm{Al}\left(\mathrm{Al}_{2} \mathrm{O}_{3}\right. \\
\text { included })\end{array}$ \\
\hline 1 & 17.38 & 0.70 & 20.25 & 61.67 & $0.86 / 0.03 / 1.00$ & 0.04 & 45.34 & 1.83 & 37.30 & 15.53 \\
\hline 2 & 15.53 & 0.05 & 20.80 & 63.62 & $0.75 / 0 / 1.00$ & 0 & 42.69 & 0.14 & 43.98 & 13.19 \\
\hline 3 & 21.61 & 0.00 & 18.25 & 60.14 & $1.18 / 0 / 1.00$ & 0 & 54.21 & 0 & 32.22 & 13.56 \\
\hline 4 & 18.78 & 0.05 & 24.15 & 57.02 & $0.78 / 0 / 1.00$ & 0 & 43.69 & 0.12 & 29.59 & 26.60 \\
\hline
\end{tabular}

\subsubsection{Nickel-based superalloy}

The development of wetted cathodes and inert anodes for the primary aluminum industry has intensified during the last few years. These investigations cover composition, structure, electrical conductivity, mechanical properties, and thermal shock resistance of electrodes, as well as wetability and corrosion resistance to various electrolytes, etc. However, none of the results to date meet the critical requirements listed in the Inert Anode Roadmap.

Developing a metallic anode is one of the research efforts. Successful application of a metallic anode will eliminate the emission of carbon dioxide and perfluorocarbons associated with the current carbon anode, resulting in significant environmental benefits. A metallic anode also has potential advantages including good electrical conductivity, high fracture toughness, excellent thermal shock resistance, and ease of fabrication into complex shapes for use in an advanced cell design.

The inert anode and wetted cathode material must be electrochemically and thermodynamically stable in the fluoride electrolyte at operating temperature. Corrosion resistance of a metallic anode in the molten fluoride of a primary aluminum cell is the major issue. The "erosion rate" has been chosen as the criterion for measuring stability. The specific target is an erosion rate less than $10 \mathrm{~mm} /$ year, under conditions of current density of $0.8 \mathrm{amps} / \mathrm{cm}^{2}$.

Nickel-based alloys have been used in a wide variety of severe operating conditions involving corrosive environment, high temperature, high stress, and their. In this study, the erosion rate of an Inco nickel-based superalloy in a standard fluoride melt was investigated metallographically.

The nickel-based superalloy used in this study is Hastelloy and Inco Alloy HX, which is a commercial product purchased from McMaster-Carr Supply Company, Chicago, IL. This superalloy contains $47.5 \%$ nickel, $21.8 \%$ chromium, $18.5 \%$ iron and $9 \%$ molybdenum (ASTM Specification ASTM B435). It features outstanding oxidation resistance and exceptional strength 
at temperature up to $1204^{\circ} \mathrm{C}$. It has great weld-ability and is especially suited for use in hot and highly corrosive environments.

The fluoride used in this study (as described in Section 4.1.1) is a mixture of aluminum fluoride, sodium fluoride, calcium fluoride and alumina, provided by Century Aluminum Co. The solid mixture was crushed with a vibrated mill and passed through 16 mesh $(1 \mathrm{~mm})$. The composition of the mixture is (wt \%) aluminum fluoride $55.23 \%$, sodium fluoride $34.42 \%$, calcium fluoride $5.66 \%$ and alumina $4.69 \%$. The theoretical melting temperature of this compound is $700^{\circ} \mathrm{C}$.

\section{(1) Cathode tests}

The nickel-based superalloy was used to fabricate the cathode. As in early fluoride corrosion tests, we heated the fluoride electrolyte in the cell to about $800^{\circ} \mathrm{C}$ and applied positive voltage to the cathode, introducing 100A current for 4 hours. Such tests were repeated several times. The cathode internal surfaces showed no obvious changes. In comparison, a stainless steel shelled thermocouple was used to measure the bath temperature. The thermocouple did not last for more than 30 minutes if submerged into the hot fluoride electrolyte. It was completely eroded. We had to insert the thermocouple into the hot fluoride to obtain a temperature reading and raise it to above the fluoride immediately. In normal electrowinning tests, a negative voltage was applied to the cathode. Reaction between the superalloy and the molten aluminum occurred. It is obvious that this alloy is not suitable for use as a cathode material. In most of the electrowinning tests, we had to use a graphite lining to protect the alloy from fluoride erosion.

\section{(2) Anode tests}

\section{Corrosion of superalloy specimens in fluoride solution}

Nickel-based superalloy plate was cut into rectangular specimens of $4 \times 4 \times 50 \mathrm{~mm}$. To conduct a corrosion test, a specimen was ground to expose fresh surfaces and immersed in $100 \mathrm{~g}$ of the fluoride powder contained in a ceramic crucible. The crucible was then placed into an electrical box furnace and heated to $1000^{\circ} \mathrm{C}$. After the fluoride reached temperature, the specimen was held there for a predetermined time. The specimen was then removed from the furnace and cooled in air to room temperature. Four $1000^{\circ} \mathrm{C}$ holding times were selected: 0.5, 1.0, 2.0 and 3.0 hours.

\section{Polishing of superalloy specimens}

The superalloy specimens were cut perpendicular to their length. Then the cross-sections were polished using 6 micron diamond paste and 0.05 micron alumina solution. The entire crosssection was then etched with an acid solution.

\section{Etching of superalloy specimens}

The etchant in this study was prepared by mixing equal volume of concentrated nitric acid and glacial acetic acid. The etchant solution was heated to $60^{\circ} \mathrm{C}$, and the superalloy specimens were 
swabbed with warm etchant for 2 minutes. The testing procedure flowchart is given in Figure 4.33.

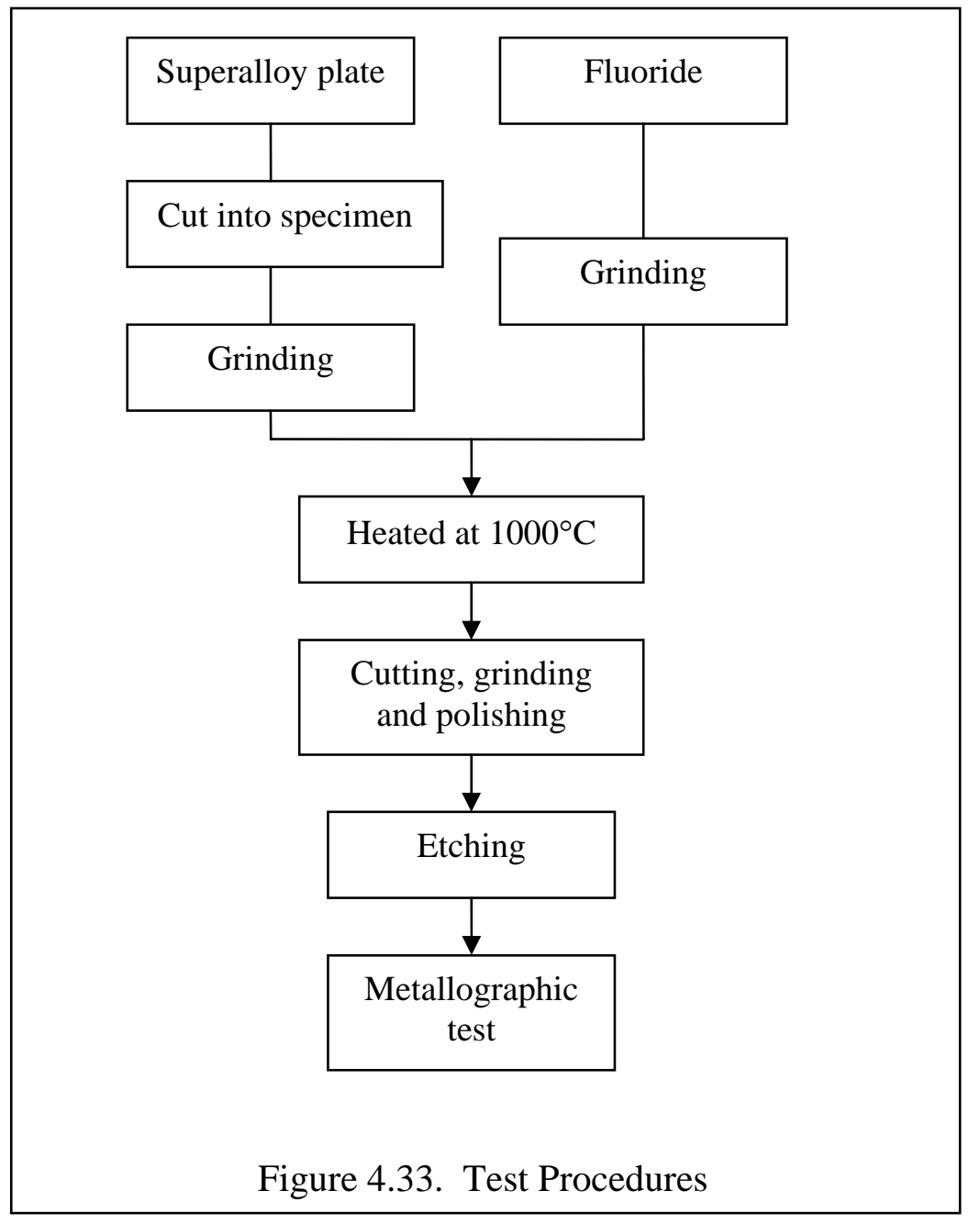

\section{Results and discussion}

After cooling, the solidified fluoride had a porous structure. The superalloy specimen was easily removed from the fluoride mass. However, the specimen surfaces were bonded with the fluoride, which indicates high wet-ability to the alloy (Figure 4.34).

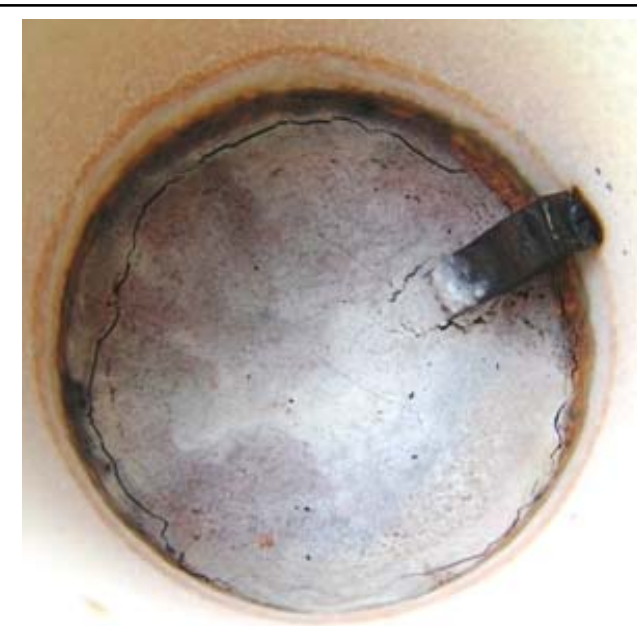

Figure 4.34. Ni-based superalloy in solidified fluoride melt 
As observed by the metallographic examination, when the corrosion time was less than 0.5 hours, the microstructure of the specimen surface had no obvious change except oxidation. With the increase of holding time, the grain boundaries at the specimen surface were clearly exposed by the etchant (Figure 4.35). The depth of corrosion, represented by the grain boundary exposure, increased with the increase of the holding time. The depth was less than 10 microns for one hour corrosion holding, but it reached 20-50 microns (average 40 microns) for two hours holding and 55-80 microns (average 70 microns) for three hours holding. Figure 4.36 shows a non-etched sample after 2 hours.

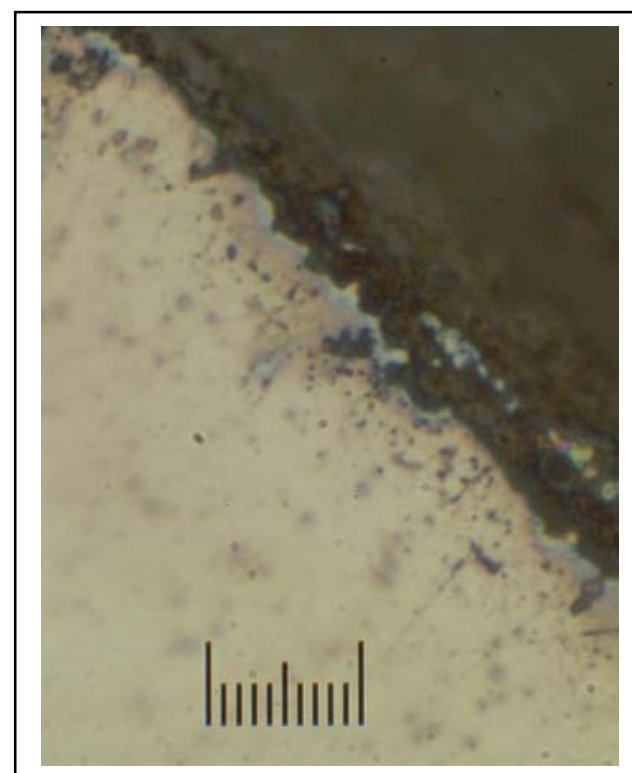

(1)

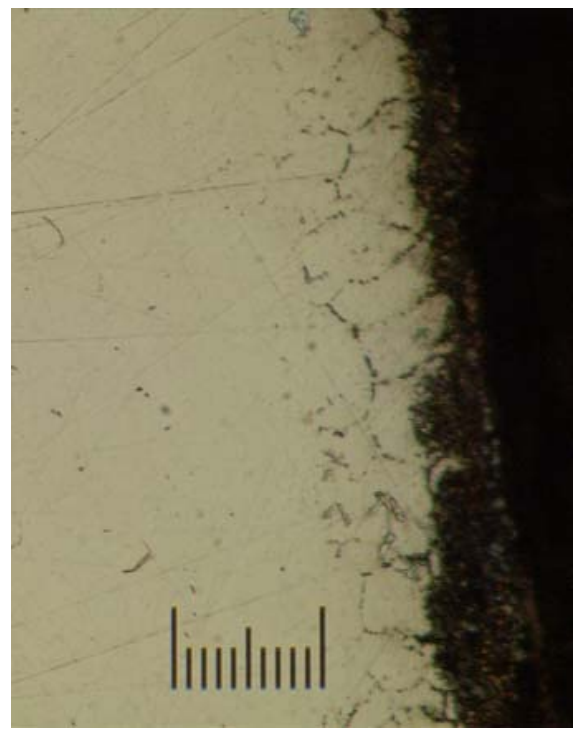

(3)

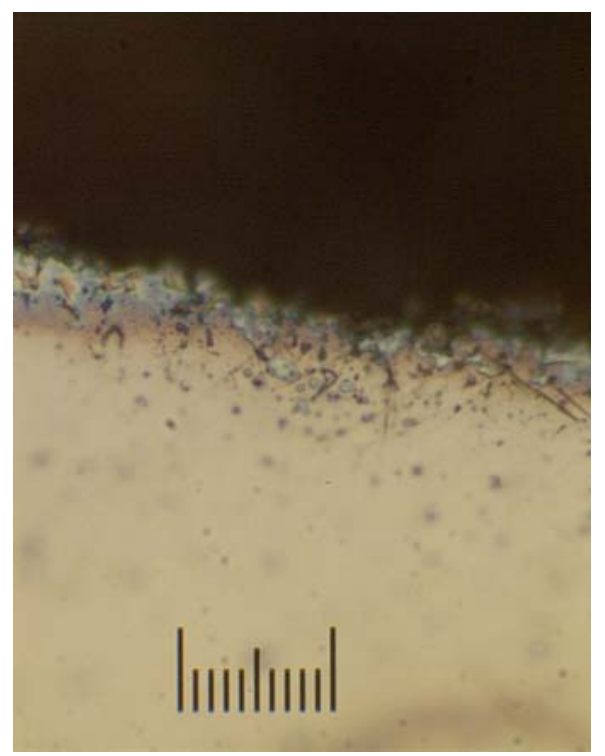

(2)

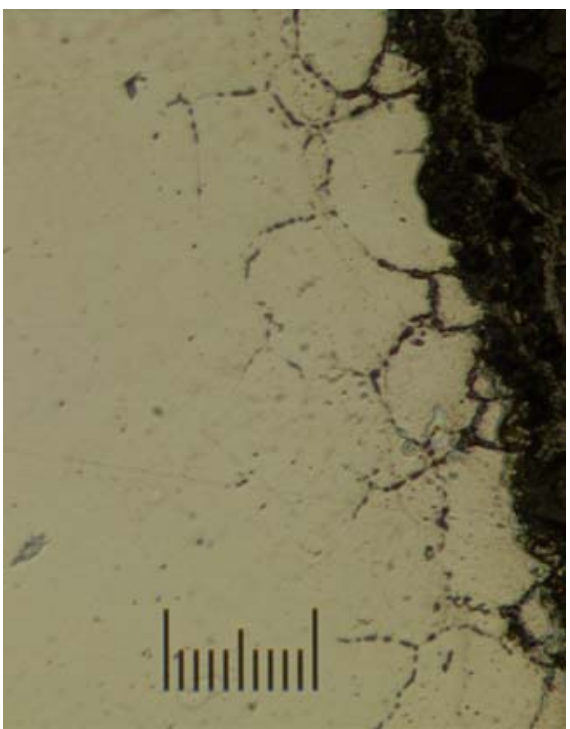

(4)

Figure 4.35. Corrosion of Ni-based alloy in fluoride melts (Etched with combined solution of nitric acid and glacial acetic acid)

(1) 0.5 hours, scale length: 10 microns; (2) 1 hour, scale length: 20 microns;

(3) 2 hours, scale length: 50 microns; (4) 3 hours, scale length: 50 microns; 


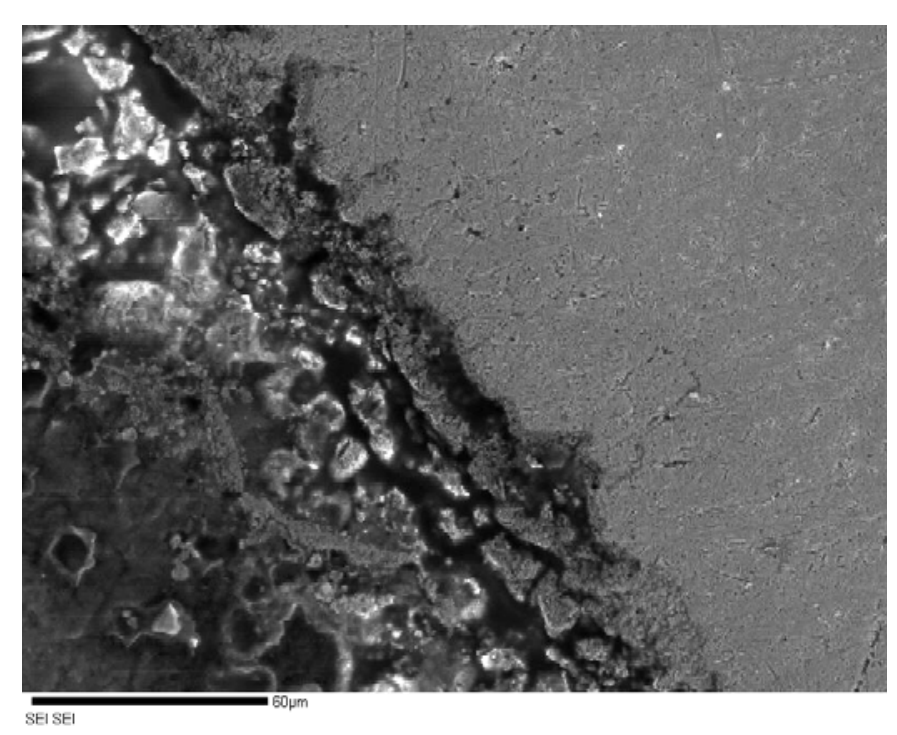

Figure 4.36. SEM picture of superalloy specimen after 2 hours corrosion (Non-etched)

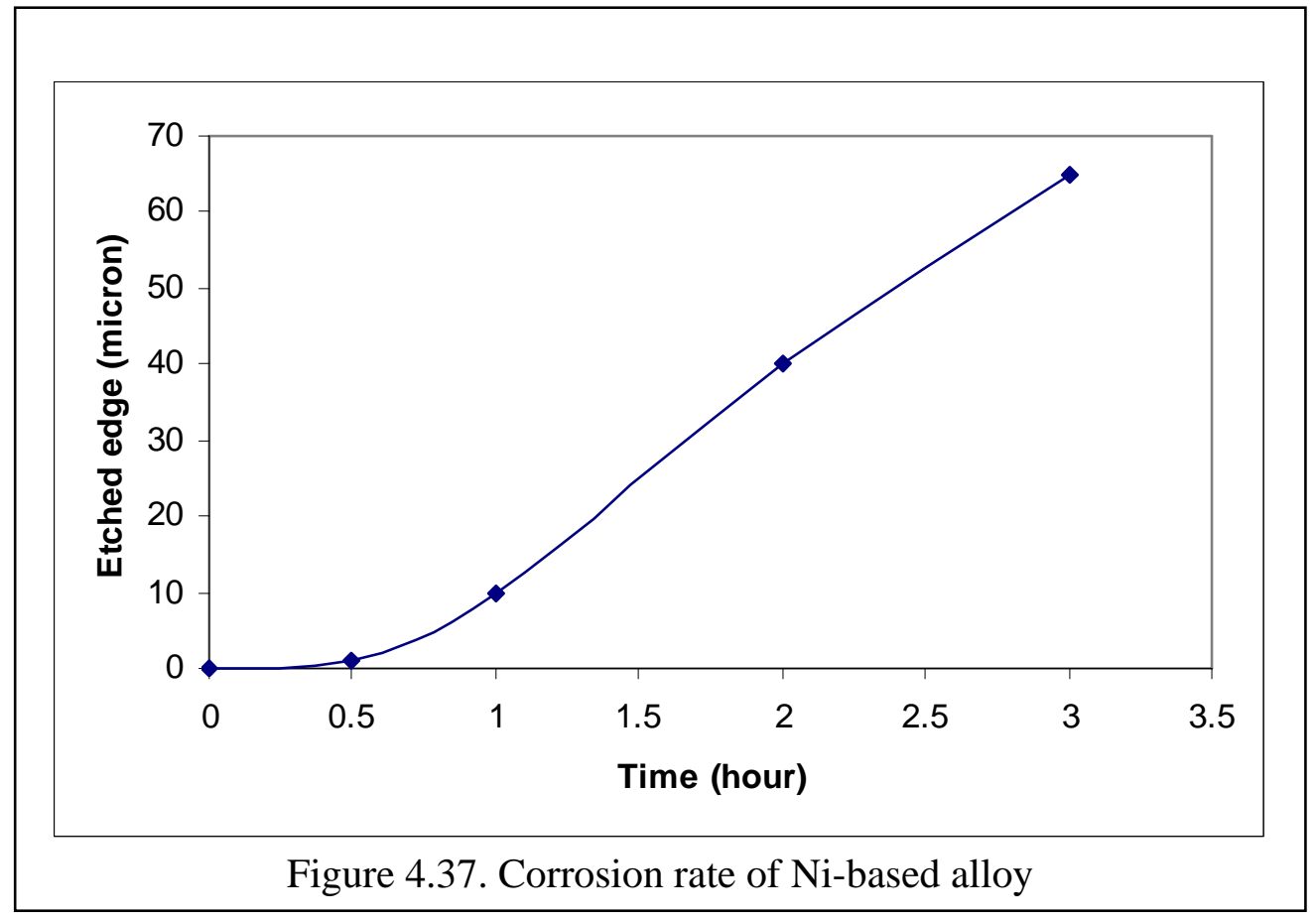

The corrosion rate of the fluoride solution to the superalloy is approximately 30 microns per hour (Figure 4.37). This corrosion rate is correspondingly equal to about $260 \mathrm{~mm} /$ year, much higher than the target rate of less than $10 \mathrm{~mm} /$ year. 
The superalloy used for this test contains nickel, chromium, iron and molybdenum. Nickel is a good corrosion resistance material. It offers excellent corrosion resistance to non-oxidizing acids and caustic alkalis. In a nickel based alloy, chromium imparts improved resistance to oxidizing media such as nitric acid $\left(\mathrm{HNO}_{3}\right)$ and to hot $\mathrm{H}_{3} \mathrm{PO}_{4}$. Molybdenum in nickel substantially improves resistance to non-oxidizing acids. However, iron is typically used to reduce costs, not to promote corrosion resistance. Therefore, at high temperature with fluoride melt, the iron atoms on the surface and interfaces of grains would be easily diffused into the fluoride solution. Based on this experiment, the chosen superalloy did not meet the corrosion resistance requirements. A nicked based alloy without iron content could be further investigated.

\subsubsection{Problems and discussions}

We found several problems in conducting the electrowinning tests. The biggest problem was the temperature homogeneity and the continuous addition and melting of fluoride.

The molten fluoride has a low thermal conductivity. This led to a large vertical temperature gradient in the bath. The temperature difference between the bath bottom and surface could reach $250-350^{\circ} \mathrm{C}$, which means that the temperature gradient of the fluoride was as high as $300^{\circ} \mathrm{C} /$ inch $^{2}$ (Figure 4.38).

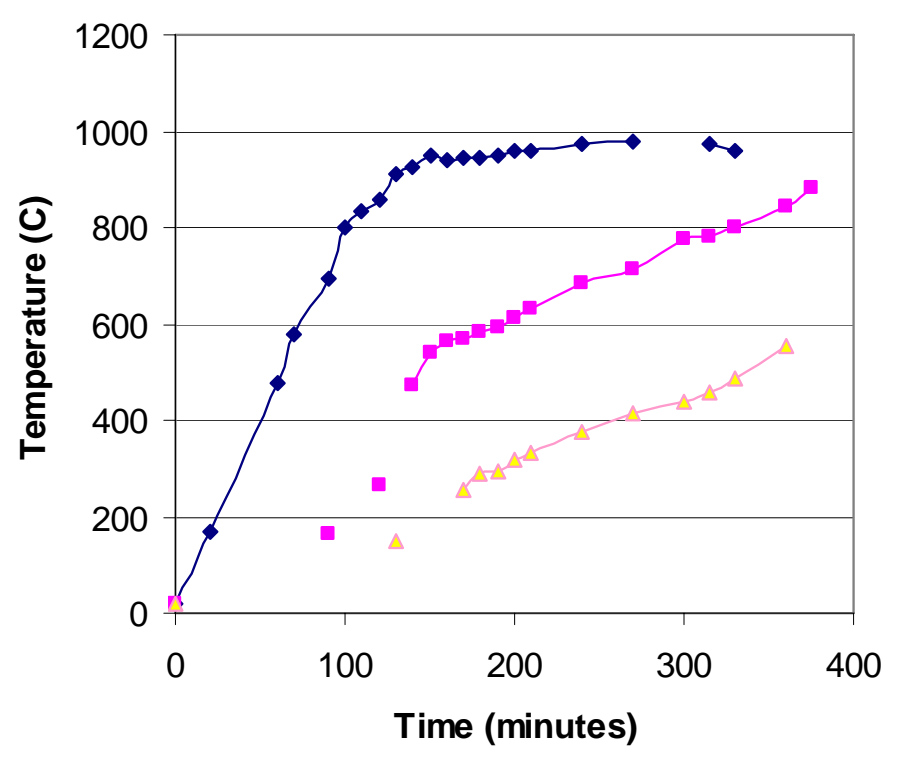

$\longrightarrow$ Anode surface

- - Anode bottom

$\triangle$ Bath bottom

Figure 4.38 Bath temperature difference 
As the result of the temperature gradient, the fluoride inside the channel of the graphite anode did not completely melt without microwave irradiation (Figure 4.39). Microwave irradiation helped to melt some of the fluoride inside of the channel (Figure 4.40).

Microwave irradiation during electrowinning shows some effects on the bath temperature. It did not show any benefits in increasing the aluminum electrowinning rate. On the contrary, it decreased the output of aluminum for reasons that are not clear.

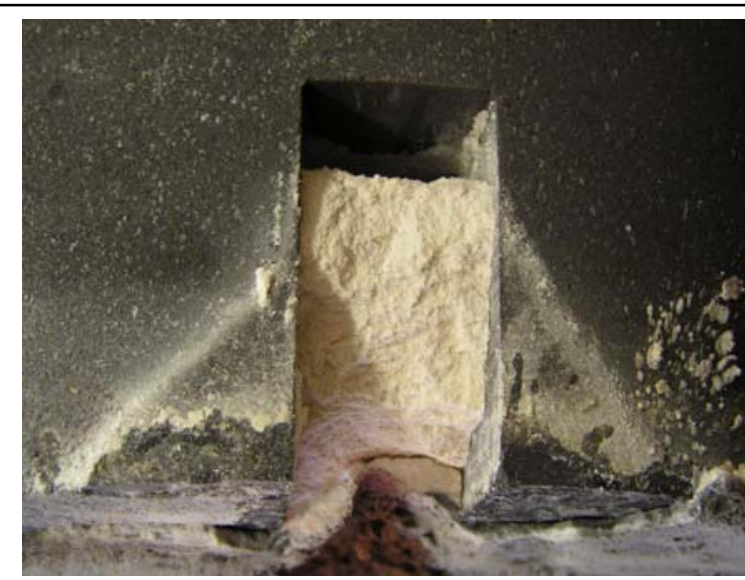

Figure 4.39 Fluoride in graphite channel without microwave irradiation

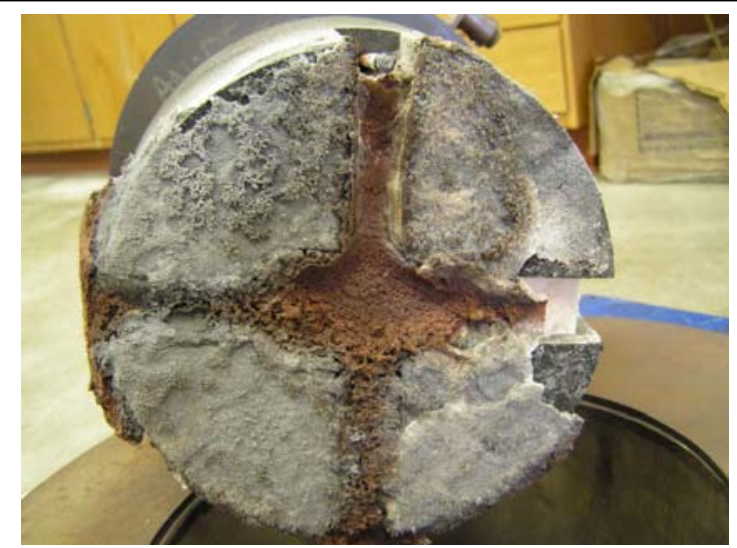

Figure 4.40 Fluoride in graphite channel with microwave irradiation 


\subsection{Conclusions}

The commonly used fluorides for aluminum electrowinning are not good microwave absorbing materials at room temperature. However, the typical industry used fluoride compound for aluminum electrowinning is an excellent microwave absorbing material above $550^{\circ} \mathrm{C}$.

Microwave irradiation did not appear beneficial to the aluminum electrowinning process in our experiments.

Nickel-based superalloy is not suitable for use as a cathode material; although it wets with molten aluminum, it causes severe reactions. In the anode experiments, the chosen superalloy did not meet corrosion resistance requirements. A nicked based alloy without iron content could be further investigated. 


\section{References}

1. J. Thonatad, P. Fellner, G.M. Haarberg, J. Hives, H. Kvande and A. Sterten, "Aluminium Electrolysis ( $3^{\text {rd }}$ Edition)", Germay: Aluminium-Verlag, 2001

2. D. F. Craig and J. J. Brown,Jr., "Phase equilibrium in the system $\mathrm{CaF}_{2}-\mathrm{AlF}_{3}-\mathrm{Na}_{3} \mathrm{AlF}_{6}$ and Part of the System $\mathrm{CaF}_{2}-\mathrm{AlF}_{3}-\mathrm{Na}_{3} \mathrm{AlF}_{6}-\mathrm{Al}_{2} \mathrm{O}_{3}$ ", Journal of the American Ceramic Society, 1980, 63(5-6):254-261

3. The Aluminum Association, 2003, http://www.aluminum.org

4. Bob Cheatham, Julian Copenhaver and Euel Cutshall etc, "Inert Anode Roadmap", The Aluminum Association, 1998.

5. K. E. Haque, "Microwave Energy for Mineral Treatment Processes: a Brief Review”, Int. J. Miner. Process., volume 57, 1999

6. J. E. Gerling, "Microwave Oven Power: A Technical Review”, J. Microwave Power and Electromagnetic Energy, 28, 1987

7. D. E. Clark, W. H. Sutton, "Microwave Processing of Materials", Annu. Rev. Mater. Sci., volume 26, 1996

8. L. Chunpeng, X. Yousheng, H. Yixin, “Application of Microwave Radiation to Extractive Metallurgy”, Chin. J. Met. Sci. Technol., volume 6, 1990

9. J. Jacob, L. Chia, F. Boey, "Thermal and Non-thermal Interaction of Microwave Radiation with Materials”, J. Mater. Sci., volume 30, n 21, 1995

10. D. K. Xia, C. A. Pickles, "Applications of Microwave Energy in Extractive Metallurgy", CIM Bulletin, volume 90, 1997

11. Y. V. Bykov, K. I. Rybakov and V. E. Semenov, "High-Temperature Microwave Processing of Materials”, J. Phys. D: Appl. Phys., volume 34, n 13, 2001

12. H. S. Shulman, "Microwaves in High-Temperature Processes", Industrial Heating, volume 70, n 3, 2003

13. M. A. Janney, "Enhanced Diffusion in Sapphire during Microwave Heating“, J. Mater. Sci., volume 32, n 5, 1997

14. R. N. Gedye, J. B. Wei, "Rate Enhancement of Organic Reactions by Microwaves at Atmosphere Pressure“, Can. J. Chem., volume 66, 1988

15. R. N. Gedye, F. E. Smith and K. C. Westaway, "Microwaves in organic and organometallic synthesis", J. Microwave Power and Electromagnetic Energy, volume 26, n 1, 1991

16. Y. V. Bykov, "Evidence for Microwave enhanced Mass Transport in the Annealing of Nanoporous Alumina Membranes”, J. Mater. Sci., volume 36, issue 1, 2001

17. J. H. Booske, "Non-equilibrium Excitation of Mass Transport under Microwave Irritation”, J. Mater. Res., volume 7, 1992

18. Ahmad, "Effect of Microwave Heating on the Solid State Reactions and Mass Transport in Ceramics”, Dissertation Abstracts International, volume 52, n 10, 1992

19. W. H. Sutton, "Microwave Processing of Ceramic Materials", Ceramic Bulletin, volume 68, n 2, 1989

20. Bowen Li, Xiaodi Huang, Jim Y. Hwang, Shaolong Qu, Shangzhao Shi, and Zhiyong Xu, "Acceleration of Microwave Irradiation on the Melting of Fluoride", 2004 AIChE Annual Meeting Proceedings (CD-ROM).

21. The Aluminum Association, Inc., “Aluminum Industry Technology Roadmap”, 2003

22. Evan Pert, Yuval Carmel, Amikam Birnboim, Tayo Olorunyolemi, David Gershon, Jeff Calame, Isabel K. Lloyd, and Otto C. Wilson Jr., “Temperature Measurements during 
Microwave Processing, The Significance of Thermocouple Effects”, J. Am. Ceram. Soc. ,2001, 84 (9): 1981-86.

23. D. R. Bradford, R. J. Barnett and M. B. Mezner. Anode for use in aluminum producing electrolytic cell. U.S. Patent No. 6,558,525, May 6, 2003

24. C.W. Brown, T. R.Beck and P. B. Frizzle. Cathode connector for aluminum low temperature smelting cell. U.S. Patent No. 6,419,813, July 16, 2002

25. X. Liu, S. P. Ray and A. F. LaCamera etc. Synthesis of multi-element oxides useful for inert anode application. U.S. Patent No. 6,419,813, July 3, 2003

26. R. A. Rapp. Development of a novel non-consumable anode for electrowinning primary aluminum. Report DOE-OIT Project DE-FC07-99ID13813, 2003

27. F. Rioult, M. Pijolat and F. Valdivieso. High-Temperature oxidation of a $\mathrm{Cu}-\mathrm{Ni}$ based cermet: kinetic and microstructural study. J. Am. Ceram. Soc., 2006, 89(3) 996-1005

28. Aluminum Association. Inert Anode Roadmap, February 1998

29. R.P. Pawlek. Inert anodes: an update. Light Metals 2002. Edited by Wolfgang Schneider, TMS (The Minerals, Metals \& Materials Society), 2002

30. McMaster-Carr Supply Company: www.mcmaster.com

31. D. L. Klarstrom. Characteristics of nickel-base alloys. ASM Handbook, Vol.13, Corrosion, ASM International, 1987, pp 641-643

32. N. Sridhar. Behavior of nickel-base alloys in corrosive environments. ASM Handbook, Vol. 13, Corrosion, ASM International, 1987, pp 643-647 


\section{Project publication}

Bowen Li, Xiaodi Huang, Jim Y. Hwang, Shaolong Qu, Shangzhao Shi, and Zhiyong Xu, "Acceleration of Microwave Irradiation on the Melting of Fluoride", 2004 AIChE Annual Meeting Proceedings (CD-ROM).

\section{Project presentation}

Bowen Li, Xiaodi Huang, Jim Y. Hwang, Shaolong Qu, Shangzhao Shi, and Zhiyong Xu. "Acceleration of Microwave Irradiation on the Melting of Fluoride", The 4th World Congress on Microwave and Radio Frequency Applications, Nov.7-12, 2004, Austin, Texas. 